\title{
The NIST 3 Megawatt Quantitative Heat Release Rate Facility
}

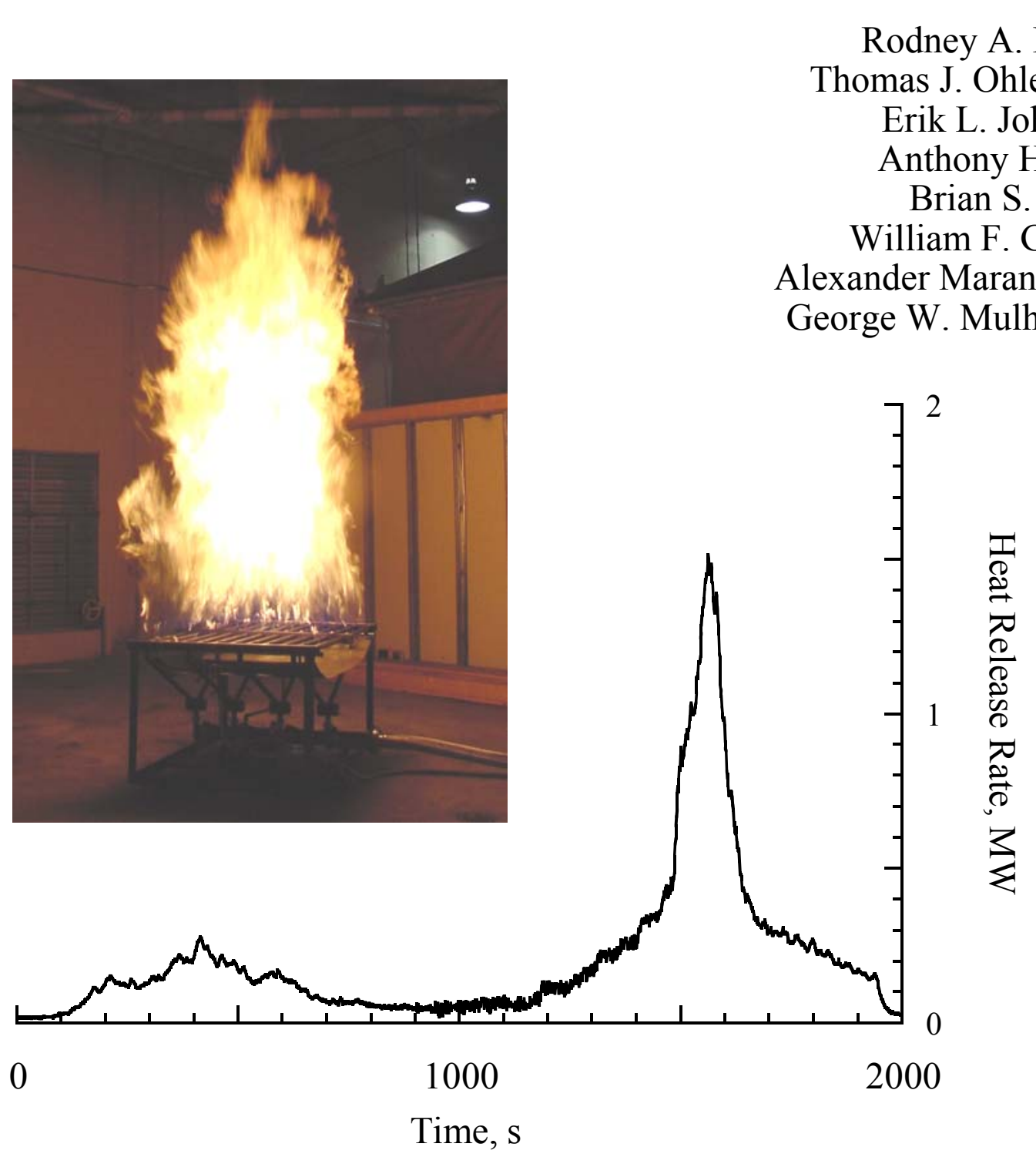




\title{
The NIST 3 Megawatt Quantitative Heat Release Rate Facility
}

\author{
Rodney A. Bryant \\ Thomas J. Ohlemiller \\ Erik L. Johnsson \\ Anthony Hamins \\ Building and Fire Research Laboratory \\ Brian S. Grove \\ Department of Justice \\ Alcohol Tobacco and Firearms \\ Fire Research Laboratory \\ William F. Guthrie \\ Information Technology Laboratory \\ Alexander Maranghides \\ George W. Mulholland \\ Building and Fire Research Laboratory
}

December 2003

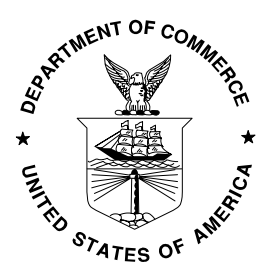

U.S. Department of Commerce

Donald L. Evans, Secretary

Technology Administration

Phillip J. Bond, Under Secretary for Technology

National Institute of Standards and Technology Arden L. Bement, Jr., Director 
Certain commercial entities, equipment, or materials may be identified in this document in order to describe an experimental procedure or concept adequately. Such identification is not intended to imply recommendation or endorsement by the National Institute of Standards and Technology, nor is it intended to imply that the entities, materials, or equipment are necessarily the best available for the purpose.

National Institute of Standards and Technology Special Publication 1007

Natl. Inst. Stand. Technol. Spec. Publ. 1007, 81 pages (December 2003)

CODEN: NSPUE2

U.S. GOVERNMENT PRINTING OFFICE

WASHINGTON: 2003

For sale by the Superintendent of Documents, U.S. Government Printing Office

Internet: bookstore.gpo.gov — Phone: (202) 512-1800 — Fax: (202) 512-2250

Mail: Stop SSOP, Washington, DC 20402-0001 


\section{EXECUTIVE SUMMARY}

The 3 Megawatt Heat Release Rate Facility (3MWHRRF) was developed at NIST as a first step toward having broad capabilities for making quantitative large scale fire measurements. Such capabilities will be used at NIST to validate fire models and to develop sub-grid models. It will also serve to provide a data base for studying a broader range of fire phenomena, and to address issues related to material acceptance and fire codes. An equally important objective is to provide templates for use by other laboratories including commercial testing facilities to improve the quality of their data.

Heat release is the result of the combustion of a fuel with the oxygen in air. The fuels of primary interest are those found in constructed facilities and include wood, plastics, foam materials used in furnishings (such as polyurethane), wire insulation (such as polyvinyl chloride), and carpet materials (such as nylon).

The rate at which heat is released is the single most important quantity in terms of fire safety. Thus it is important that this measurement be made in a quantitative manner. It is a key predictor of the hazard of a fire; directly related to the rate at which heat and toxic gases build up in a compartment or the rate at which they are driven into more remote spaces. Heat release rates on the order of $1 \mathrm{MW}$ to $3 \mathrm{MW}$ are typical in a room that is flashed over or from a single large object such as a bed or sofa.

It is important that heat release rate measurements be made accurately because fire regulations are frequently based on peak rates of heat release. Testing laboratories must be confident that the objects tested pass the required regulation and manufacturers need accurate information in defining the fire safety characteristics of their products. A second need for accurate heat release rate data is for the development of quantitative models for predicting heat release rate. In comparing a fire experiment and a model prediction, it is essential that the heat release rate measurement have an estimated uncertainty.

The 3MWHRRF developed at NIST meets the needs described above for objects that can be placed under the $6 \mathrm{~m} \times 6 \mathrm{~m}$ hood, which is approximately $4 \mathrm{~m}$ above the floor, or for enclosures whose effluent can all be directed into the hood. It is capable of measuring heat release rates in the range of 0.10 to $3.0 \mathrm{MW}$ including brief peaks as high as $5 \mathrm{MW}$. As documented in this publication, the expanded uncertainty (95\% confidence interval) is $11 \%$ of the heat release rate for fire sizes larger than $400 \mathrm{~kW}$. The response time of the system is such that it can accurately resolve dynamic heat release rate events of 15 seconds or more.

This document is intended to serve as a description of the NIST 3 Megawatt Heat Release Rate Facility and as a general guide for implementing, operating and maintaining quality control of similar quantitative large scale heat release rate measurement facilities. The measurement system consists of a hood and duct system, a duct flow rate measurement, a gas flow sampling system, and a gas analysis system. Key features of the design and fabrication of these systems are presented including detailed schematics and the rationale 
for the choices made. Transient response and gas dispersion in the sampling system, sampling from a non-uniform duct flow, and making accurate total flow measurements using bi-directional probes are dealt with in the design.

A calibration burner is essential for the operation of the 3MWHRRF and for characterizing its time response. The design of the natural gas burner including the special flow control and flow metering capabilities are presented.

The general design of the software allowing the display of nearly real-time heat release rates with corrections for sampling/instrumental delay and response times, is described. The uncertainty analysis described in the report includes the effect of the drift in the gas analyzer outputs, the correlation effects in computing the oxygen difference relative to the background value, and combining the uncertainties from over 50 variables in the heat release equation. 


\section{ACKNOWLEDGEMENTS}

The success of any project of this scope and magnitude is due to more than just the work of the authors. Therefore the authors wish to thank the following NIST staff for their valuable contributions: Laurean A. DeLauter, David W. Stroup, Roy A. McLane and Gary Roadarmel for construction of the calorimeter, and William H. Twilley, Laurean A. DeLauter, and Jay A. McElroy for construction of the natural gas calibration burner. 


\section{TABLE OF CONTENTS}

EXECUTIVE SUMMARY III

ACKNOWLEDGEMENTS V V

1 BACKGROUND 1

2 DESCRIPTION OF SYSTEM

2.1 CALORIMETER 7

2.2 DATA ACQUISITION SYSTEM

2.3 CALIBRATION BURNER SYSTEM

2.4 DESIGN CONSIDERATIONS 22

3 OPERATION AND SAFETY

$\begin{array}{lll}3.1 & \text { CALORIMETER } & 40\end{array}$

$\begin{array}{ll}3.2 & \text { DATA ACQUISITION SYSTEM }\end{array}$

3.3 CALIBRATION BURNER 41

$\begin{array}{lll}3.4 & \text { SAFETY } & 42\end{array}$

3.5 Baseline Heat Release Rate 42

4 ASSESSMENT OF UNCERTAINTY 45

4.1 TYPE A UNCERTAINTY 46

4.2 TYPE B UNCERTAINTY

4.3 UNCERTAINTY PROPAGATION 49

4.4 REPEATABILITY, EXPANDED UNCERTAINTY, AND CONFIRMATION COMPARISON 60

5 INTERNAL QUALITY CONTROL PROCEDURES

$\begin{array}{lll}5.1 & \text { CERTIFIED OPERATOR } & 63\end{array}$

5.2 CALIBRATION OF INSTRUMENTS

5.3 CALIBRATION RECORDS 65

$\begin{array}{lll}5.4 & \text { TRAPS AND FILTERS } & 65\end{array}$

$\begin{array}{ll}5.5 & \text { DATA ACQUISITION } \\ 5.6 & 66\end{array}$

5.6 DATA ARCHIVING 66

5.7 CONFIRMATION OF HRR FACILITY 66

6 CONCLUDING REMARKS $\quad 67$

REFERENCES

APPENDIX A NOMENCLATURE

$\begin{array}{lll}\text { APPENDIX B UNCERTAINTY COMPARISON EXAMPLE } & \mathbf{7 3}\end{array}$

B.1 UnCERTAINTY IN THE DifFERENCE OF CORRELATED MEASUREMENT QUANTITIES 


\section{Background}

Heat release rate is defined as the enthalpy change per unit time as a result of the conversion of the chemical energy of a fuel to heat in a combustion process. Most commonly the fuel is carbon-based and the combustion process is one of oxidation, usually by the oxygen in air. Heat release rate is typically reported in kilowatts $(\mathrm{kW})$ or megawatts (MW). Its importance follows from the fact that it is a key predictor of the hazard of a fire, directly controlling the rate at which heat and toxic gases build up in a compartment or are buoyantly driven into more remote spaces [1]. It is, in effect, the most pertinent measure of the size of a fire [2].

Understanding the heat release rate potential of an object or an assembly of objects is essential to estimating the hazard such an object or arrangement could pose if ignited. Rational limitation and regulation of such a hazard is based on such understanding. Although substantial progress is being made, the present state of fire growth models is such that accurate prediction of heat release rate for common room contents such as chairs or beds cannot be made with full confidence. Thus measurements of heat release rate on real objects are currently essential. The measured results may be used as input for hazard calculation models such as CFAST (The Consolidated Model of Fire Growth and Smoke Transport) [3] or for product regulation. In either case, accurate heat release rate measurements are essential to meaningful results.

For a simple object made from a pure substance with a known constant heat of combustion the heat release rate measurement requires only a mass loss rate measurement on the object since the former is proportional to the latter, i.e.

$$
\dot{q}=\dot{m} \Delta H_{c}
$$

where $\dot{q}$ is the measured rate of heat release, $\dot{m}$ is the mass loss rate (time derivative of decreasing object mass) and $\Delta H_{c}$ is the known heat of combustion (e.g., $\mathrm{kJ} / \mathrm{kg}$ ). In practice the heat of combustion of a complex object is rarely tabulated and in any case is variable for charring materials. Thus reliance on mass loss to quantify heat release is unreliable for real objects. On the other hand, mass loss is useful if the "object" is a welldefined gas or a liquid supplied at a known rate. This is, in fact, the basis for calibration of more general heat release rate calorimeters, where the calorimeter output can be compared with a precisely measured flow of a fuel whose heat of combustion is also accurately known.

Early measurements of heat release rate focused on the heat output as represented by the temperature of the product gases. Thus an array of thermocouples was positioned in a duct which captured all these gases to measure their average gas temperature [ ASTM 1321 (LIFT test); ASTM 906 (OSU calorimeter)]. This approach assumes the flow is adiabatic, which is never a reality. The heat emitted from the fire as radiation, for example, can be $35 \%$ or more of the total chemical heat release rate. More sophisticated 
variants of this thermal approach, based on measuring the fuel gas flow rate required to maintain a constant product stream temperature, had the same limitation [4].

Huggett [5] first suggested a very different approach, now termed oxygen consumption calorimetry. ${ }^{1}$ He followed up on the much earlier finding that the amount of heat evolved from most organic materials per unit mass of oxygen consumed in their complete combustion is nearly constant. For example, for butyl alcohol:

$$
\begin{aligned}
& \mathrm{C}_{4} \mathrm{H}_{9} \mathrm{OH}+6 \mathrm{O}_{2}+6(3.76) \mathrm{N}_{2} \rightarrow 4 \mathrm{CO}_{2}+5 \mathrm{H}_{2} \mathrm{O}+6(3.76) \mathrm{N}_{2} \\
& \left(\Delta \mathrm{H}_{c}\right)_{\text {Mass_o }}=-12.79 \mathrm{MJ} / \mathrm{kgO}_{2}
\end{aligned}
$$

Huggett shows that for a wide variety of molecules from pure hydrocarbons, to partially oxygenated species, to partially halogenated species, and a wide variety of polymers and natural materials such as wood and coal, the heat release per unit mass of oxygen falls within a narrow range. He showed that, for most common materials containing $\mathrm{C}, \mathrm{H}, \mathrm{O}$, and $\mathrm{N}$, the average heat release per unit mass of oxygen is $13.1 \mathrm{MJ} / \mathrm{kg} \mathrm{O} \mathrm{O}_{2}$; the standard deviation of the heat release rate for materials examined by Hugget is $0.35 \mathrm{MJ} / \mathrm{kg} \mathrm{O} \mathrm{O}_{2}$. Thus the oxygen deficit in the duct flow (relative to ambient air) is a measure of the heat release rate in the flow which the duct captures.

Sensenig built the first working apparatus based on oxygen consumption calorimetry [7]. The heat release rate was inferred from the measured oxygen deficit in the flow of a hood that captured the fire plume as shown in the following equation:

$$
\dot{q}=\left(\Delta H_{c}\right)_{V_{\text {Ol_ }} O_{2}} \dot{V}_{D} X_{O_{2}}^{o} \theta
$$

where

$$
\theta=\left(X_{O_{2}}^{o}-X_{O_{2}}\right) / X_{O_{2}}^{o}
$$

with $X_{\mathrm{O}_{2}}^{o}$ being the oxygen volume fraction in the ambient air, $X_{\mathrm{O}_{2}}$ the oxygen volume fraction in the duct after the captured smoke plume (and any excess air) is well-mixed, $\dot{V}_{D}$ is the measured volume flow rate in the hood duct, and $\left(\Delta H_{c}\right)_{V_{0 l} O_{2}}$ is the heat of combustion per unit volume of oxygen consumed (e.g., $\mathrm{MJ} / \mathrm{m}^{3} \mathrm{O}_{2}$ ). This simplified equation is approximate since it neglects other gases that are present such as water vapor and $\mathrm{CO}_{2}$. The equation does convey, however, the role of the primary variables: duct flow rate and duct oxygen depletion.

Equation (3) may be rewritten on a mass basis as follows:

$$
\dot{q}=\left(\Delta H_{c}\right)_{\text {Mass_o }}\left(\dot{m}_{O_{2}}^{o}-\dot{m}_{O_{2}}\right)
$$

\footnotetext{
${ }^{1}$ Factory Mutual also uses a related approach in which the production of carbon dioxide and carbon monoxide, rather than the loss of oxygen, are taken as a measure of heat release [6]
} 
where $\left(\Delta H_{c}\right)_{\text {Mass_ } O_{2}}$ is the heat released per unit mass of oxygen, $\dot{m}_{O_{2}}^{o}$ is the mass flow rate of oxygen in the duct prior to the fire test, and $\dot{m}_{\mathrm{O}_{2}}$ is the mass flow rate of oxygen in the duct during the fire test.

For an open system only the exhaust flow rate, which includes the flow rate of incoming air and combustion products, is measured. It is necessary to relate the measured exhaust flow rate to the incoming air flow rate. Therefore it is useful to define the oxygen depletion factor, $\phi$, as the fraction of incoming air that is depleted of its oxygen.

$$
\phi=\frac{\dot{m}_{O_{2}}^{o}-\dot{m}_{O_{2}}}{\dot{m}_{O_{2}}^{o}}
$$

In relating the mass flow of air into the system to the mass flow in the duct, the assumption is employed that nitrogen is not involved in the combustion process and therefore the nitrogen flow is constant. Nitrogen analysis is not performed so its volume fraction is replaced using the assumption that only $\mathrm{N}_{2}, \mathrm{O}_{2}, \mathrm{CO}_{2}, \mathrm{CO}$ and $\mathrm{H}_{2} \mathrm{O}$ are present. This substitution is most accurate if all of the other gas species are measured. Accurate water analysis is difficult, so it is typically approximated on the basis of the humidity of the incoming air. Using the substitution for nitrogen, $\phi$ is expressed in terms of the measured volume fractions of the gas species.

$$
\phi=\frac{X_{O_{2}}^{o}\left(1-X_{C_{2}}-X_{C O}\right)-X_{O_{2}}\left(1-X_{C_{2}}^{o}\right)}{\left(1-X_{O_{2}}-X_{C O_{2}}-X_{C O}\right) X_{O_{2}}^{o}}
$$

It is apparent in Eq. (2) that the combustion process of hydrocarbon fuels can result in a greater number of moles of products than reactants. Parker [8] defines a chemical expansion factor as follows:

$$
\alpha=1+X_{O_{2}}^{o}(\beta-1)
$$

where $\beta$ is the ratio of the moles of combustion products to the moles of oxygen consumed. In the case of hydrocarbon fuels the average value of $\alpha$ is 1.10 .

The number of moles in the fraction of air depleted of its oxygen is replaced by an equal or greater number of moles of combustion products (second term of the equation below). Therefore, the mass flow rate of air into the system, $\dot{m}_{\text {air }}$, may be related to the measured mass flow rate in the exhaust, $\dot{m}_{e}$, by the following relation:

$$
\frac{\dot{m}_{e}}{M_{e}}=\frac{\dot{m}_{\text {air }}}{M_{\text {air }}}(1-\phi)+\frac{\dot{m}_{\text {air }}}{M_{\text {air }}} \phi \alpha
$$


Assuming that the molecular weight of the exhaust duct gas is approximately equal to the molecular weight of the incoming air $\left(M_{e} \approx M_{\text {air }}\right)$, the mass flow rate of the incoming oxygen is expressed as:

$$
\dot{m}_{O_{2}}^{o}=\dot{m}_{\text {air }} X_{O_{2}, \text { inc }}^{o} \frac{M_{O_{2}}}{M_{\text {air }}}=\frac{\dot{m}_{e}}{1+\phi(\alpha-1)} X_{O_{2}, \text { inc }}^{o} \frac{M_{O_{2}}}{M_{\text {air }}}
$$

Paramagnetic oxygen analyzers require the water to be removed from the sampled gas, therefore a correction must be made to the ambient oxygen volume fraction measurement.

$$
X_{O_{2}, \text { inc }}^{o}=\left(1-X_{H_{2} O}^{o}\right) X_{O_{2}}^{o}
$$

Using Eq. (6), (10), and (11), Eq. (5) may be rewritten as follows with $\phi$, as described in Eq. (7), representing the case where $\mathrm{O}_{2}, \mathrm{CO}_{2}$, and $\mathrm{CO}$ are measured while $\mathrm{H}_{2} \mathrm{O}$ is removed from the sampled gas:

$$
\dot{q}=\left(\Delta H_{c}\right)_{\text {Mass_o }_{2}} \phi \frac{\dot{m}_{e}}{1+\phi(\alpha-1)}\left(1-X_{H_{2} O}^{o}\right) X_{O_{2}}^{o} \frac{M_{O_{2}}}{M_{\text {air }}}
$$

Incomplete combustion, especially $\mathrm{CO}$ formation, often occurs in fires and $\mathrm{CO}$ formation yields only about half as much heat per unit mass of $\mathrm{O}_{2}$ consumed as does $\mathrm{CO}_{2}$ formation. Huggett points out that even if the $\mathrm{CO}$ concentration is $10 \%$ of the $\mathrm{CO}_{2}$ concentration, the effect on the net heat released per mass $\mathrm{O}_{2}$ consumed is small. However, flame retardants frequently boost $\mathrm{CO}$ formation and oxygen-starved burning, as in flashover conditions, does so as well. Often $\mathrm{CO}$ formation may exceed $10 \%$ of $\mathrm{CO}_{2}$ formation. In general, it is recommended to measure $\mathrm{CO}$ and correct the heat release rate for its formation as shown in the following equation:

$$
\begin{gathered}
\dot{q}=\left[\left(\Delta H_{c}\right)_{\text {Mass_o }}^{H C} \phi-\left(\left(\Delta H_{c}\right)_{\text {Mass_o }}^{C O}-\left(\Delta H_{c}\right)_{\text {Mass_o }}^{\text {HC }} \mathrm{O}_{2}\right) \frac{1-\phi}{2} \frac{X_{C O}}{X_{O_{2}}}\right] \\
\frac{\dot{m}_{e}}{1+\phi(\alpha-1)}\left(1-X_{\mathrm{H}_{2} \mathrm{O}}^{o}\right) X_{\mathrm{O}_{2}}^{o} \frac{M_{\mathrm{O}_{2}}}{M_{\text {air }}}
\end{gathered}
$$

where

$\left(\Delta H_{c}\right)_{\text {Mass_ }}^{H C}=$ heat of combustion of hydrocarbon fuel, $\mathrm{MJ} / \mathrm{kg} \mathrm{O}_{2}$

$\left(\Delta H_{c}\right)_{\text {Mass }}^{C O} \mathrm{O}_{2}=$ heat of combustion of carbon monoxide, $\mathrm{MJ} / \mathrm{kg} \mathrm{O}$

$\phi=$ oxygen depletion factor

$\dot{m}_{e}=$ mass flow rate in exhaust duct, $\mathrm{kg} / \mathrm{s}$

$\alpha=$ combustion products expansion factor

$M_{i}=$ molecular weight of gas $\mathrm{i}, \mathrm{kg} / \mathrm{kmole}$

$X_{i}=$ volume fraction of exhaust gas $\mathrm{i}$ 
$X_{i}^{o}=$ volume fraction ambient gas i

The algebraic complexity of Eq. (13), compared to Eq. (3) or (5), arises essentially from a more thorough treatment of the mass balances (and atom balances) on the species between the fire, where they are generated, and the instruments, where they are measured. Parker [8] and Parker and Janssens [9] discuss the details of the heat release rate calculation based on the extent to which the duct gas flow is characterized, i.e., whether one measures only oxygen or also includes $\mathrm{CO}, \mathrm{CO}_{2}$ and water. The NIST calorimeter system measures oxygen, $\mathrm{CO}$ and $\mathrm{CO}_{2}$; a correction is made for ambient humidity as an estimate of the water concentration in incoming air. The heat release rate is not corrected for the soot yield ${ }^{2}$. Details concerning the input measurement quantities for Eq. (13) are discussed in Sec. 4, Assessment of Uncertainty.

It is important to realize that the oxygen deficit in the duct flow, even in large fires, is typically rather small. This is a consequence of the need to prevent overheating of the exhaust duct and to allow completion of the combustion reactions before the fire plume enters the duct. Thus the best one can do with regard to capturing the plume is draw it and no other diluting air into the duct inlet at the top of the hood [10]. However, fire plumes are typically already quite diluted at the flame tips [11] and, as a result, one can expect an oxygen reduction only from $21 \%$ by volume to about $19 \%$. Rarely is it actually possible to capture the plume in this manner, so additional plume dilution is the norm. An implication of this is that the oxygen meter needs to have high resolution if the inferred heat release rate is to be precise. Suffice it to say that oxygen measurement and duct flow rate are the two measurements in need of greatest attention.

\section{Description of System}

The 3 MW Heat Release Rate Facility is located in the Large Fire Research Facility and became operational in August, 2001. It employs oxygen consumption calorimetry in the standard manner to measure the total heat output of a fire. The description of the facility may be segmented according to three major functions: calorimetry, data acquisition, and operational validation. Each of these functions is shown as boxes in Figure 1. Within each box are the subsystems that combine to complete the function. To summarize the functions, calorimetry consists of collecting all of the gases produced by the fire, measuring the rate of flow of the gases, sampling a small and well mixed portion of the gases, and measuring the volume fractions of specific gas species (especially oxygen volume fraction). Data acquisition consists of sampling the electrical output of each calorimetry instrument as it responds to the physical conditions that it monitors, converting the electrical output to a digital signal, recording a time history of the digital signal and converting the record to a value of scientific significance and displaying it in near real-time. The data acquisition system also provides a user interface to control the

\footnotetext{
${ }^{2}$ A first order thermodynamic analysis indicates that for highly sooting toluene flames the effect on the heat of combustion is less than the uncertainty in the heat of combustion per $\mathrm{kg} \mathrm{O}_{2}$ for an unknown fuel.
} 
output of the calibration burner and record the subsequent response of its instruments. Operational validation consists of putting a controlled flow of chemically released heat into the system and measuring the heat flow independent of the calorimeter measurement. The calorimeter and data acquisition systems are essential for measuring the heat released from a burning item. The calibration burner is essential for confirming the measurement. Detailed descriptions of each system and selected subsystems are presented in the sections that follow.

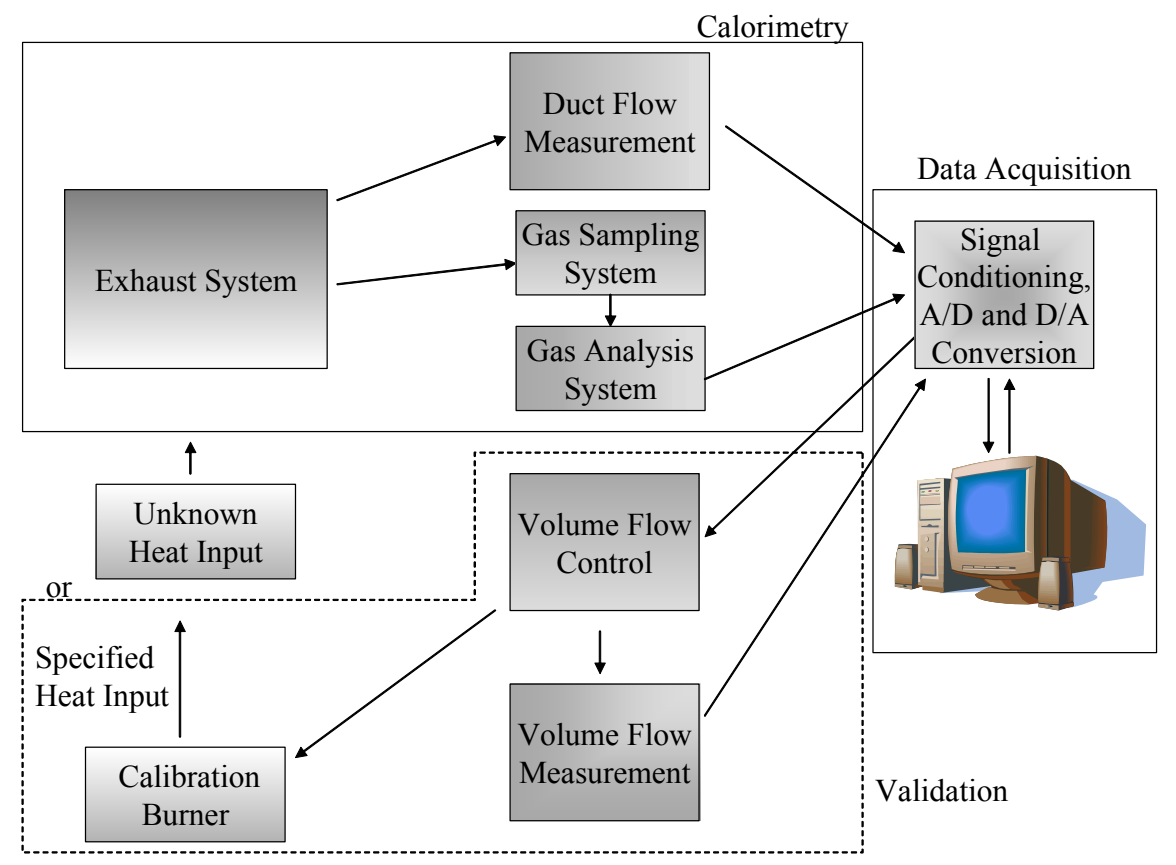

Figure 1 Schematic overview of the 3 MW Heat Release Rate Facility.

The system is nominally rated at $3 \mathrm{MW}$ total heat release rate but fires with brief peaks as high as $5 \mathrm{MW}$ have been successfully measured. (The hood skirt provides a temporary buffer capacity, as discussed below.) Calorimeter capacity may be limited either by the ability of the hood to capture fire plumes (i.e., by the total volumetric flow capacity of the hood) or by the height of the flame tips. The user must have a reasonable idea beforehand whether either of these factors will make this hood suitable for a specific fire situation. The literature and/or experience is the only guide as to probable maximum fire size. Flame tip height can be calculated from the available pool fire correlations [11] (and some results of this type are included below) but the user should be aware that not all fires behave like simple pool fires. The vertical extent of a burning object can affect flame tip height and plume entrainment, as can a tendency for wide objects to burn with more than one fire plume. (Multiple plumes may entrain more air than a single plume involving the same total heat release rate.) Reference [11] also includes formulas for the calculation of plume entrainment and thus the total volumetric or mass flow which a hood must swallow; again these are based on pool fires. 
Fires as small as $50 \mathrm{~kW}$ can be measured in the $3 \mathrm{MW}$ calorimeter, if a degraded signal to noise behavior is acceptable. Objects giving peak heat release rates this small are best measured in a smaller calorimeter hood.

\subsection{Calorimeter}

\subsubsection{Hood and Duct System}

Side and top view diagrams of the $9 \mathrm{~m} \times 12 \mathrm{~m}$ and $6 \mathrm{~m} \times 6 \mathrm{~m}$ hoods and duct systems are shown in Figure 2. The test area beneath the $6 \mathrm{~m} \times 6 \mathrm{~m}$ hood is open on three sides. The fourth side is relatively close to one wall of the building; this could impact air inflow symmetry, especially for fires larger than $2 \mathrm{MW}$, though no problems have been noted to date. The base of the hood is located $4.57 \mathrm{~m}$ above the laboratory floor. The effective height of the hood inlet has been lowered to $3.0 \mathrm{~m}$ by the addition of a vermiculite glass fiber skirt (rated for a maximum temperature of $923 \mathrm{~K}$ ) ${ }^{3}$. The skirt (in addition to the $1.80 \mathrm{~m}$ depth of the hood itself) offers a buffer volume for plume accumulation in the event of a transient peak in fire behavior that yields a plume flow too great for the hood to swallow. It can also serve to limit plume entrainment for fires that persist in exceeding the rated capacity of the hood. Both roles come at a price, as discussed below in the Design Considerations section. ${ }^{4}$ The effectively lowered hood inlet also helps assure that a weakly buoyant plume from a small fire is fully captured before it can drift out from under the hood.

The interior surface of the hood is coated with a fibrous cement mix to provide thermal insulation of the steel structure. This is an essential function, particularly to accommodate large fires that persist tens of minutes. However, for large and sustained fires, heating of the insulation material (and of the hood skirt) could cause it to become a source of re-radiation back to the burning object, accelerating the rate of burning.

A $1.52 \mathrm{~m}$ inside diameter steel duct emerges from the top of the hood and immediately turns to become horizontal, running under the high bay roof (Figure 2). Immediately downstream of this are inlets for ducts from smaller calorimeter hoods. These are normally sealed off to preclude dilution of the captured plume gases from the six-meter hood. ${ }^{5}$ The duct then makes a right angle turn upward, passes through the roof and makes a second right angle turn to run along the top of the roof. The entire length of the duct is thermally insulated to minimize condensation of plume moisture.

\footnotetext{
${ }^{3}$ Above the fiber cloth is a lighter layer of fiberglass material used to seal the gap between the fiber cloth (hanging from a cable) and the interior surface of the hood. This seal is necessary to prevent significant escape of smoke in some circumstances.

${ }^{4}$ In general it is much better to use a skirt than to risk losing part of the fire plume. When part of the plume is lost, the oxygen deficit generated by the fire is underestimated and thus so also is the heat release rate. Quantifying this is very difficult since one cannot judge the fraction of a plume that is being lost unless it is very obviously negligible.

${ }^{5}$ Small inward leaks of air at this point in the duct system should not be problematical since they would have time to mix over the duct cross section before the gases are sampled for calorimetry. Such leaks are analogous to fire plume dilution, however, and the larger they are the more they lower the oxygen deficit in the duct and thus the system sensitivity to heat release rate.
} 

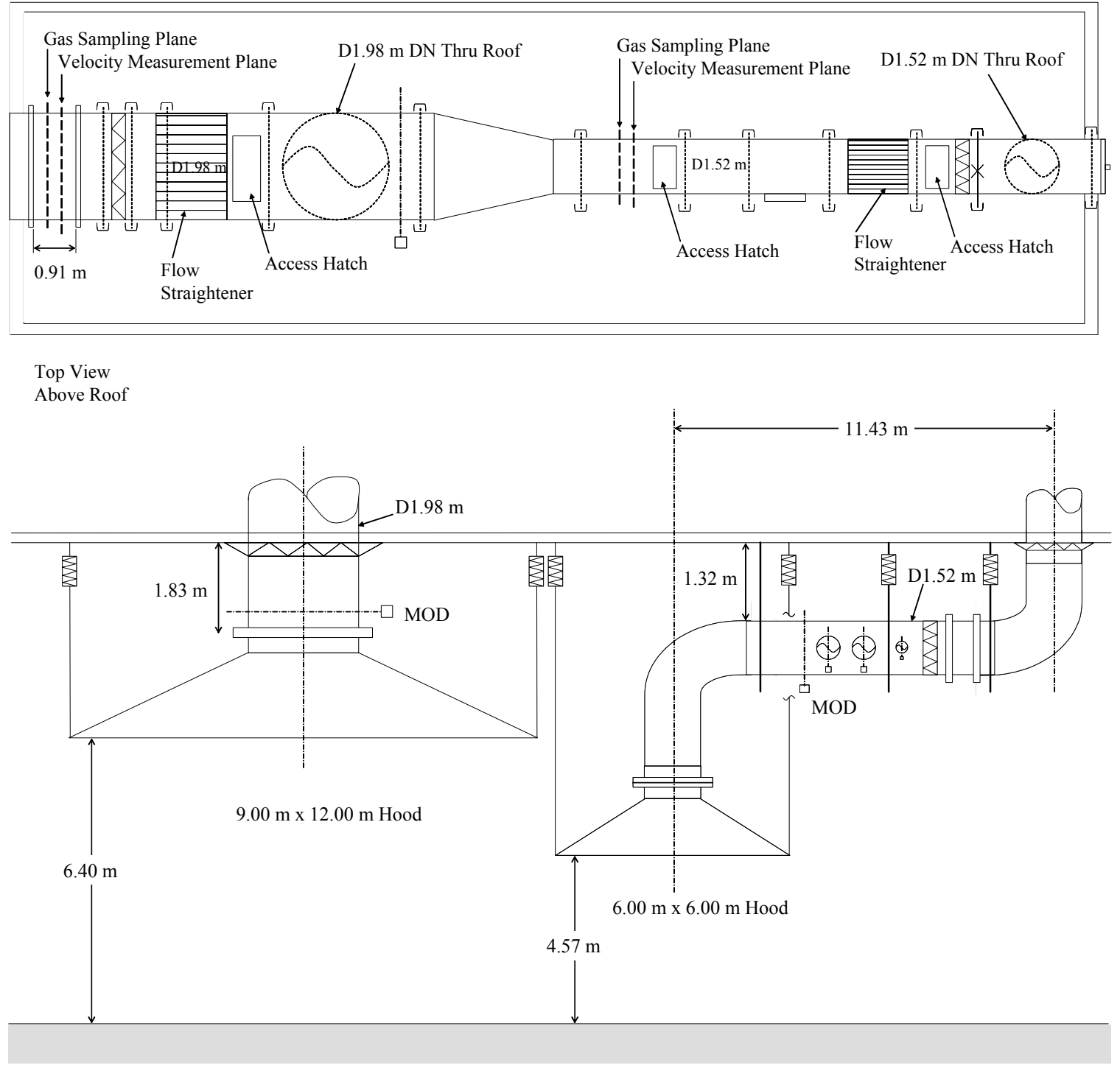

Figure 2 Large Fire Research Facility exhaust hoods and duct system.

The last turn includes a dead end duct section (with an access hatch) that has been sealed off with a flat bulkhead having small holes to assure pressure equilibration. Dead volumes in the flow system such as this, not cleanly swept by flow, are sources of dispersion or spread of the time history of the heat release rate information carried in the plume flow and should be avoided throughout the duct system and the entire gas sampling system. They provide pockets of gas that are re-distributed into the duct flow at times later than the time at which they originally reached the pocket location. This tends to smear out heat release rate peaks and slow the system response time. There are dispersive processes of this nature occurring at various locations in any real flow and gas analysis system and minimization of these must be factored in to the system design. A more extensive discussion of those pertinent to this system is given below in Sec. 2.4.3. 
The three turns plus turbulence in the duct serve to mix the flow reasonably well. The mixedness of the flow was checked with helium injected at the hood duct inlet, sampled downstream and measured with a helium detector. These results indicated a uniform concentration over the sampled cross-section to within $\pm 5 \%$. The sampled section of the duct was the same section as that used for normal heat release rate measurements.

The turns in the duct leave the time-averaged velocity profile skewed toward the top of the duct ${ }^{6}$. There is not sufficient duct length available on the roof to guarantee a fullydeveloped turbulent flow profile after the last turn in the duct. A flow straightening section was added between the last turn and the gas velocity measurement section to reduce the eddy size and remove any swirl. The flow straightener is of a simple tube bundle design [12]; it consists primarily of $10 \mathrm{~cm}$ diameter thin wall steel pipe sections, $1.5 \mathrm{~m}$ long. These are stacked in the section indicated in Figure 2 so as to fill the entire duct cross section. While the pressure head loss it induces is insufficient to fully flatten the velocity profile, measurements of the velocity at six locations across the duct cross section are sufficient to determine the total flow, as described in the next section.

Approximately $2.3 \mathrm{~m}$ downstream of the gas flow characterization section, the duct expands asymmetrically to an approximate $1.98 \mathrm{~m}$ inside diameter, just prior to joining with the duct from the $9 \mathrm{~m}$ by $12 \mathrm{~m}$ hood. To minimize any effect of this asymmetry, the gas velocity measurement plane in the $1.52 \mathrm{~m}$ diameter section was kept $1 \frac{1}{2}$ diameters upstream of the duct expansion section.

Water condensation in the duct is a possibility in cold weather when humid lab air, or even more so, smoke, contacts the duct surfaces in the area atop the roof. If the duct walls are below freezing (there is no heating system in the duct), condensed water will freeze. Ice on the duct walls is probably of little concern. Ultimately the warm air will heat up the duct walls to the point that any ice melts and the water will then re-evaporate. Thermocouples on the duct wall allow monitoring of its temperature.

\subsubsection{Duct Flow Rate Measurement}

The velocity is measured approximately 4.2 duct diameters downstream of the outlet of the first flow straightener (located in the $1.52 \mathrm{~m}$ diameter section of the duct). Six bidirectional pressure probes of conventional design [13] are used. They are arrayed vertically on a duct diameter ${ }^{7}$ (in one plane) and placed at the Tchebyachev locations recommended in Ref. [14] (see Figure 3). The six velocity measurements are equally weighted in calculating the total flow rate in the duct. The temperature near each velocity probe location is measured with a $1.6 \mathrm{~mm}$ diameter sheathed chromel/alumel thermocouple (one thermocouple per velocity probe). The velocity probes are held in place by a rigid, $13 \mathrm{~mm}$ wide, vertical steel support spaced about $15 \mathrm{~cm}$ away from the

\footnotetext{
${ }^{6}$ This skewing was predicted by LES modeling of the flow and was confirmed by actual mapping with a probe inserted from the top of the duct at the normal velocity measurement cross section.

${ }^{7}$ The implicit assumption of bi-lateral flow symmetry appears justified by the lack of left/right asymmetry in the system before this plane and by the probing of the flow in this region.
} 
probes to minimize any impact its cross section may have on the local velocity around the probes. The thermocouples are wound around the lead tubes of the bi-directional probes.
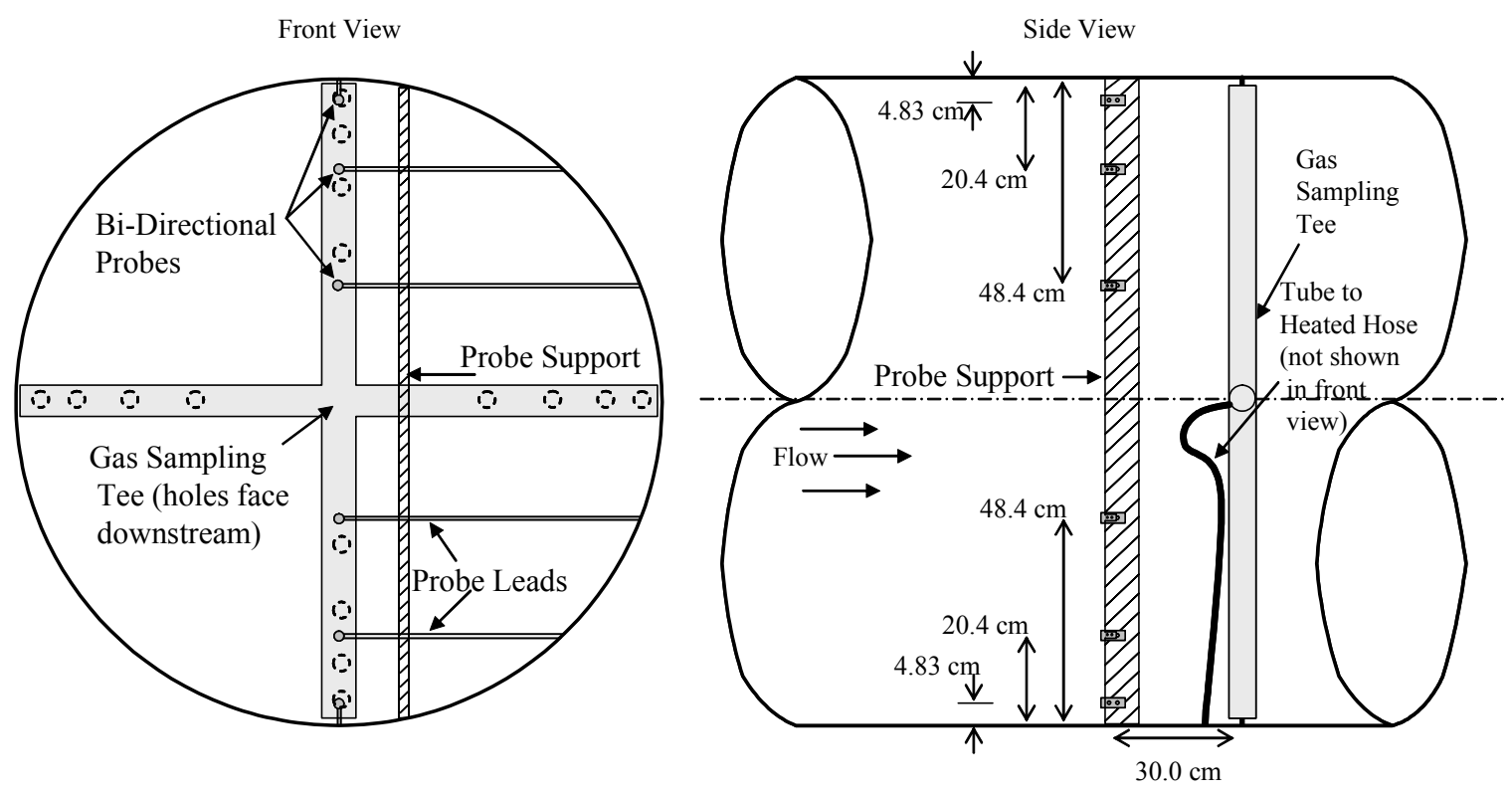

Figure 3 Schematic of velocity probes and gas sampling tee mounted in the exhaust duct. The size of the gas sampling tee is exaggerated in order to clarify the location of the sampling holes.

External to the duct and shown in Figure 4, the bi-directional probe lead tubes are bundled together and insulated with polyurethane foam pipe insulation (covered with aluminum tape for weathering) to minimize any temperature differential in the lead pairs from any given probe, since this can cause a zero offset and/or zero drift via differing gas column densities in the vertical portions of the probe leads ${ }^{8}$.

The bi-directional probe leads and their associated thermocouple leads go directly into an air-conditioned enclosure (see Figure 4) sitting on the building roof, next to the gas characterization section of the duct. Temperature control is necessary to minimize drift in the output of the six pressure transducers (MKS Baratron 220; range 0 to $133 \mathrm{~Pa}$ ) that read the pressure differentials across the six bi-directional probes.

The six pressure transducers used here have all been calibrated using a Dwyer Model 1430 point gage manometer. This is a simple device that allows accurate imposition of the very low pressures seen in the duct flow velocity range that is pertinent here (less than 100 pascals). The calibration results confirmed the factory-supplied data.

\footnotetext{
${ }^{8}$ This is potentially a significant source of zero drift in the pressure signal as the sun moves across the sky; thus the thermal shielding is necessary.
} 
At a volumetric flow of $10.8 \mathrm{~m}^{3} / \mathrm{s}$, the velocities range from about $4 \mathrm{~m} / \mathrm{s}$ to about $8 \mathrm{~m} / \mathrm{s}$. The local velocity values have fluctuations of roughly $\pm(2$ to 5$) \%$ for this case, presumably due to turbulence in the duct.

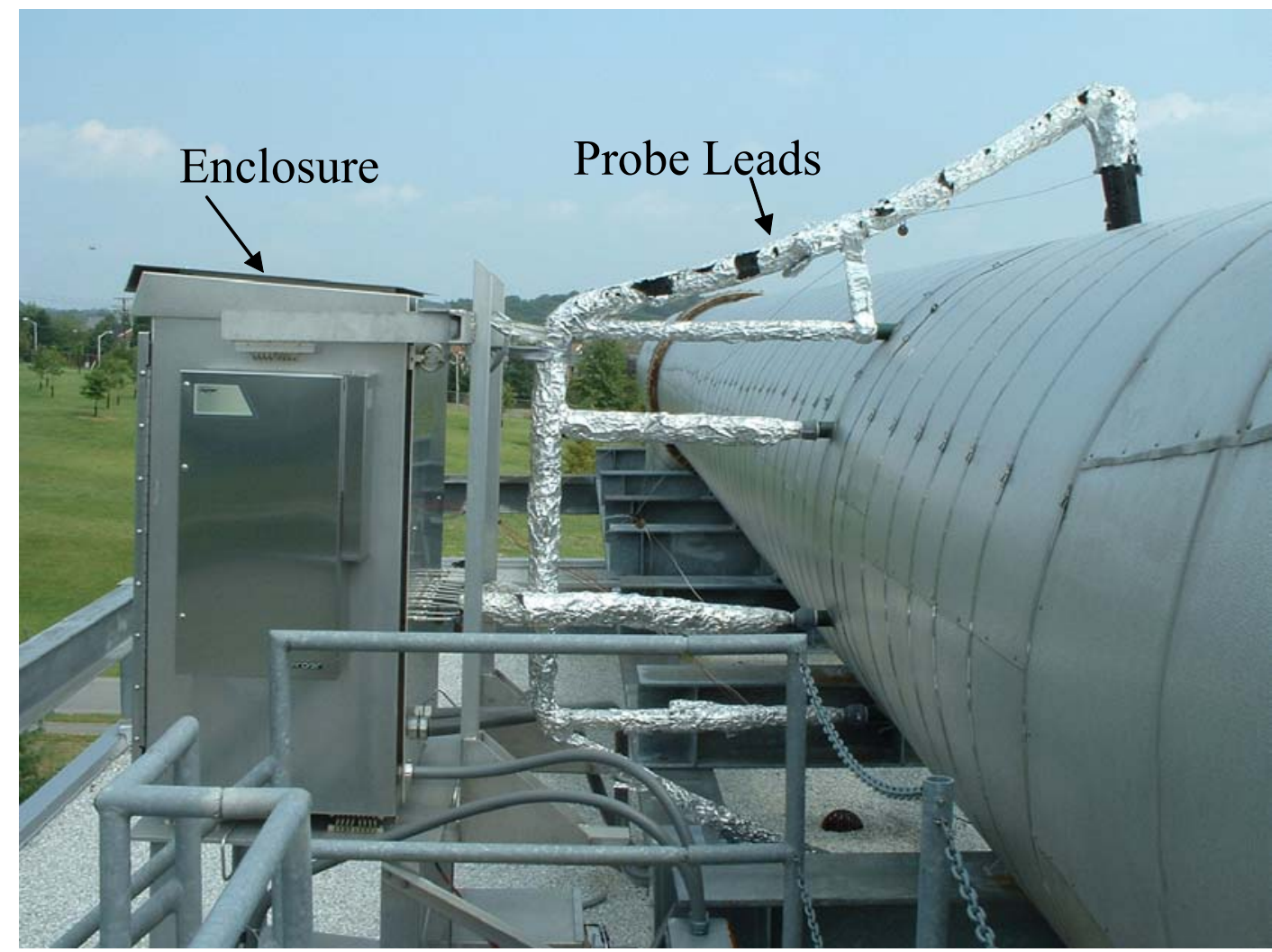

Figure 4 Exhaust duct velocity measurement and gas sampling station.

\subsubsection{Gas Flow Sampling System}

The gas in the duct is sampled approximately $30 \mathrm{~cm}$ downstream of the plane of the bidirectional probes. The sampler is a four-armed cross that spans the duct diameter vertically and horizontally, as shown in Figure 3. The ends of the arms are anchored to the duct wall. The arms are $25.4 \mathrm{~mm}$ OD tubing, each having four $6 \mathrm{~mm}$ diameter holes spaced at equal duct area points along the arm span. The holes face downstream to lessen the chances of their being plugged by soot or ash drawn onto the hood, and they are located on equal annular area radii. The gas is pulled through the center of the cross and then goes into a lead tube that passes out the bottom of the duct. The line from the exit of the duct to the pump enclosure is a $12.7 \mathrm{~mm}$ ID Teflon-lined heated hose, typically operated at $363 \mathrm{~K}$.

Suction is provided by an Air Dimensions Inc. Model 19320 TM heated double-head diaphragm pump that delivers $36 \mathrm{~L} / \mathrm{min}$ at $35 \mathrm{kPa}$ above atmospheric pressure when run at room temperature. When run at $373 \mathrm{~K}$, it is expected to deliver about $20 \%$ less volumetric flow (at NTP conditions), since it is a constant volume flow device. This 
pump is mounted in a separate enclosure beneath the enclosure containing the pressure transducers. The pump is protected from soot deposition with a filter on the inlet side.

The flow rate of the gas sample is much more than is needed by the analytical instruments; together they require less than $5 \mathrm{~L} / \mathrm{min}$ at one atmosphere. The reason for the excess gas flow is to shorten the time for getting the sample to the control room. The time to go from the gas sample tee to the control room is roughly $3 \mathrm{~s}$.

Condensation of water (especially) and any other volatiles in the sampled gas is a concern, especially in cold weather. The heads on the gas sampling pump are heated to minimize condensation. The pump enclosure is also heated. The line leading from the pump enclosure to the control room is $9.5 \mathrm{~mm}$ ID by $19.5 \mathrm{~m}$ long, Teflon-lined, heated tube. The line is typically run at a set point temperature of $348 \mathrm{~K}$.

Both the pump enclosure and the pressure transducer enclosure are mounted with wire rope vibration isolators (Enidine, Inc., Orchard Park, NY) between the enclosures and the adjacent supports. The principal reason for this is the sensitivity of the pressure transducers to any form of vibration. Both the gas sampling pump and the burners in the pollution control system can be significant sources of vibration of relatively low frequency (below about 30 hertz). The wire rope isolators offer better low frequency isolation than do rubber mounts.

\subsubsection{Gas Analysis System}

Figure 5 is a photograph of the flow control panel for the gas analysis system and Figure 6 shows a complete diagram of the gas analysis system located in the control room. As soon as the gas arrives at the analysis system, much of the excess flow is dumped to an exhaust line. ${ }^{9}$ The excess flow that is being dumped at the system inlet can be read with the large flowmeter. The flow normally bypasses this meter to minimize deposition of soot that may have passed through the pump filter. When the valves are switched so as to send the dump flow temporarily through the flowmeter one can check that the roof pump is behaving normally. The meter should read full scale (42.5 SLM) when the roof pump and the heated transfer lines are at their normal operating temperatures.

The pressure in the region where the flow from the roof enters the gas analysis system is normally kept at $500 \mathrm{~Pa}$ above atmospheric pressure to assure positive flow out through the exhaust line.

A pair of disposable flat disk filters is used to remove any particulates from the sample flow. The pressure drop across the filters is monitored by a Dwyer pressure gage attached to the flow line through $1.6 \mathrm{~mm}$ OD (1/16 in) stainless steel tubing. This small tubing minimizes any dead volume in these side lines.

\footnotetext{
${ }^{9}$ The reason for dumping much of the flow before the instruments are reached is the need to dry and filter the instrument flows. The water traps or the filters would tend to clog rapidly if presented with the full flow.
} 


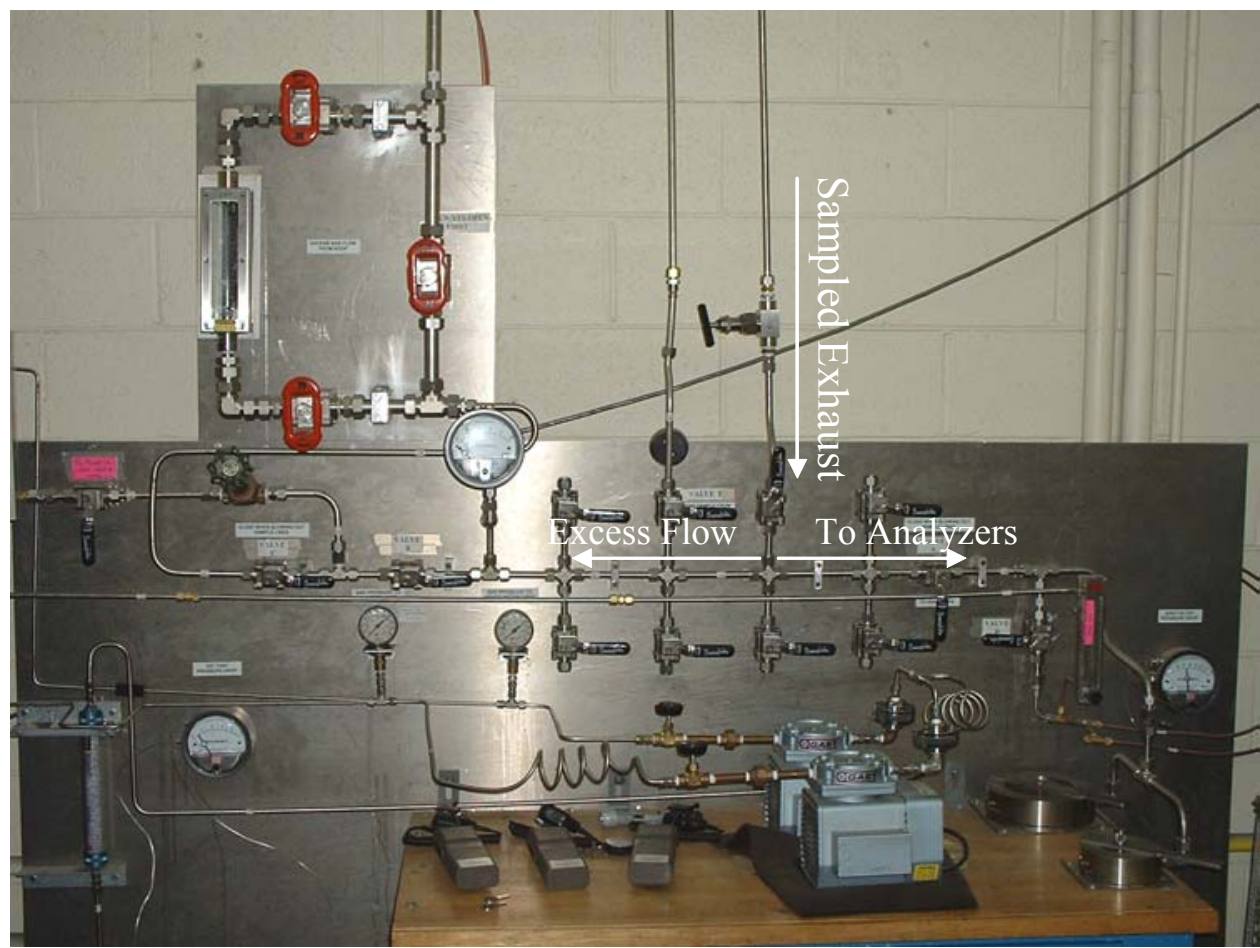

Figure 5 Gas sampling system flow control panel.

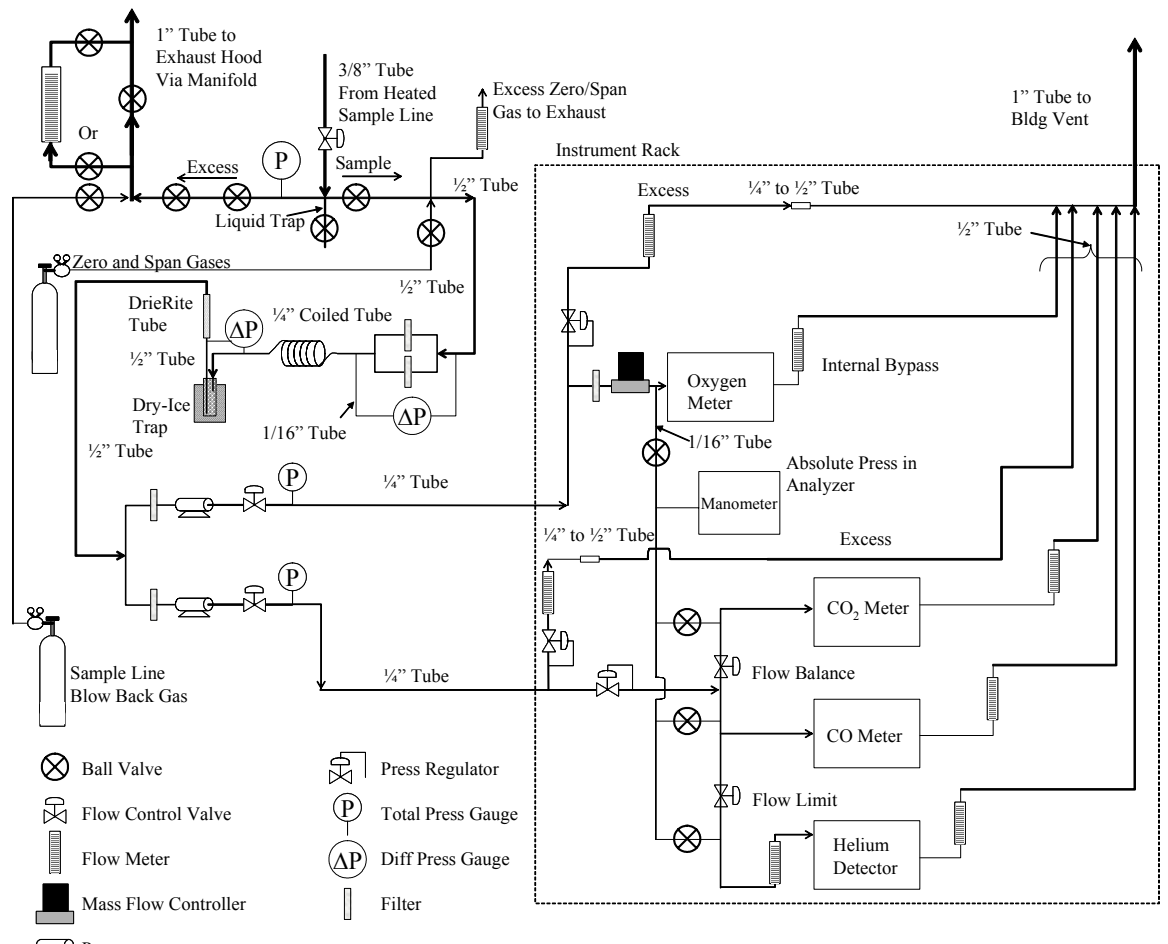

Figure 6 Diagram of the gas analysis system for the 3 MW HRR Facility. 
The flow runs through a dry ice trap for moisture removal. The trap is filled with glass beads to improve heat and mass transfer, thus assuring that most of the water is removed. The trap is designed to easily handle a 30 min fire test without clogging. The pressure drop across the trap is monitored by a Dwyer pressure gage. The dry ice trap is backed up by a Drierite dessicant trap since a water aerosol (that may form at the trap inlet) could pass through the ice trap ${ }^{10}$. The flow emerging from the Drierite tube is filtered once again before going into the control room diaphragm pumps (GAST Model DOA-P109$\mathrm{FB}$, rated at $54 \mathrm{~L} / \mathrm{min}$ ) to remove any Drierite dust.

Flow from one of the control room pumps goes to the Servomex 540a oxygen analyzer; the flow from the other pump goes to the Siemens Ultramat $5 \mathrm{e} \mathrm{CO}$ and $\mathrm{CO}_{2}$ analyzers. Each line has a manual valve, immediately downstream of the pump, to control the flow. The pressure gage in each outlet line helps monitor normal behavior; a faltering pump will be reflected in drift of its output pressure.

All of the gas analyzers measure the partial pressure of the gas being sensed; thus they are all sensitive to total pressure variations in the instruments. Of particular importance is the need to keep the pressure in the instrument the same during a test as it was during the instrument calibration preceding the test. Since the oxygen measurement is the most critical, it is given extra attention in this regard.

On the oxygen meter side of the pump, the flow is split just before a portion of it goes to the meter; the remaining flow is dumped to the exhaust line. The dumped flow passes through a pressure regulator (Porter Instrument Co., Model 8286) intended to help keep the flow in this path constant despite any upstream pressure variations. The flow rate is indicated by a Dwyer flowmeter downstream of the regulator. The flow to the oxygen meter is set by the controls on the oxygen meter itself.

The Servomex 540a oxygen analyzer is a paramagnetic device that takes advantage of the strong magnetic susceptibility of oxygen molecules. The current output of the device is a direct measure of the oxygen partial pressure. Since the device measures partial pressure, it is sensitive to temperature as well as pressure. The sample cell is in a specially thermostatted enclosure to keep its temperature constant. The pressure in the sample cell depends on total ambient pressure and on the flow rate to the cell. As indicated above, special efforts are taken to hold the flow constant. The total cell pressure is actively measured (see below), and any change (from the level during the span gas measurement) is compensated in the data acquisition program.

To assure further stability in the oxygen signal, an absolute pressure transducer (MKS Baratron Model 628, 0 to $133 \mathrm{kPa}$ ) is used to monitor the measurement cell pressure and to actively correct (in the data acquisition system) for any variations (with the value during calibration as the reference). A fitting internal to the oxygen meter, just upstream of the measurement cell, was modified to include a small diameter tube leading to this pressure transducer.

\footnotetext{
${ }^{10}$ The oxygen meter is sensitive to moisture in the gas sample. Past experience has shown that if about half
} of the Drierite tube length is showing a color change from blue to pink, the oxygen signal can begin to drift. 
The Siemens Ultramat 5e $\mathrm{CO}$ and $\mathrm{CO}_{2}$ analyzers both utilize a non-dispersive infrared absorption principle. Light from a broadband infrared source is split into two beams, one going through the sample cell and the other through a nitrogen-filled reference cell. A pair of double-layer detector cells is placed at the ends of both sample and reference cells. The four detector cells all contain a fixed percentage of the gas to be analyzed ( $\mathrm{CO}$ or $\mathrm{CO}_{2}$ ). A chopper wheel causes a pulsating signal whose amplitude is proportional to the amount of $\mathrm{CO}$ or $\mathrm{CO}_{2}$ in the sample cell.

The pump flow going to the $\mathrm{CO}$ and $\mathrm{CO}_{2}$ meters is in excess of instrument requirements so as to decrease the transit time and the excess is dumped as it enters the instrument rack area. The dump flow and the combined instrument flows are each controlled by a pressure regulator (Porter Instruments Model 8286). The flow to the two instruments is set using their built-in controls and flowmeters.

\subsection{Data Acquisition System}

\subsubsection{Signal Input and Output}

The signals from the various measurement devices used for oxygen-depletion calorimetry determination of heat release rate are collected using the NIST Large Fire Research Facility data acquisition system (DAQ). The DAQ is currently configured to collect data both from instruments for calorimetry calculations and from other instruments or sensors being utilized for the experiment.

The DAQ hardware components (manufactured by National Instruments) are stored in an instrument rack in the instrument control room of the Large Fire Research Facility. The DAQ components are separate from the computer and transfer of data between the DAQ and computer is via a PCI (Peripheral Component Interconnect) bus computer interface. The primary DAQ board has 16 analog input channels at 16 bit digital resolution and is capable of a sampling rate of $333 \mathrm{kHz}$. A total of 40 analog input signals are required for the calorimetry computation. Seven signal conditioning and multiplexing modules are employed and each module has a capacity for 32 input channels. The channels are scanned at a rate of $200 \mathrm{~Hz}$ and the signals are dumped to a single channel on the primary DAQ board. Each multiplexed channel is electronically averaged for $1 \mathrm{~s}$ and the digital value is stored to the computer. The signal conditioning features of the modules include an electronic filter (200 Hz low pass) and gains (up to 100 times). The gains are typically applied to low voltage signals such as those produced by thermocouples. Each module is connected to a shielded terminal block which collects signals up to $10 \mathrm{~V}$ amplitude and provides cold junction compensation for thermocouples voltages.

\subsubsection{Real Time Display}

The user interface for the DAQ is written in a LabView program to compute the heat release rate and display user-specified data and computations. The program is run on a Windows workstation with dual $733 \mathrm{MHz}$ processors and is located in the instrument 
control room of the Large Fire Research Laboratory. The output is displayed on the workstation monitor and updated as the fire test occurs.

During a fire test, all measurement channels are available for display. Calorimetry instrument readings, velocities, and heat release rate (both from the oxygen calorimetry calculations and the calibration burner) are displayed graphically with up to 6 min of history (see Figure 7). Additional plots of instrument raw voltages are available to assist with the zeroing and spanning processes. In addition, plots of other important, but noncalorimetry-related measurements are displayed when specified.

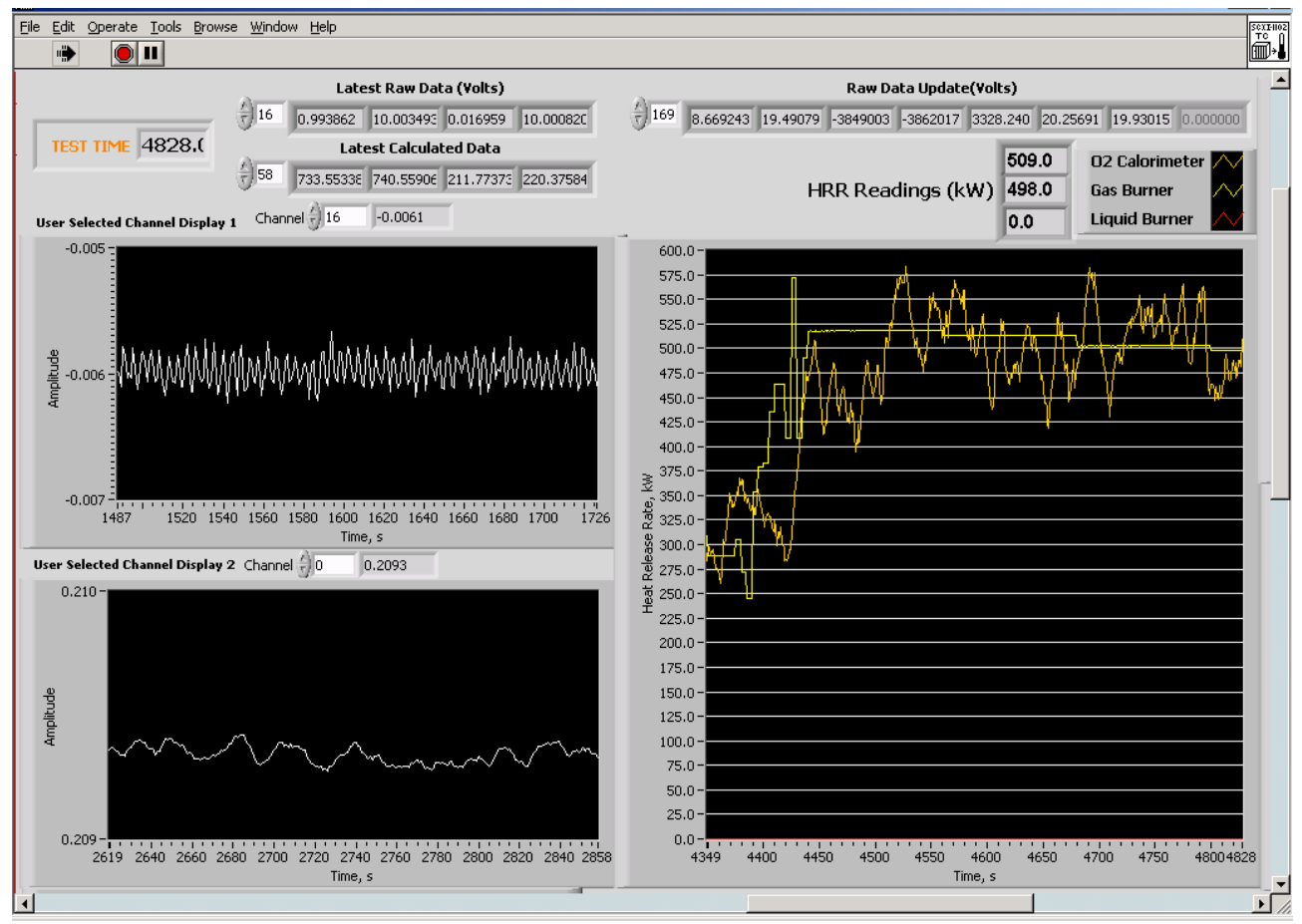

Figure 7 Real time display of oxygen sensor cell pressure ratio (upper left), oxygen volume fraction (lower left) and heat release rate (right).

Two marker channels are available and are used to keep track of specific events during a fire test. These markers are initiated with pushbuttons which are prominent on the display screen. Event marking puts simulated voltage spikes from 0 to $5 \mathrm{~V}$ and 10 to 15 $\mathrm{V}$ for one second in the channels set up for the markers. Plotting the data in these channels along with a basic measurement or calculated value enables relating the events to the response of the calorimetry system or a particular component of it. Such events include the beginning of zeroing, spanning, and background averaging periods, ignition and extinguishment of the fire, and step increases and decreases that are of importance for delay and system smoothing characterization. 


\subsubsection{Computation Algorithm}

Most data are stored as voltages without modification. (The exception is the temperature measurements, which are converted in real time to degrees Celsius.) A second data file is created simultaneously in which the raw voltages are converted to $\mathrm{CO}, \mathrm{CO}_{2}$, and $\mathrm{O}_{2}$ dry volume fractions, pressures, etc. These are in turn combined to generate flow velocities, duct volume flow, duct mass flow, and heat release rate. For heat release calorimetry testing, data are combined after estimating the relative delays for each instrument (described below) and synchronizing the data generated by a given moment of the fire.

Each channel of raw or computed data has an associated delay time. The delay time is the period between when a fire event occurs under the hood and when the particular sensor begins to respond to the change associated with the fire event. There are two main categories of delay. The first is for those sensors located at the sampling section of the duct which include pressure transducers and thermocouples. These sensors respond in less than a second to changes in their environment, but the input from an event under the hood is delayed in reaching the sensors by the flow time for the gas at the flame tip to enter the hood and progress through the duct to the sampling section. The second category of delay is for the gas analyzers located in the experiment control room. These instruments experience the duct flow delay as well as a sampling line flow delay and their own inherent sample processing delays (response times). These delays, which vary with the exhaust flow, are determined from specific tests that investigate instrument response to step changes under the hood.

The data acquisition and analysis program uses the delays to combine the outputs of sensors and instruments in such a way that the responses to particular phenomena under the hood are synchronized. In other words, output from fast responding sensors is stored in memory to be combined with output from the more slowly responding sensors at the appropriate time. Thus the faster sensor outputs are actually delayed in their combinations and calculations while the slowest outputs are utilized instantly.

The concept of storing varying histories of sensors with different response times is straightforward. The maximum delay time experienced by any sensor in the whole set of sensors defines how much history is stored for all sensors in the "history array". A delay time for each sensor is converted to an integer number of seconds. This also represents the position in the array that corresponds to the appropriate age of the data relative to that of the slowest sensor (the age and position correspond directly due to the $1 \mathrm{~Hz}$ sampling rate).

As the fire test proceeds, the calculations are grouped in several sets. Each set builds on variables calculated in the previous sets. The algorithm flowchart in Figure 8 displays these calculation steps. 


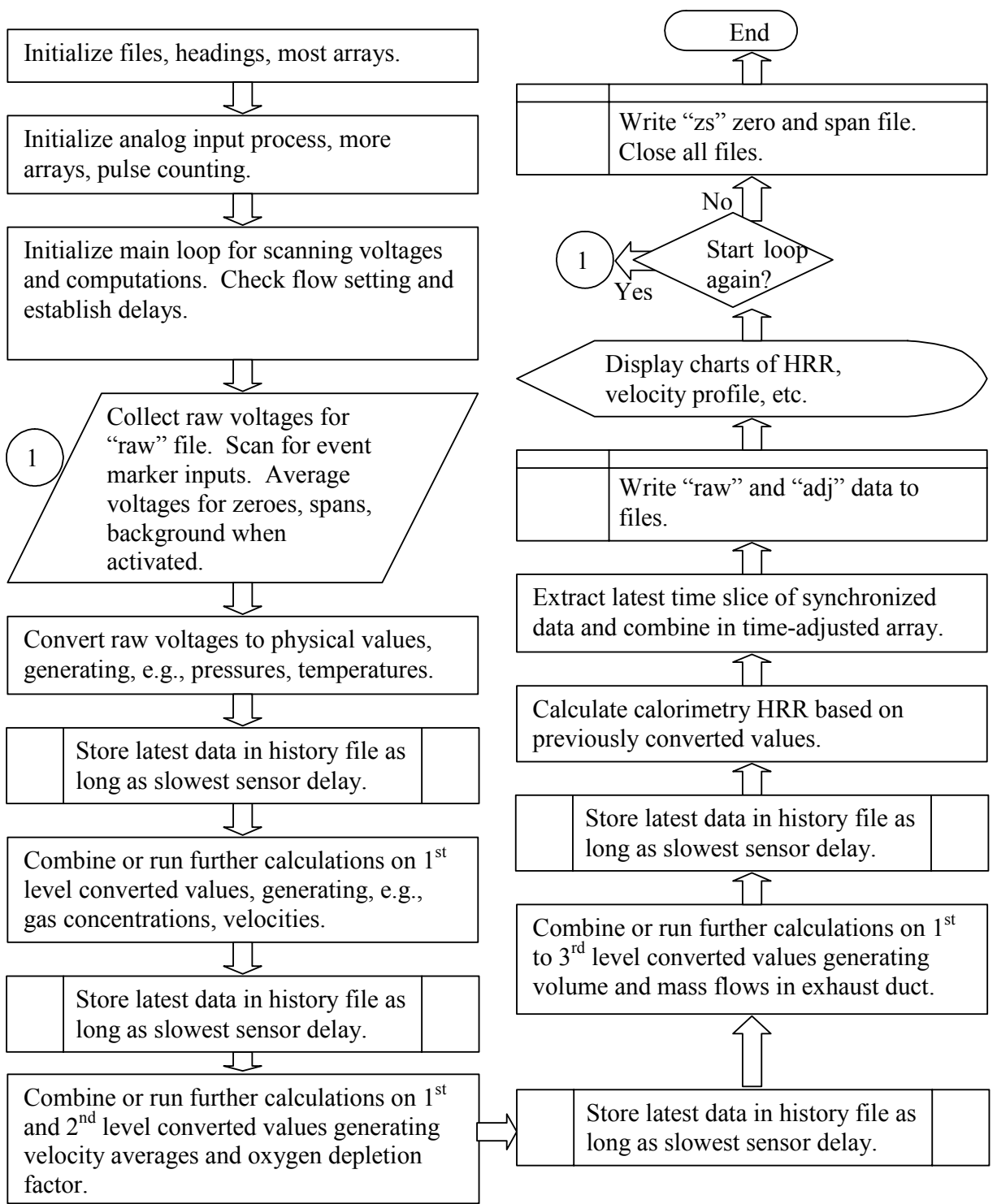

Figure 8 Heat release rate computation algorithm.

In the first set, the calculations include all temperatures, basic $\mathrm{O}_{2}$ volume fraction, $\mathrm{CO}$ and $\mathrm{CO}_{2}$ range factors, pressures, and mass losses. The second set of calculations includes those for oxygen volume fraction pressure correction, $\mathrm{CO}$ and $\mathrm{CO}_{2}$ volume fractions, bi-directional probe velocities, water vapor volume fraction at ambient temperature, and average duct gas temperature near the sampling section (and the uncorrected natural gas flow and pressure for calibration burns). The third set of calculations includes the average duct velocity, and the oxygen depletion factor, $\phi$ (and the heat release rate of the natural gas for calibration burns). The fourth set consists of calculations of the volumetric duct flow and the mass flow in the duct. The last step calculates the heat release rate based on the duct mass flow, $\phi$, and the $\mathrm{O}_{2}, \mathrm{CO}, \mathrm{CO}_{2}$, and $\mathrm{H}_{2} \mathrm{O}$ volume fractions. 


\subsubsection{Data Storage}

Three files are generated during a fire test with suffixes "raw," "adj," and "ZS:" The "raw" file records the raw voltage values, thermocouple temperature values, and the two event marker channel values.

The "adj" file records the simple one-step conversions applied to the raw voltages to give values in terms of scientific significance such as species volume fraction and pressure. In addition the results of calculations for velocity, mass flow rate, and oxygen depletion factor are stored. Finally, the computation of the heat release rate is stored. The "raw" and "adj" files are updated each second with each sample of the data acquisition system and the associated time stamps are stored.

The "ZS" file lists the voltages generated by the zeroing and spanning processes for the gas analyzers as well as the calibration signals for the response of pressure transducers, load cells, etc. For some of the instruments, such as the gas analyzers, the calibration curve is linear and interpolation between two calibration points enables assignment of volume fractions to the recorded voltages. Other instruments, such as the pressure transducers and load cells, are generally non-linear or nearly linear and have been precalibrated over the necessary range. These calibration equations require a single point each to enable conversions from voltage to, e.g., Pa or kg.

\subsection{Calibration Burner System}

Because the calculation of heat release rate requires a large number of individual measurements, it is essential to have an independent confirmation of measurement accuracy. This is accomplished by burning an accurately measured flow of natural gas having a well-defined heat of combustion.

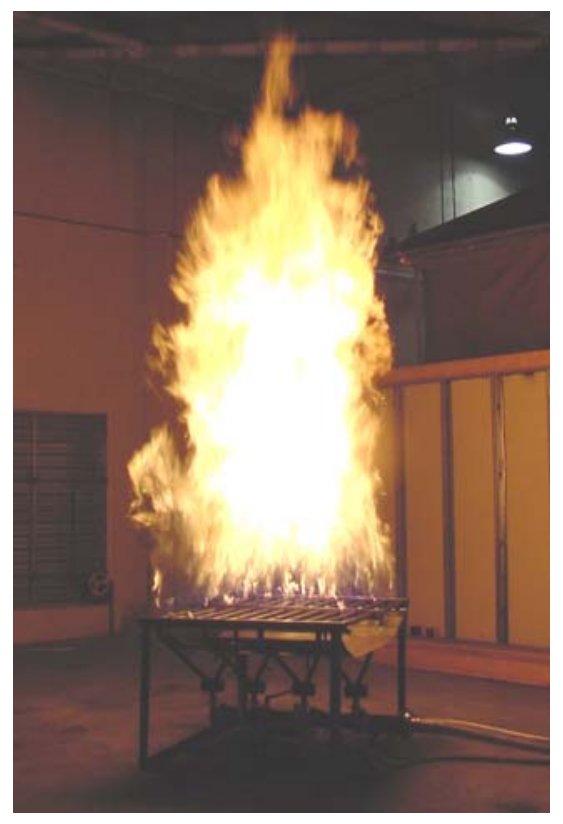

Figure 9 Photo of 3 MW fire from the natural gas burner. 
The natural gas burner, shown in Figure 9, has been designed, fabricated and tested for this purpose. The burner can produce flows that correspond to a wide range of heat release rates, from $50 \mathrm{~kW}$ to over $6 \mathrm{MW}$ in any increments specified by the user. The burner and flow system are configured to use natural gas as supplied by the local gas company. The energy content of the gas supply is measured by a natural gas calorimeter (COSA CW95) located in the instrument control room. Operation of the burner is automated with control and monitoring executed from the DAQ system.

\subsubsection{Burner}

The natural gas burner has a height of $96 \mathrm{~cm}$ (measured from floor to exit holes) and plan view dimensions of $112 \mathrm{~cm} \times 150 \mathrm{~cm}$ (width $\times$ length). It is capable of producing controlled fires up to $6 \mathrm{MW}$ using natural gas as fuel. The natural gas is delivered to the combustion zone above the burner through eleven primary rows of tubes. Two pilot tubes are located below and perpendicular to the primary tubes. The eleven primary tubes are grouped into four separate banks, which are independently opened and closed using solenoid valves. Operation of the four primary banks is dependent upon the amount of energy released in order to regulate flame-height, maximize efficiency and minimize the risk of flame blow-off. Each bank consists of three tubes except for Bank 1 which consists of two tubes. Each primary tube is split in half and capped at the end to allow for thermal expansion, thereby minimizing stress on the burner. Each tube has 56, $3 \mathrm{~mm}$ diameter holes drilled every $2.54 \mathrm{~cm}$. Flow is initiated to the pilot tubes by a solenoid valve and the pilots are ignited using a $10,000 \mathrm{~V}$ spark igniter. Figure 10 is a photograph of the burner.

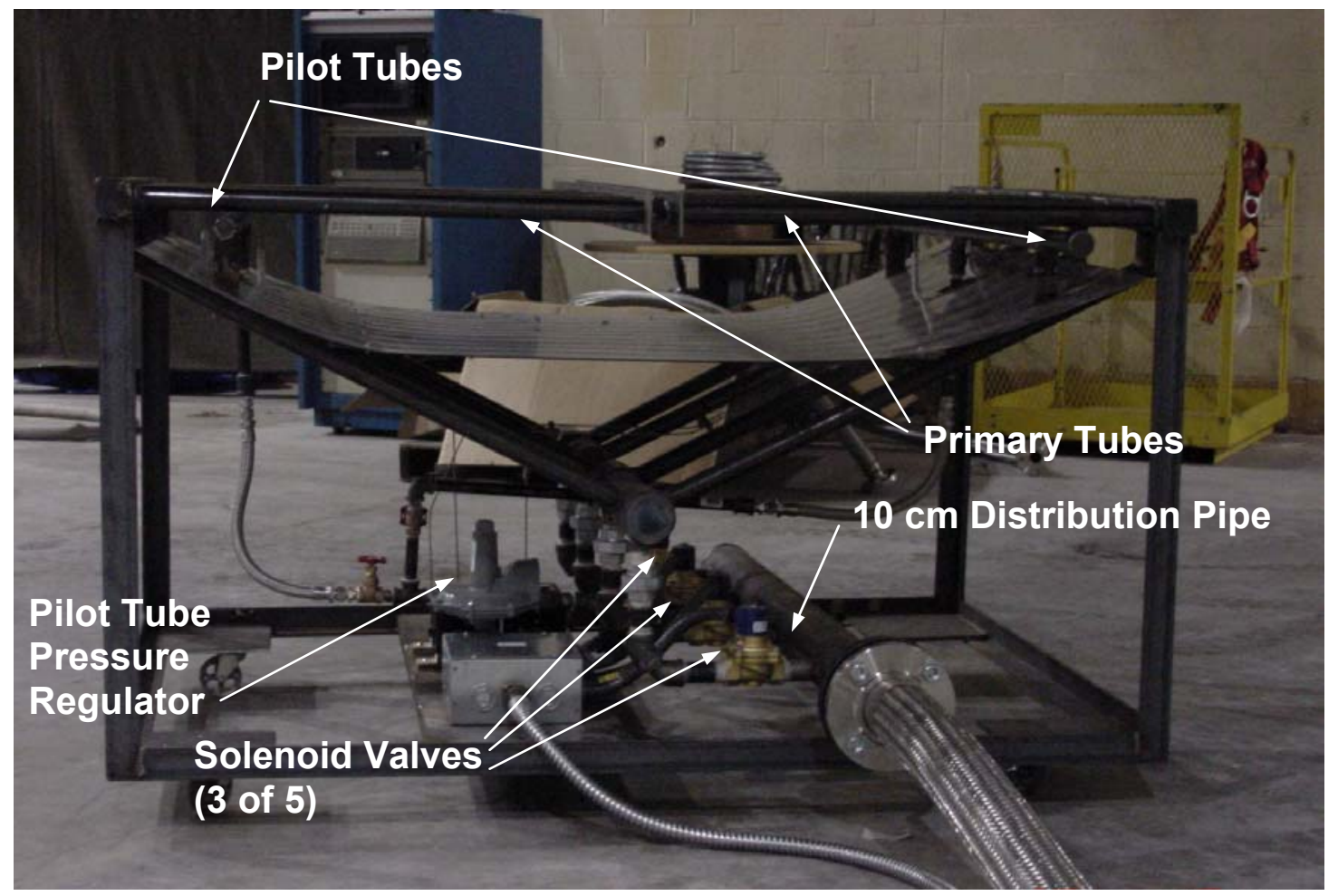

Figure 10 Calibration burner. 
The burner is supplied with natural gas by a $7.5 \mathrm{~cm}$ diameter (i.d.) flexible stainless steel wound hose line, which feeds into the burner through a $10 \mathrm{~cm}$ diameter (i.d.) main distribution pipe. The main distribution pipe feeds both the two pilot lines and the 11 primary tubes. An electronic photoelectric sensor monitors the pilot flame and is linked to a shutoff valve to assure that a flame is burning when the gaseous fuel is flowing.

\subsubsection{Flow Control and Flow Measurement}

The burner is supplied with natural gas through an overhead gas train, which controls and measures the amount of gas supplied to the burner. Gas pressure is regulated to approximately $100 \mathrm{kPa}$ above atmospheric pressure prior to reaching the overhead train. The gas train consists of a filter, a flow control valve, a volumetric gas flow meter, and a safety shut-off valve. The flow control valve is a pneumatically driven, programmable, high precision valve that is controlled by current provided by the data acquisition system. The volumetric flow meter is a rotary displacement meter that provides an amplified pulse output that is detected by the data acquisition system. A thermocouple and a pressure transducer are located in the volumetric flow meter so that mass flow may be deduced from the volumetric flow measurement. Figure 11 is a photograph of the gas train installed overhead in the Large Fire Research Laboratory.

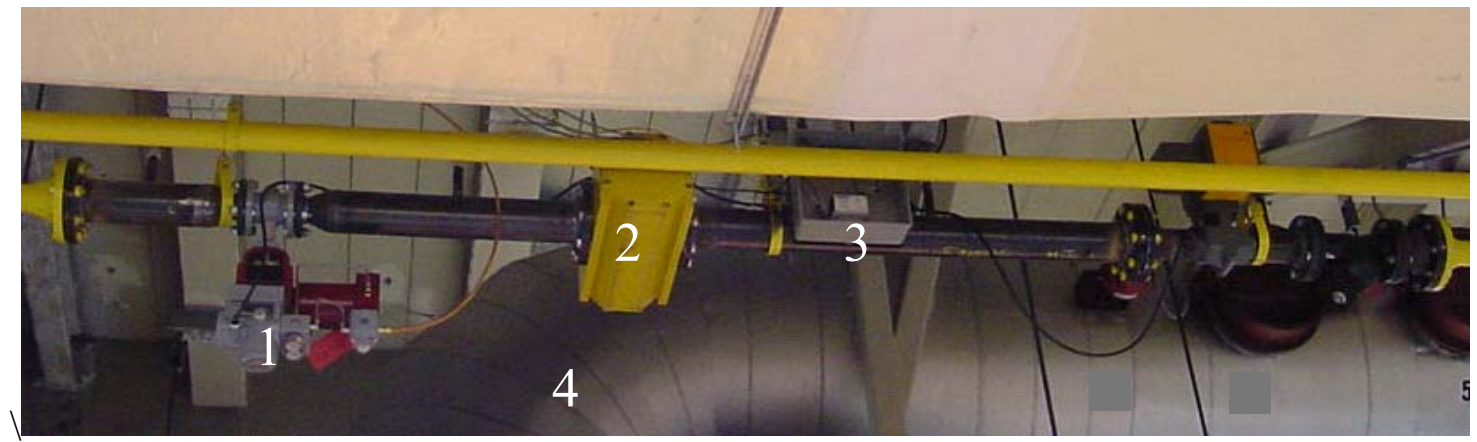

Figure 11 Overhead gas train including the (1) control valve, (2) rotary displacement meter, and (3) emergency shut-off valve. The exhaust duct (4) is also shown.

Figure 12 is a schematic diagram of the burner and the systems used to measure and control the flow of gas. The automated safety system is also shown on the diagram and includes a photoelectric sensor (FireEye), the Safety Panel, and Emergency Cut-Off switches. The input and outputs to the Safety Control panel are shown schematically in Figure 12. The panel is used to initiate the gas flow and to cut-off the gas flow in the event of an emergency. The manual cut-off closes the emergency shut-off valve labeled as item (3) in Figure 11. For emergencies, manual cut-offs are also positioned at doors on the east and west sides of the Large Fire Research Laboratory. 


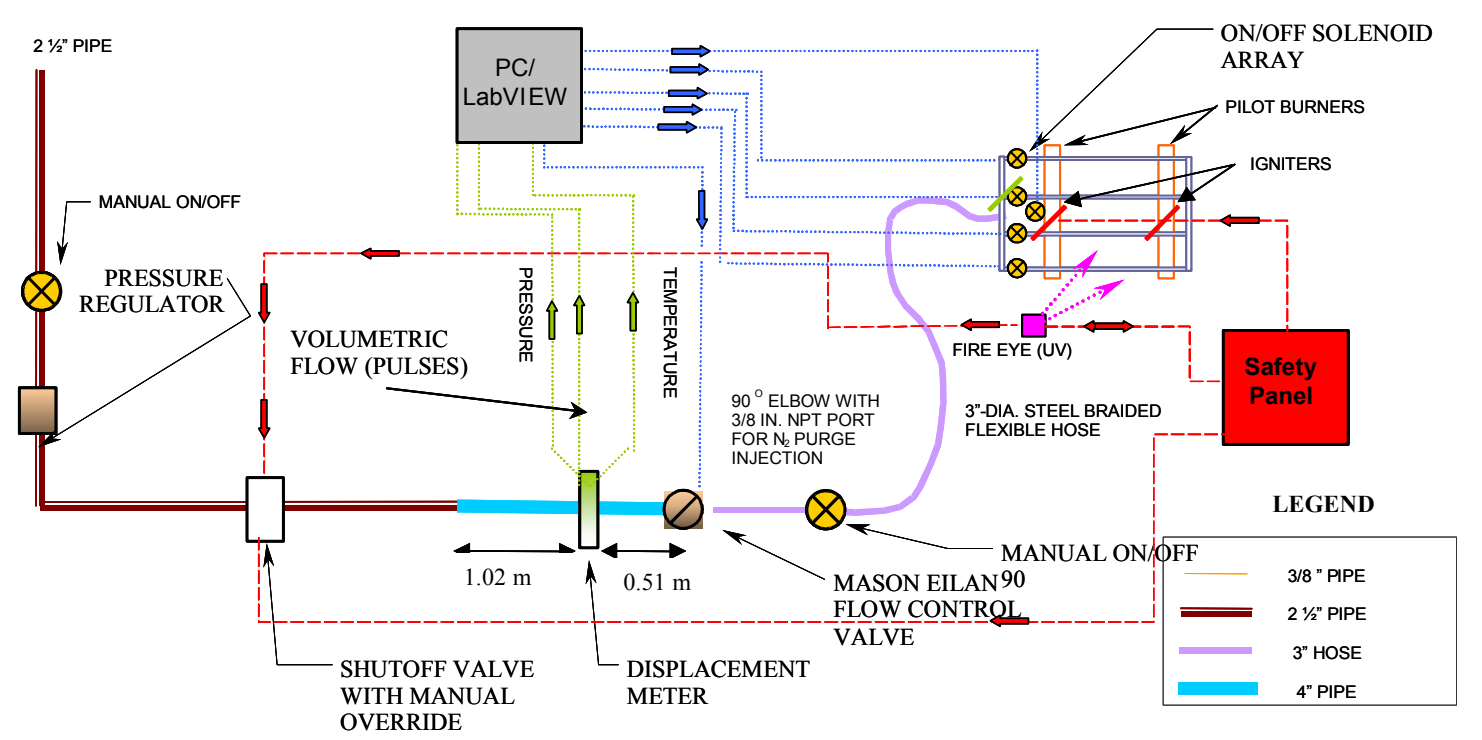

Figure 12 Schematic diagram of the natural gas burner system.

\subsection{Design Considerations}

\subsubsection{System Time Delays and Time Response}

The computed heat release rate is displayed on the computer monitor during a test; however, the numbers lag behind the actual fire output. There are several components to the overall transient response of the system to an instantaneous event in the fire being measured. Initially there will be no response since the information about a change has not reached the analyzers whose data go into the heat release rate calculation. So the first component of transient response is the gas travel time from the flame tips to the location in the duct where the gases are sampled; this varies with the hood flow rate. Next there is the gas travel time from the gas sampler on the roof to the inlet of the instruments in the control room (which includes the travel time through the plumbing in the control room). These are independent of hood flow rate but depend on the pumping speed of the system and the use of bypassed flows. Finally there is the response time of the instruments themselves. This is fixed when the flow rate to each instrument is set at its manufacturerrecommended value. Along the entire path, the gas does not travel as a rigid slug; rather it tends to undergo mixing with gases originating later as a result of various turbulent mixing processes. This process, called dispersion, also affects time response of the overall system to a change in the fire behavior. Careful design helps minimize this effect.

In general one needs to measure the lag time (total sample flow time) from the fire to the instrument inlet. This has a differing value for the oxygen meter and the $\mathrm{CO} / \mathrm{CO}_{2}$ meters since they involve differing flow paths (and flow rates) in the control room. Lag time is used to synchronize the measurements that go into the heat release rate calculation. One also needs to measure and take note of the system response times for the individual gases. These are to be kept within a certain range since they affect how closely the system will 
follow a given time-varying heat release rate process from the fire being measured. In particular, system response times affect accurate measurement of brief heat release rate peaks (see section on transient effects below).

As a first approximation, a few of these times break out as follows:

- Duct flow time (fire to sampling point at $9.9 \mathrm{~m}^{3} / \mathrm{s}$ ) $\approx 7 \mathrm{~s}$

- Gas sample flow time from roof to control room $\approx 2 \mathrm{~s}$ to $3 \mathrm{~s}$

- Instrument response times at nominal flow rates $\approx 5 \mathrm{~s}$ to $10 \mathrm{~s}$

The total system delays are somewhat longer than the sum of these numbers, however; for example, the total delay is $25 \mathrm{~s}$ for a particular experiment discussed below.

Precise values of the lag time for each instrument are needed since they must be incorporated into the data handling that results in a correct calculation of heat release rate. Measurement of these times is facilitated by a heat source that can be changed abruptly in magnitude (up and down). This capability is achieved via the data acquisition computer which commands the degree of opening of the gas flow control valve in the line to the multi-tube calibration burner; this system itself has an approximately one second lag time in response to computer commands.

The first time interval, the flow delay to reach the gas sampling plane in the duct on the roof, is measured by putting an event mark in the test file when the gas flow to the burner is turned on and then by finding the time at which any ${ }^{11}$ of the thermocouples on the bidirectional probes begins to register a gas temperature increase. Reference [15] recommends a specific value of a temperature increase of $3 \mathrm{~K}^{12}$ and that is what is used for the NIST system. Again, this time interval varies with the hood flow rate.

The second component of the lag time for a given instrument, the time to go from the gas sampler on the roof to the inlet of the instrument, is a constant if the speeds of the roof and control room pumps are constant and the fraction of the excess sample flow dumped at the first flow split is unchanged. However, as noted, it can vary between the oxygen meter and the $\mathrm{CO} / \mathrm{CO}_{2}$ meters, because the flow paths differ from the laboratory pump(s) onward. This component of the lag time is found by noting the time between the above thermocouple response and the first instrument response to the fire-altered gases. Reference [15] recommends taking the time when the oxygen meter reading shows an increment of $0.05 \%$ and the $\mathrm{CO}_{2}$ meter an increment of $0.02 \%$; these are also adopted for the NIST system. Note that the CO level from a gas burner can be difficult to read. One can safely assume that the lag time component for it is the same as for the $\mathrm{CO}_{2}$ meter since they are effectively in the same flow system.

\footnotetext{
${ }^{11}$ The duct flow has been found to be well-mixed at flow rates of $9.4 \mathrm{~m}^{3} / \mathrm{s}$ and above. It is prudent to check more than one thermocouple at lower flow rates.

${ }^{12}$ To get a sharply readable increase of this size may require a fire of several hundred $\mathrm{kW}$. Larger hood flows require a larger fire. Too small a fire will give erratic results.
} 
The system response time is defined in Ref. [15] as the time for the oxygen meter $^{13}$ to go from $10 \%$ to $90 \%$ of the change induced by a step change in fire size. Again, any and all dispersion in the system, from the fire plume tip all the way to the gas analysis instrument, contributes to the time it takes for this signal to change from $10 \%$ to $90 \%$. This dispersion smears the original time sequence of events in the fire. In particular, it decreases the reading of any heat release rate peak that occurs on a time scale comparable to or shorter than this $10 \%$ to $90 \%$ response time of the system. This raises an issue that is discussed further in the next section.

\subsubsection{Transient Effects on Peak Heat Release Rate}

Fire regulations are frequently based on maximum allowed rates of heat release. Different calorimeter facilities have differing time responses and thus differing tendencies to smooth out a brief peak. Some facilities use an open hood while others use a compartment which allows smoke to build up prior to spilling into the hood, thus adding a delay in measurement of heat release rate.

Messerschmidt and Van Hees [15] discuss this transient response issue in the context of the European Community's Single Burning Item Test, which is based on heat release rate measurement. It is shown that different laboratories could end up rating a product differently in this test solely as a result of the differing transient behavior characteristics of their measurement systems. They recommend that the oxygen meter's apparent response time (defined as above) fall within a window of $9 \mathrm{~s}$ to $12 \mathrm{~s}$, in order to minimize the tendency of differing labs to rate a product differently in the Single Burning Item test.

Another aspect of transient system response is related to noise in the calculated heat release rate. System noise (a result of the random variations in all of the variables entering into the heat release rate calculation) can affect the apparent magnitude of a heat release peak, and thus its uncertainty. The effect depends on the root mean square noise level and its frequency characteristics relative to the peak duration. An approach that is sometimes used is to judge a tested product's performance on the basis of a heat release rate curve subjected to a running time averaging process. The longer the time interval used for averaging, the more the noise is filtered out but also the more real, rapid heat release rate changes are damped. This raises the question as to how rapid a heat release rate fluctuation matters when an object is burning in some context such as a compartment fire. There may not be a unique answer to this and it is a subject of planned research at NIST. For now one can estimate that in a compartment fire context, upper layer gas temperature changes and second object ignition processes begin to respond significantly to heat release rate alterations in a time of the order of $5 \mathrm{~s}$ to $15 \mathrm{~s}$, suggesting this range as the appropriate upper limit for time smoothing of the data. In practice, it is easy to use graphing software to examine the effect of varied time smoothing intervals on the heat release rate peak of a test object. For mattress fires it was found that $20 \mathrm{~s}$ smoothing reduced the apparent peak values by a couple of percent. In Ref. [15], a 30 s interval was

\footnotetext{
${ }^{13}$ The $\mathrm{CO}$ and $\mathrm{CO}_{2}$ meters' response times (inherent to the instruments, not the overall system) tend to be a little faster than the oxygen meter and thus do not limit the system response. In any event, they tend to be secondary in importance to HRR calculation.
} 
used without any discussion. The smoothing interval, if any, should be reported along with the heat release rate data.

\section{Determining the Role of Transient Effects on Measured Peak Heat Release Rate and} Energy Conservation

As part of the present work, a series of experiments was performed to characterize the response of the $3 \mathrm{MW}$ heat release rate calorimeter to square-wave pulses in terms of peak heat release rate, the width of the peak, and the conservation of energy. The results of these experiments were used to establish a criterion for assessing whether the peak heat release rate for an experiment is being underestimated because of the time response of the system.

In principle this is a problem which can be treated as a deconvolution of the actual heat release rate vs time from the measured heat release and the system response characteristics [16,17]. Thus one solves an integral equation relating observed heat release rate to the time integral of actual heat release rate modulated by the measurement system response. Differing mathematical techniques have been demonstrated in the noted references. The inferred correction to the apparent heat release rate history is sometimes large $(\mathrm{O}(100 \%))$, particularly for cases in which the heat release rate peak width is comparable to the time response of the measurement system. However, it is pointed out in Ref. [18] that the deconvolution process is quite sensitive to noise in the data and to the errors in the system response function. Thus it is of unclear value here where both of these issues are significant. Rather than proceed in this manner, we focus on characterizing the time response domain in which the $3 \mathrm{MW}$ hood system gives accurate results. Deconvolution remains an area for further exploration.

The basic approach to assessing system time response was to produce a square-wave pulse heat release rate using the natural gas calibration burner described in Sec. 2.3. The peak heat release rate was set at nominal values of $0.5 \mathrm{MW}, 1.0 \mathrm{MW}$, and $2.5 \mathrm{MW}$ using a flow control valve. A signal was manually initiated from the computer control panel to open the flow control valve to a preset value and a second signal was sent to reset the flow to the pilot level. The loop time of the program for controlling/acquiring data is $1 \mathrm{~s}$.

The heat release rate of the burner is computed from the heating value of the natural gas, its pressure, and the flow rate. As discussed in Sec. 2.3.2, the flow meter is a rotary device which displaces a fixed volume of gas four times per revolution. Digital pulses are produced at a rate of about 1 pulse per $2 \mathrm{~L}$ of gas. A heat release rate of $1.0 \mathrm{MW}$ corresponds to about 7 pulses per second and $2.5 \mathrm{MW}$ to about 18 pulses per second. The relatively low number of pulses per second limits the resolution for $1 \mathrm{~Hz}$ measurements such as needed in this study, but it does allow an accurate estimate of the average heat release rate.

A Schmidt-Boelter type radiometer with a time constant of $0.1 \mathrm{~s}$ to $0.2 \mathrm{~s}$ was used to provide a more rapid response to the actual peak heat release rate. The radiometer was set up a distance of $4 \mathrm{~m}$ from the burner with the view including the entire flame volume. The corrected burner peak heat release was obtained by multiplying the radiometer output 
times a calibration factor determined for each of the three heat release rates. To determine this calibration factor, the heat release rate computed from the calibration burner volume flow measurement and radiometer output were averaged over a $20 \mathrm{~s}$ period during the steady burning for each of the three heat release rates. The calibration factor is computed as the ratio of the average heat release rate to the average radiometer voltage. The ratios have a dependence on fire size with values decreasing by $30 \%$ for a five-fold increase in the heat release rate $(2.62 \mathrm{GW} / \mathrm{V}$ at $0.5 \mathrm{MW}, 2.20 \mathrm{GW} / \mathrm{V}$ at $1 \mathrm{MW}$, and $1.85 \mathrm{GW} / \mathrm{V}$ at $2.5 \mathrm{MW}$ ).

Figure 13 provides a detailed comparison for the burner heat release rate based on the flow meter and the output from the radiometer. Qualitatively the pulse shapes are similar as measured by both devices. The limited signal resolution of the flow meter is apparent from the discrete change in heat release rate around $4955 \mathrm{~s}$ and again around $4970 \mathrm{~s}$. There appears to be a one to two second delay in the processing of the pulse counting relative to the radiometer measurement. This delay was observed in all the tests. The inflection point of the radiometer output near the end of the pulse is thought to result from continued flow through the burner after the valve for the flow controller has been reset to the baseline level. The gas continues to drain as pressure in the gas line to the burner equilibrates to the lower baseline level.

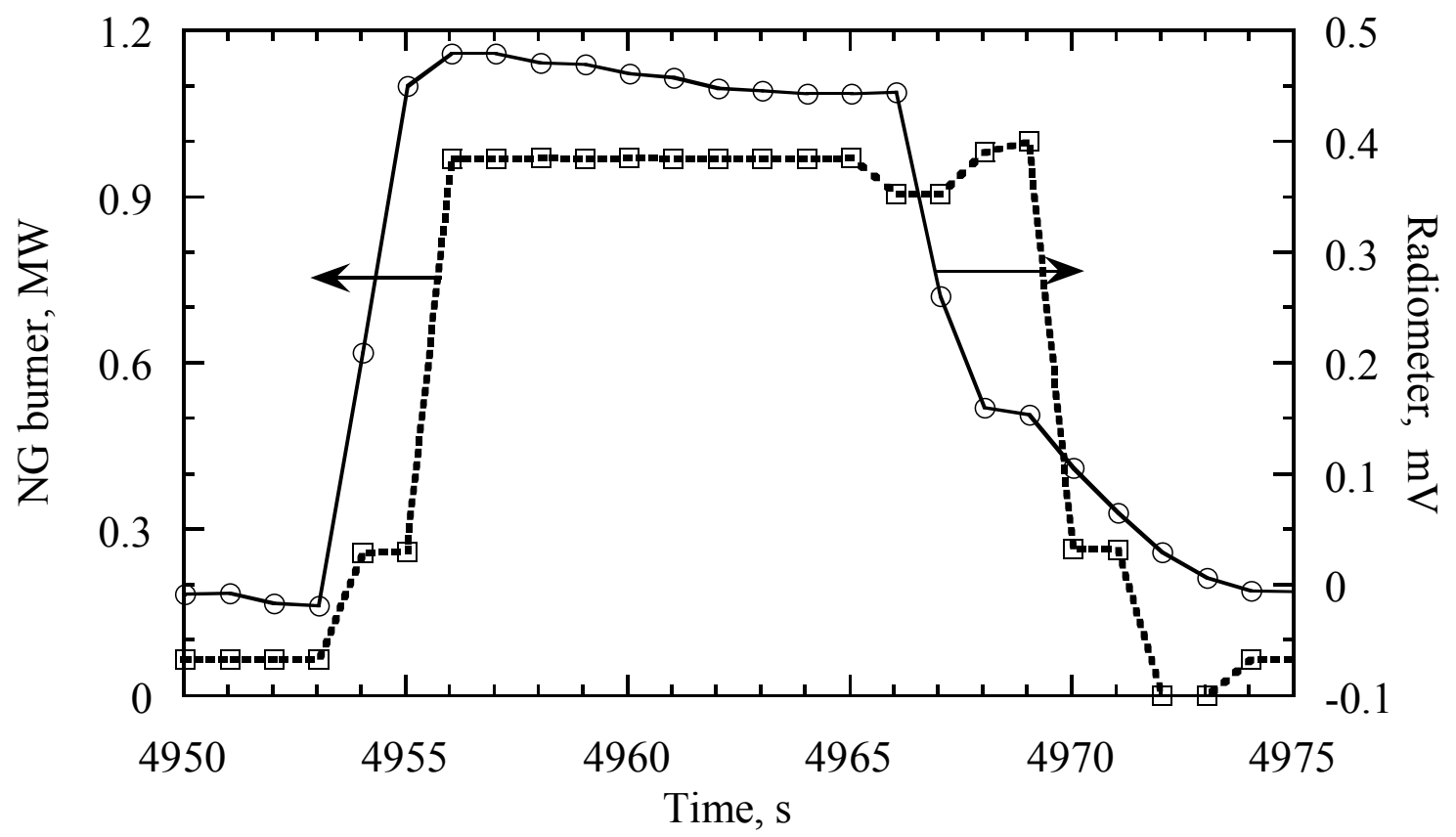

Figure 13 The square-wave pulse from a $15 \mathrm{~s}$ release of natural gas for a $1 \mathrm{MW}$ heat release rate as measured by a radiometer and the burner flow meter.

The measurement sequence began by setting the calibration burner at a heat release rate of $0.10 \mathrm{MW}$. This pilot level of heating is needed to efficiently ignite the rapidly increasing gas flow. The mass flow controller was set for a flow corresponding to $1 \mathrm{MW}$ heat release rate and then a switch was activated which in turn opened the mass flow 
controller valve. After a fixed time, the sequence was reversed and the heat release set back at $0.1 \mathrm{MW}$. After the calorimeter reached a steady heat release at this low value, a repeat run would be made following the same procedure as above. Typically three runs were made for each of four pulse times: $30 \mathrm{~s}, 15 \mathrm{~s}, 10 \mathrm{~s}$, and $5 \mathrm{~s}$. At least one measurement was also made for a $60 \mathrm{~s}$ pulse. This sequence was then repeated for heat release rates of $0.5 \mathrm{MW}$ and $2.5 \mathrm{MW}$.
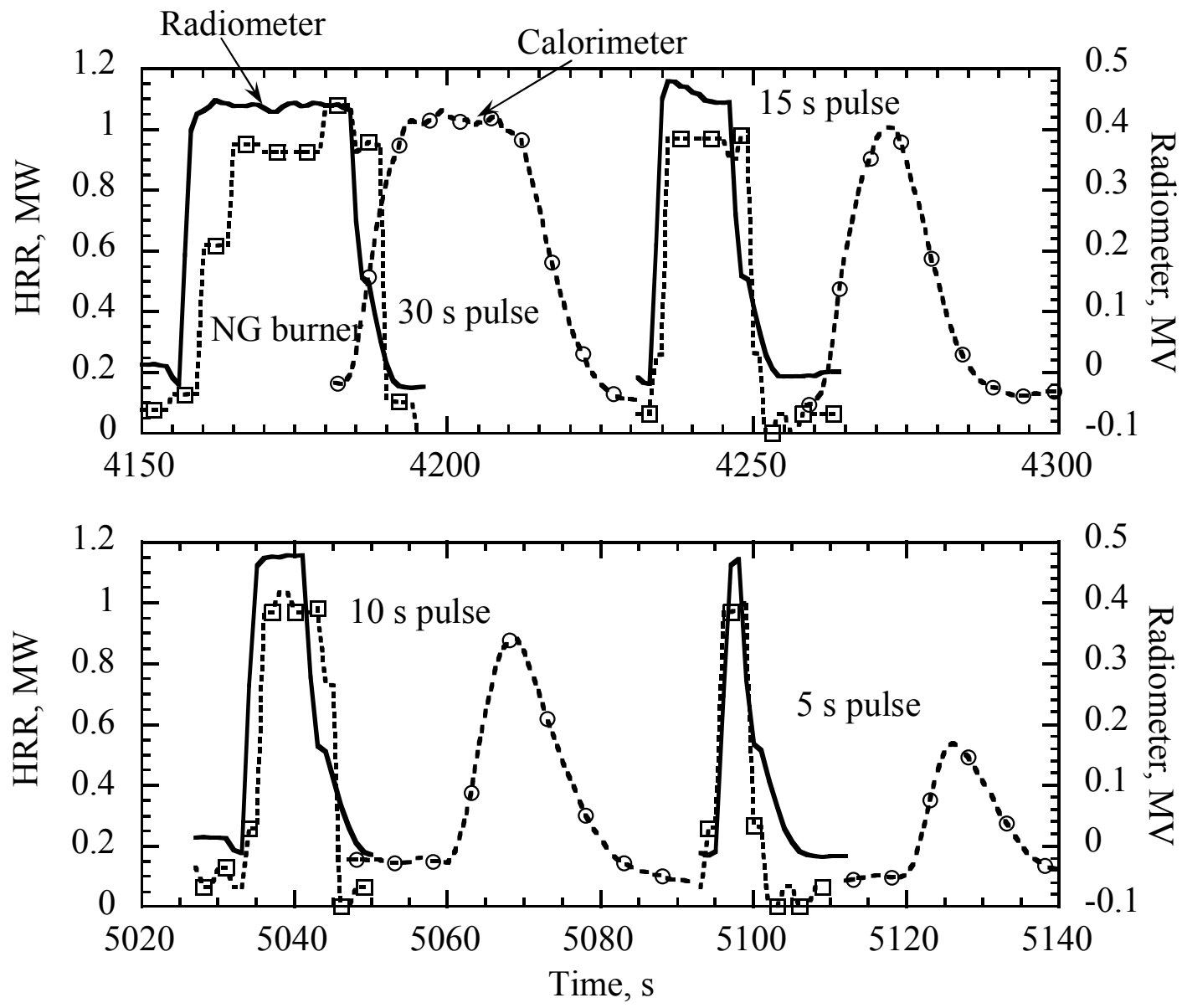

Figure 14 The measured output versus time for the NG burner ( ), calorimeter ( $(\circ)$, and radiometer (solid line) resulting from $1 \mathrm{MW}$ square-wave pulses of $30 \mathrm{~s}, 15 \mathrm{~s}, 10$ $\mathbf{s}$, and $5 \mathbf{s}$.

Figure 14 illustrates the characteristics of the square-wave pulse shapes for the $1 \mathrm{MW}$ fire for the four different pulse widths. The $25 \mathrm{~s}$ time delay for the calorimeter is a result of the gas sampling time together with the nominal $9 \mathrm{~s}$ response time of the oxygen analyzer. The relatively low resolution of the natural gas flow measurement is apparent from the step changes in the heat release rate. The radiometer provides a better representation of the heat release pulse shape since it responds to the flame intensity, and it has a higher resolution (and faster response time) than the gas flow meter. For the $30 \mathrm{~s}$ and $15 \mathrm{~s}$ pulses, the peak in the calorimeter output is close to that of the burner and the 
full time widths at the half peak height (FWHH) are similar though the curve shape produced by the calorimeter is rounded rather than square. The calorimeter peak is slightly reduced for the $10 \mathrm{~s}$ pulse and is reduced by about a factor of two for the $5 \mathrm{~s}$ pulse. In these two cases the FWHH values are also increased relative to the radiometer output.
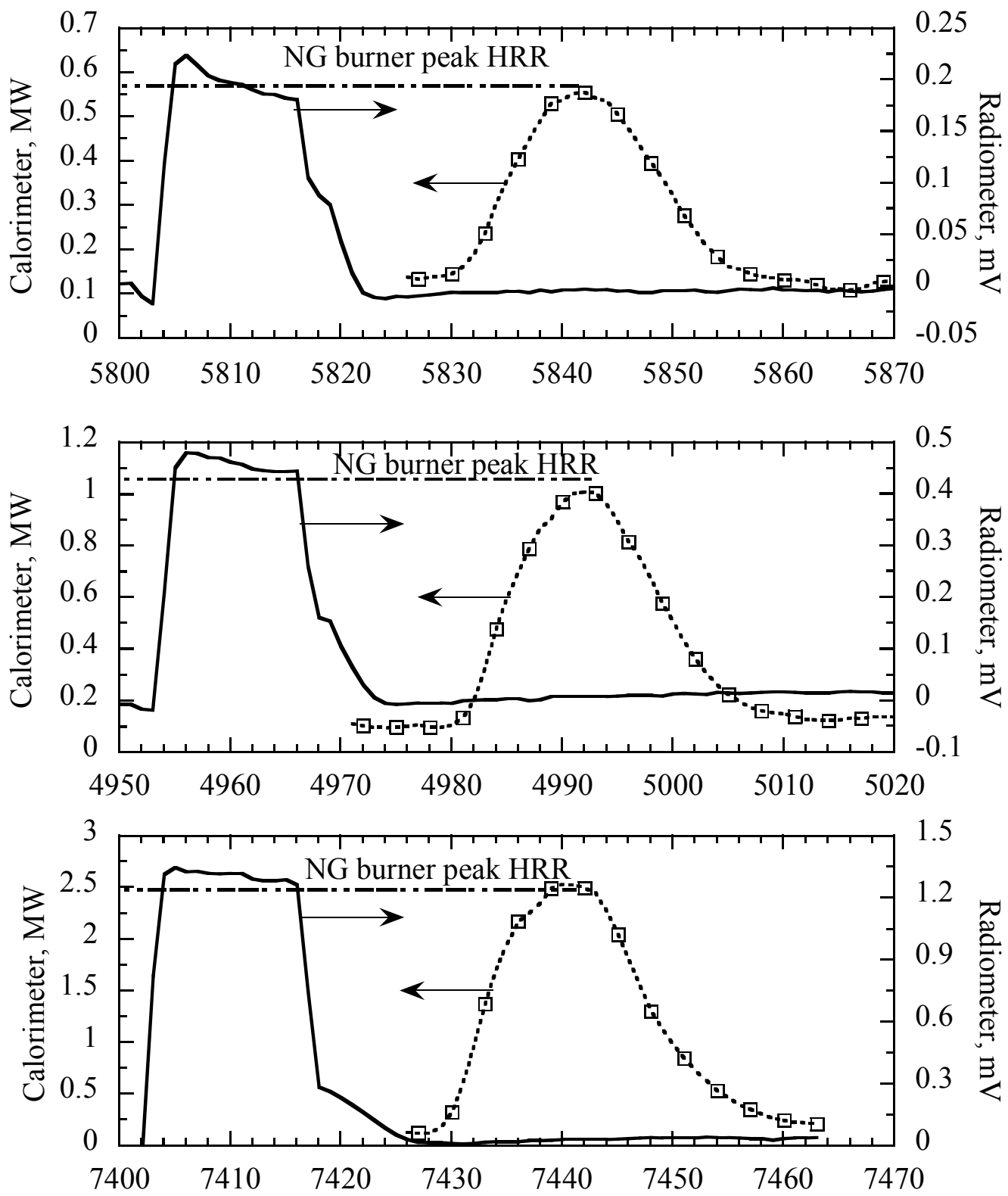

Time, $\mathrm{s}$

Figure 15 The heat release rate and the radiometer output as plotted versus time for $15 \mathrm{~s}$ pulses for HRR of $0.5 \mathrm{MW}, 1 \mathrm{MW}$, and 2.5 MW 
The pulse experiments for the other two heat release rates provided similar results. It is seen in Figure 15 for the $15 \mathrm{~s}$ square-wave pulses for the three heat release rates that the peak heights are similar to those of the NG burner, the FWHH are similar to those from the radiometer, and that the scaled shapes of all three calorimeter-generated curves are similar. There are slight differences in the radiometer-generated pulse shapes such as a flatter top section and a more abrupt decrease in the HRR at the end of the pulse for the larger heat release rates. These subtle changes do not seem to be reflected in the calorimeter-generated curves.

The total heat released by the pulse is equal to the area under the burner output curve. For energy conservation for the calorimeter system, the area under the calorimeter curve should equal the area under the burner curve. In Figure 14 the two areas appear to approximately match for the longer two pulses, but it is difficult to determine if this is the case for the shortest two pulses. A quantitative assessment of energy conservation was made by determining the total integrated heat released computed based on the burner flow and on the calorimeter output. The integrated area is that above the nominal 100 $\mathrm{kW}$ baseline. The baseline correction is estimated as the average of the baseline values before and after the pulse. The variation in the average ratio of the integrated calorimeter output to the integrated burner output for a fixed heat release rate (see Table 1) is within a range of $10 \%$ except for the $1 \mathrm{MW}$ fire, for which the ratio decreased by as much as 11 $\%$ for the $5 \mathrm{~s}$ pulse. It is thought that the low number of pulses, about 3 , counted per second is responsible for this decrease.

It was decided to again take advantage of the more rapid response time of the radiometer. A corrected total burner heat release was obtained by integrating the radiometer output and then multiplying by a calibration factor determined for each of the three heat release rates. The calibration factor was selected so that the radiometer "energy" equaled the integrated heat release rate from the gas burner for the 30 second experiment. The flow meter accuracy of the gas burner is improved about five-fold with the longer integration time. Using this approach, it was found that the average ratio of energies deviates by $6 \%$ or less for the shortest to the longest pulse for any one burner setting. There is an increased uncertainty for the shortest pulse length. For the 5 second pulses, the range in the standard deviation is $4 \%$ to $7 \%$ of the mean compared to a more typical range of $1 \%$ to $3 \%$ of the mean for the longer pulses.

Energy conservation has been established to within the resolution of the experiment (see Table 1). This basic premise for obtaining a quantitative measurement of the total energy released regardless of how small a pulse is that the total oxygen consumed in the combustion reactions is obtained from the integrated oxygen analyzer output. This premise has been validated. 
Table 1 Energy conservation results

\begin{tabular}{|c|c|c|}
\hline $\begin{array}{l}\text { Nominal pulse } \\
\text { width, } s\end{array}$ & $\frac{\text { Integrated calorimeter output }}{\text { Integrated burner output }}$ & 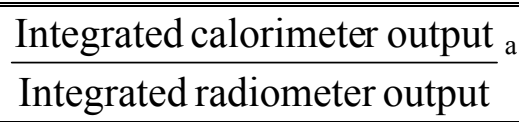 \\
\hline \multicolumn{3}{|c|}{$0.5 \mathrm{MW}$} \\
\hline 30 & $0.97 \pm 0.01$ & $0.97 \pm 0.04$ \\
\hline 15 & $1.01 \pm 0.03$ & $0.98 \pm 0.02$ \\
\hline 10 & $0.96 \pm 0.01$ & $0.92 \pm 0.03$ \\
\hline 5 & $0.90 \pm 0.06$ & $0.92 \pm 0.04$ \\
\hline \multicolumn{3}{|c|}{$1 \mathrm{MW}$} \\
\hline 30 & $1.06 \pm 0.02$ & $1.06 \pm 0.02$ \\
\hline 15 & $0.96 \pm 0.03$ & $1.05 \pm 0.03$ \\
\hline 10 & $0.98 \pm 0.02$ & $1.10 \pm 0.02$ \\
\hline 5 & $0.89 \pm 0.04$ & $1.05 \pm 0.06$ \\
\hline \multicolumn{3}{|c|}{$2.5 \mathrm{MW}$} \\
\hline 30 & $1.02 \pm 0.01$ & $1.02 \pm 0.01$ \\
\hline 15 & $1.02 \pm 0.02$ & $1.05 \pm 0.01$ \\
\hline 10 & $1.02 \pm 0.02$ & $1.07 \pm 0.01$ \\
\hline 5 & $0.97 \pm 0.04$ & $1.06 \pm 0.07$ \\
\hline
\end{tabular}

a The integrated radiometer output for each of the three heat releases was multiplied by a factor to match the total burner heat release rate for the $30 \mathrm{~s}$ square-wave pulses.

A summary of the average peak HRR and FWHH and the associated standard deviations are given in Table 2 and Table 3 for each set of three or more repeat measurements. The FWHH is computed based on the half-height above the baseline value. The peak HRR is not adjusted for the baseline value. For pulse lengths of $15 \mathrm{~s}$ and longer, the calorimeter peak is within $9 \%$ of the burner peak. The peaks correspond to the instantaneous maximum values recorded by the calorimeter, the corrected burner, or the radiometer. The five second-smoothed peaks were found to yield similar results except for the shortest pulse widths. The results indicate that the calorimeter peak is about $15 \%$ smaller than the burner peak for the $10 \mathrm{~s}$ pulse and about $50 \%$ smaller for the $5 \mathrm{~s}$ pulse. The results in Table 2 indicate that the calorimeter value on average is a factor of $1.03 \pm$ 0.04 greater than the corrected burner peak for square-wave pulses having widths equal to or greater than $13 \mathrm{~s}$. The calorimeter significantly underestimates the peak height for square wave pulses lasting less than $10 \mathrm{~s}$.

The corrected calibration peak heat release rate is not affected by the pulse width down to $5 \mathrm{~s}$. The standard deviation of the burner peak heat release rate for the four pulse widths is at most $5 \%$ of the average for any of the three HRR (see Table 3 ).

The FWHH time based on the calorimeter for the $1 \mathrm{MW}$ fire is at most $10 \%$ longer than the radiometer time for the $15 \mathrm{~s}$ and $30 \mathrm{~s}$ pulse experiments while it is about $25 \%$ longer for the $10 \mathrm{~s}$ pulse and more than a factor of two longer for the $5 \mathrm{~s}$ pulse. Another observation is that the FWHH measured by the calorimeter remains relatively constant as the pulse width is reduced from $10 \mathrm{~s}$ to $5 \mathrm{~s}$. In this limit, the calorimeter response is controlled by the time response of the oxygen analyzer so that the response approaches a constant independent of how short the square-wave pulse might be. 
Table 2 Gas burner square-wave pulse results for peak HRR and FWHH

\begin{tabular}{cccc}
\hline $\begin{array}{c}\text { Pulse width, } \\
\mathrm{s}\end{array}$ & \begin{tabular}{c} 
Calorimeter peak \\
\cline { 2 - 3 } Burner peak
\end{tabular} & $\begin{array}{c}\text { Radiometer } \\
\text { FWHH, } \mathrm{s}\end{array}$ & $\begin{array}{c}\text { Calorimeter } \\
\text { FWHH, }\end{array}$ \\
\hline $60^{\mathrm{a}}$ & 1.03 & 59 & 58 \\
30 & $0.97 \pm 0.02$ & $28.0 \pm 0.2$ & $29.3 \pm 0.3$ \\
15 & $1.01 \pm 0.06$ & $12.6 \pm 0.1$ & $14.4 \pm 0.2$ \\
10 & $0.89 \pm 0.05$ & $8.7 \pm 0.6$ & $11.1 \pm 0.4$ \\
5 & $0.58 \pm 0.02$ & $3.8 \pm 0.6$ & $8.9 \pm 0.7$ \\
\hline \multicolumn{4}{c}{$1 \mathrm{MW}$} \\
60 & $1.06 \pm 0.03$ & $58.6 \pm 0.7$ & $59.3 \pm 0.8$ \\
30 & $1.06 \pm 0.01$ & $29.3 \pm 1.2$ & $30.0 \pm 1.7$ \\
15 & $0.96 \pm 0.01$ & $13.8 \pm 0.5$ & $15.2 \pm 0.7$ \\
10 & $0.82 \pm 0.06$ & $8.1 \pm 0.5$ & $10.8 \pm 0.3$ \\
5 & $0.52 \pm 0.03$ & $3.4 \pm 0.2$ & $8.9 \pm 0.3$ \\
\hline \multicolumn{4}{c}{$2.5 \mathrm{MW}$} \\
$60^{\mathrm{a}}$ & 1.09 & 58 & 58 \\
30 & $1.05 \pm 0.03$ & $28.2 \pm 0.9$ & $28.2 \pm 0.8$ \\
15 & $1.04 \pm 0.02$ & $14.4 \pm 0.1$ & $14.7 \pm 0.2$ \\
10 & $0.88 \pm 0.03$ & $8.7 \pm 0.8$ & $10.6 \pm 0.1$ \\
5 & $0.47 \pm 0.02$ & $3.4 \pm 0.2$ & $10.3 \pm 0.4$ \\
\hline
\end{tabular}

${ }^{\mathrm{a} O n l y}$ one test performed.

The response of the calorimeter to the square-wave pulses suggests a possible method for checking whether the peak heat release rate is changing too rapidly to obtain an accurate heat release rate with the calorimeter. If the FWHH is $15 \mathrm{~s}$ or longer for the HRR calorimeter, then one has confidence from this study that the heat release is accurately represented by the data. However, if the FWHH is less than $11 \mathrm{~s}$ the peak heat release will likely be underestimated by $15 \%$ or more. It does not appear to be possible to correct the peak heat release rate based on the FWHH, since small changes in the FWHH can result in a factor of two or more increase in the peak heat release rate, as seen in the data in Table 2. On the other hand, the square-wave pulse data may be useful in testing algorithms such as that developed by Abramowitz and Lyons [17] for deconvoluting the actual heat release rate from the measured values.

A second important issue is the effect of the random system noise on the apparent magnitude of the heat release peak and thus the uncertainty in the peak height. The random noise sources include the gas analyzers, the pressure transducers for measuring velocity, the thermocouples, real variations in the temperature, velocity, and gas levels being measured, variations in the pumps and exhaust fans, and changing ambient humidity and temperature. By looking at the peak heat release rate in repeat tests under nominally identical conditions, we can assess the effect of the calorimeter related noise sources on the measured peak. A convenient measure of repeatability is the coefficient of variation $(\mathrm{CV})$, which is defined as the ratio of the standard deviation for repeat 
measurements to the average value. We find that the $\mathrm{CV}$ for corrected peak burner heat release rate (see Table 3) is at most 0.05 for any of the 12 set of tests with at least three repeats each and is 0.02 or less for 5 of the 6 sets of tests with pulse widths of $15 \mathrm{~s}$ or 30 s. The CV for the calorimeter is also found to be in the range of 0.01 to 0.02 for 5 of the 6 sets of tests with pulse widths of $15 \mathrm{~s}$ or $30 \mathrm{~s}$. The near equality of the CV's suggest that the calorimetry repeatability may be limited by the slight lack of repeatability in the square-wave pulse produced by the burner Larger CVs up to 0.10 are obtained for heat release rate by the calorimeter for the $5 \mathrm{~s}$ and $10 \mathrm{~s}$ square-wave pulses.

Table 3 Gas burner square-wave pulse coefficient of variation (CV)

\begin{tabular}{|c|c|c|c|c|}
\hline $\begin{array}{l}\text { Nom. pulse } \\
\text { width, s }\end{array}$ & $\begin{array}{l}\text { Corrected burner } \\
\text { peak, MW }\end{array}$ & Burner CV & $\begin{array}{l}\text { Calorimeter } \\
\text { peak MW }\end{array}$ & Calorimeter CV \\
\hline \multicolumn{5}{|c|}{$0.5 \mathrm{MW}$} \\
\hline 30 & 0.59 & 0.01 & 0.56 & 0.02 \\
\hline 15 & 0.56 & 0.04 & 0.56 & 0.03 \\
\hline 10 & 0.56 & 0.05 & 0.45 & 0.02 \\
\hline 5 & 0.54 & 0.04 & 0.34 & 0.10 \\
\hline $\operatorname{Avg} \pm \sigma$ & $0.56 \pm 0.02$ & & & \\
\hline \multicolumn{5}{|c|}{$1.0 \mathrm{MW}$} \\
\hline 30 & 1.00 & 0.02 & 1.06 & 0.02 \\
\hline 15 & 1.05 & 0.01 & 1.00 & 0.01 \\
\hline 10 & 1.05 & 0.03 & 0.85 & 0.06 \\
\hline 5 & 1.04 & 0.01 & 0.53 & 0.04 \\
\hline $\operatorname{Avg} \pm \sigma$ & $1.04 \pm 0.02$ & & & \\
\hline \multicolumn{5}{|c|}{$2.5 \mathrm{MW}$} \\
\hline 30 & 2.53 & 0.02 & 2.63 & 0.02 \\
\hline 15 & 2.47 & 0.01 & 2.57 & 0.01 \\
\hline 10 & 2.52 & 0.01 & 2.23 & 0.04 \\
\hline 5 & 2.46 & 0.02 & 1.14 & 0.02 \\
\hline $\operatorname{Avg} \pm \sigma$ & $2.50 \pm 0.04$ & & & \\
\hline
\end{tabular}

It is encouraging that the contribution of the system noise to CV for the peak heat release rate for the $30 \mathrm{~s}$ and $15 \mathrm{~s}$ square-wave pulses is typically 0.01 to 0.02 . However, this does not mean that the $\mathrm{CV}$ for repeat burns of identical furnishing items, consumer products, or building materials will be as small. The CV in HRR measurements for such materials may be far greater than 0.02 because the identical items may not really be "identical" due to material and/or construction variation or because the flame spread process occurring on real objects is very sensitive to the details of the ignition process as well as the ambient flow and temperature field. Fire growth processes on real objects of any complexity (e.g., mattresses or items of upholstered furniture) are notoriously difficult to reproduce precisely. Since these help dictate the shape of the heat release rate curve from the overall object, and its peak, one can expect appreciable variations in measured heat release rate for such items, even with an ideal calorimeter. 


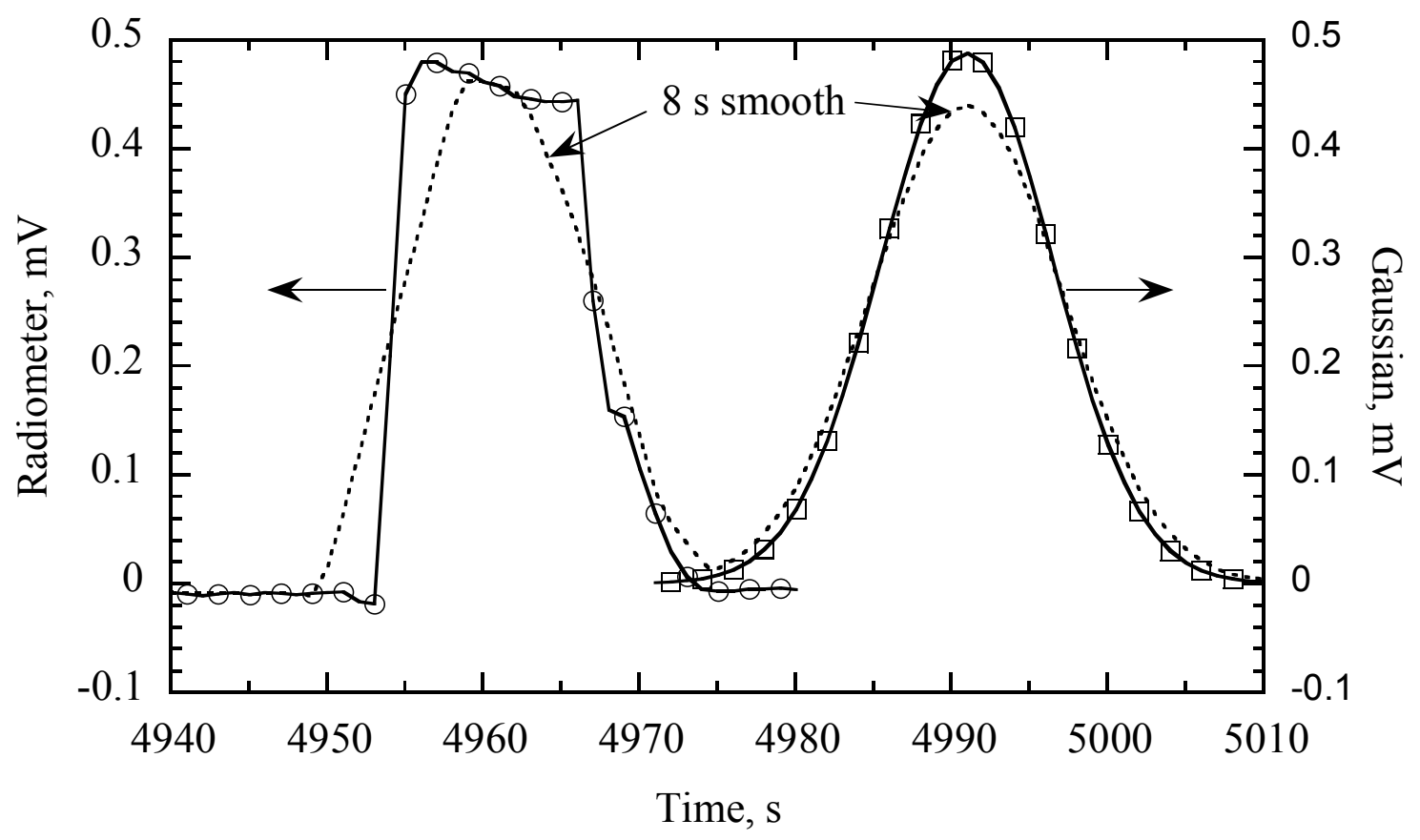

Figure 16 Comparison of the effect of $8 \mathrm{~s}$ smoothing on the peak height for a square-wave pulse vs. a Gaussian pulse. The peak heights for the square-wave pulse and Gaussian are $0.488 \mathrm{mV}$ relative to the baseline, the FWHH is $13 \mathrm{~s}$, and the standard deviation of the Gaussian is $\mathbf{5 . 5 2} \mathrm{s}$.

The analysis presented so far has computed measured time response characteristics for square-wave pulses. In reality it is likely that the peak will be more rounded in shape. A Gaussian peak is a useful example. In the domain where calorimeter response affects the results, one might expect the calorimeter peak heat release rate for a square-wave to be larger than for a Gaussian with the same FWHH. The estimate here is based on the $15 \mathrm{~s}$ square-wave pulse for the $1 \mathrm{MW}$ fire plotted in Figure 13 with a FWHH of $13.0 \mathrm{~s}$. A Gaussian pulse was modeled with a standard deviation of $5.44 \mathrm{~s}$ corresponding to the $13.0 \mathrm{~s}$ FWHH value. The magnitude of the Gaussian peak above the baseline was taken to be equal to the corresponding measured value. To simulate the system response of the calorimeter, an eight second smoothing was used for both the "square-wave" pulse and the Gaussian. As indicated in Figure 16, the Gaussian peak is decreased by about $10 \%$ by including the time response of the system through smoothing while the decrease for the Square-wave peak is about $3 \%$. The reason for the closer approach to the peak for the square-wave is the ten-second duration at the maximum value compared to a onesecond duration for the Gaussian. This effect offsets the much more rapid rise for the square-wave compared to the Gaussian. The difference in the peak heights for the two pulses will decrease for wider pulses and increase for shorter pulses.

The ability to reproducibly generate nominal square-wave heat pulses has been important to assessing the transient characteristics of the HRR calorimeter without the complicating effects of the fire spread and burning of real objects. One of the key results is the determination of the minimum pulse width needed to make an accurate measurement of 
peak HRR. For fires with FWHH of $15 \mathrm{~s}$ or longer, the calorimeter overestimates the actual peak heat release rate value by $3 \%$ on average. However, if the FWHH measured by the calorimeter is less than $11 \mathrm{~s}$, the measured peak heat release rate value underestimates the actual peak heat release rate by $15 \%$ or more.

The burner was also key to assessing the repeatability performance of the calorimeter. The coefficient of variation, $\mathrm{CV}$, for repeat measurements of the peak heat release rate (instantaneous value) of fire pulses with a duration of $15 \mathrm{~s}$ or greater is typically less than 0.02 for nominal $0.5 \mathrm{MW}, 1.0 \mathrm{MW}$, and 2.5 MW fires. Such information is important in fire tests to separate calorimeter effects from the burning characteristics of real objects.

It was found that the calorimeter is able to provide a good estimate of the total heat released for square-wave pulses changing too rapidly for the peak to be resolved by the calorimeter. That is, the integrated heat release measured by the calorimeter conserves energy to within about $5 \%$ for pulses as short as $5 \mathrm{~s}$.

The fast response time of Schmidt-Boelter type radiometer was key to obtaining the most quantitative data on the gas burner output. It may be possible to combine the output of a radiometer, which has a time response of less than $1 \mathrm{~s}$, with the integrated output from the calorimeter, which conserves energy, to estimate peak heat release rates for fires with $\mathrm{FWHH}$ as small as $3 \mathrm{~s}$.

\subsubsection{Factors Affecting Dispersion of the Gas Measurement Signals}

As noted previously, the rise time of the $\mathrm{O}_{2}, \mathrm{CO}$ and $\mathrm{CO}_{2}$ signals depends not only on the inherent instrument response time ${ }^{14}$ but also on the time-wise dispersion of the gas concentration gradient due to mixing in the plume capture and gas sampling systems. Thus, the overall system response time assessed in the previous section is a product of various dispersion processes as well as instrument response characteristics.

A transient fire under the calorimeter hood results in some time-varying stream of gas concentrations emerging from the flame tips that carries information about fire size (heat release rate). As this stream of gases enters the hood, it is paralleled by (and partially mixed with) a flow of in-drawn excess air. A series of lateral, cross-sectional slices through these parallel streams, with the gases mixed laterally ${ }^{15}$, contains a perfect history of the heat release rate behavior of the fire below the hood. However, no real system is capable of mixing these incoming gas streams in a lateral direction only. Invariably there is longitudinal mixing as well and this means that the time history of the fire is being smeared out.

\footnotetext{
${ }^{14}$ Instrument response time may be limited by the electronics and/or by the gas turnover time in the instrument's plumbing and measurement cell. The latter can be shortened by an increased sample flow rate but this is typically limited by pressure drop or other mechanical issues.

${ }^{15}$ Lateral mixing (were it alone possible) brings with it only a lowering of the system sensitivity to heat release rate since it dilutes the fire plume gases.
} 
There are numerous longitudinal mixing mechanisms in any real system; each causes the process referred to as dispersion. The mechanisms pertinent to the six-meter hood system can be listed as follows:

- Fire plume and duct flow turbulence

- Smoke build-up in the hood

- Flow separation in the bends of the hood duct

- Flow dispersion in the sampling line

- Mixing in the sample line filter and pumps

- Dilution from side arms on a sampling line

- Particle-induced mixing in the dry ice water trap and in the Drierite trap

If the fire is enclosed in a room below the hood, a configuration that is sometimes used with the six-meter hood, there will be an additional significant mechanism due to plume mixing in the room upper hot gas layer prior to emergence from the room. Assuming that the upper layer in such a room is well-mixed, this room-effect dispersion time is of the order of the upper layer volume divided by the plume volumetric flow rate. The upper layer volume is at least as great as the volume determined by the door soffit height and will be greater with increased heat release rate. A program such as CFAST [3] can provide a good estimate of the depth of the hot gas layer. CFAST agrees well with experimental results for the ISO 9705 room $(2.4 \mathrm{~m}$ by $3 \mathrm{~m}$ by $2.4 \mathrm{~m}$ high with normal size door opening) [19]. The plume flow rate depends on heat release rate as well; Heskestad [11] provides the equations for this calculation. As an example, a $500 \mathrm{~kW}$ fire in an ISO 9705 room will have an estimated upper layer mixing time of $4 \mathrm{~s}$ to $8 \mathrm{~s} .{ }^{16}$ This indicates that room dispersion effects can be substantial; as will be seen below, there is only one other element in the $3 \mathrm{MW}$ system that normally yields comparable dispersion. ${ }^{17}$

We briefly consider the first item in the above list, which includes two dispersion mechanisms over which the experimenter has no control. The dispersion in the fire plume itself is a result of the intense turbulence typically existing there. For a $1 \mathrm{MW}$ fire under the six-meter hood, one can show that the velocity-induced dispersion is of the order of $\pm 0.3 \mathrm{~s}$ in going from the top of the flames to the hood inlet. As to the second aspect, for a hood flow of $14.2 \mathrm{~m}^{3} / \mathrm{s}$, typical of that used for a large fire, the dispersion in the turbulent duct flow is of the order of $\pm 1 \mathrm{~s}$ (this dispersion mechanism is discussed further below in connection with the sampling line).

Here we elaborate further only on those mechanisms over which an experiment designer might want to try to exercise some control.

Confining the smoke build-up in the hood (including the skirted volume) might be thought of only as a safe way in which to handle a fire that temporarily becomes larger

\footnotetext{
${ }^{16}$ An object yielding a $500 \mathrm{~kW}$ fire, when placed in a room will also see substantial radiative feedback from the hot smoke layer. This could significantly increase the peak HRR seen in a room versus that in an open hood, depending on the view factor the burning surfaces have toward the upper smoke layer.

${ }^{17}$ One implication of this magnitude of room effect is that it has the potential to somewhat slow the overall system time response characteristics discussed in the above section on transient effects on HRR.
} 
than anticipated. In fact the skirt serves precisely this purpose but it also has consequences with regard to dispersion of which one should be aware. The skirt acts only by allowing a volume in which smoke can accumulate. Once the accumulation occurs to some depth, the entrainment of excess air is decreased only because the plume begins to entrain and re-cycle the air/smoke mixture in the backed-up volume, rather than further excess air (above the smoke layer base height). Thus the mechanism by which a hood skirt works is inherently dispersive. However, simulation of this process using FDS shows that the accumulated smoke volume is not well-stirred with the incoming plume. Instead the bulk of a fire plume (if centered on the hood duct inlet axis) will pass straight through the back-up volume, unchanged. Only the outer portions of the fire plume are sheared off and subjected to this re-cycling. A consequence of this is that the dispersion process is weak, mixing only a minority of the flow, but extended in time (many seconds); therefore, the accumulated smoke volume is returned to the hood duct flow at a slow pace. The system user should try to avoid having the plume partially back up into the hood/skirt volume if precise monitoring of peak heat release rate is desired. This requires having a sufficient hood flow to swallow the diluted fire plume at its peak (see Ref. [10] for a discussion of hood flow calculations based on plume entrainment).

Flow dispersion in tube flow (both laminar and turbulent) is the subject of classic studies by G. I. Taylor [20]. Taylor shows that an instantaneous plug of fluid with a constant concentration of a gas species introduced into a fully developed turbulent flow results (after about 100 diameters of tube length) in a Gaussian distribution of that species, in time (or equivalent space). The width of the distribution is characterized by a dispersion coefficient that is a function of tube diameter and Reynolds number. Interestingly, Taylor's solutions indicate that even in the ca. $25 \mathrm{~m}$ sampling lines between the roof and the instruments in the control room, turbulent flow dispersion has a negligible effect (less than $0.1 \mathrm{~s}$ ) on system dispersion, even when the added effects of flow bends are accounted for. The same reference was used for the estimate above of the more significant dispersion in the hood duct flow.

Dispersive mixing in such system elements as the sample filter upstream of the roof pump or the filters upstream of the control room pump(s) depends on the filter housing design. Such mixing would be eliminated if there are no separation zones for the flow but this tends to be incompatible with minimization of the size of the housing. Estimation of the possible mixing time constants (estimated flow separation volume over volumetric flow rate) for the existing filter housings implies that they are negligible sources of dispersion (less than $0.1 \mathrm{~s}$ ) in the current system. The same applies to the sample pumps.

Any location in the sampling system that has a pipe tee to provide an alternate flow path (or a tee to facilitate a pressure gage) ${ }^{18}$ introduces a side arm with a dead volume. Inspection of Figure 6 indicates that there are such tees in the present system. Such a dead volume communicates with the main sample flow by a combination of diffusion and

\footnotetext{
${ }^{18}$ Pressure gages do not need a significant flow in/out of their lead tube. Thus the lead tubes used in this system were made extremely small in diameter ( $1.5 \mathrm{~mm}$ OD tubing) in order to minimize their flow dispersive effects on the passing sample flow.
} 
induced flow circulation. Thus the gas in such a volume mixes with the passing sample flow, altering its composition and acting, in effect, as a dispersive mechanism. Using the pure diffusion solution for a semi-infinite, stationary gas subjected at time zero to a differing gas concentration at its outer boundary [21] one can show that pure diffusion can only cause mass fluxes that would amount to a negligible source of dispersion. On the other hand, the flow past the side arm can be expected to induce a circulation eddy in the outer end of the side arm of length comparable to the side arm tube diameter. This outer induced eddy will in turn induce another eddy of comparable dimensions. Presumably this induction continues into the side arm to a depth dictated by viscous dissipation of these induced eddy motions. Successive eddies communicate by diffusion and some flow mixing thus extracting gas from the side arm at a potentially much greater rate than by pure static diffusion alone. While there is not a quantitative treatment of this process available, one can anticipate that it could become a significant source of dispersion, especially for larger diameter side arms (worst case example, the side arm on the hood flow duct seen in Figure 2). Such dispersion could manifest itself as a drift in the gas analyzer outputs or it could extend the time to zero the gas analyzers. There is one location in the gas sampling system (in the control room) where this becomes a concern and the operating procedure therefore calls for closing a valve near the tee in this sidearm to greatly shorten its effective length and to minimize this effect. This action should eliminate this source of dispersion as an area of concern in the present system.

The dry ice trap and the Drierite traps are both examples of packed beds. Flow dispersion in packed beds is a well-studied subject [22]. The complex flow of gas around the particles in a packed bed creates numerous paths of varying lengths along with minute separation zones, all of which spread the gas out in space (or time). The effect on a step function change in flow concentration as a result of axial dispersive processes in a successive set of particle beds like those used here for drying the sample flow can be reasonably well estimated. Given the particle size, gas flow rate and the length of the two drying devices, one can estimate that the combination smears an input step function in gas concentration over a time of about 4 seconds. These two drying devices are thus the most significant and routine sources of flow dispersion in the current system, though they do not add excessively to the basic system time response as set by the gas analyzer instruments themselves. If it became desirable to lessen the system response time further, it would be necessary to abandon the use of packed beds for gas flow drying. The Cone Calorimeter, for example, uses a laminar flow, thermoelectric cooling device. The sample flow is much greater here; it is not known whether an adequate device of this type is available.

The dominant response time in the gas sample analysis system is that due to the analyzers themselves. The oxygen analyzer, for example, has a nominal response time of $8 \mathrm{~s}$ (to 90 $\%$ of input change). The above discussion indicates that, in the absence of a room as a container for the fire being measured and also in the absence of significant smoke backup in the hood, the dispersive elements in the system will add roughly $5 \mathrm{~s}$ to this, giving an overall time to response to a step change at the fire of about $12 \mathrm{~s}$ to $13 \mathrm{~s}$ (depending on the exact definition of response time one uses ${ }^{19}$ and ignoring flow lag times $)^{20}$. This is in

\footnotetext{
${ }^{19}$ Most of the dispersive times are (1/e) estimates.
} 
reasonable agreement with the results described in the preceding section on transient behavior of the heat release rate measurement system. Again it should be noted that use of a room or the existence of smoke back-up in the hood will increase the response time significantly, though the former will be more noticeable than the latter.

\subsubsection{Flame Height vs. Heat Release Rate}

The discussion by Heskestad [11] provides the basic equations governing the flame height from a pool fire, as a function of pool diameter. (Also included in the reference are other correlations for some other fire situations.) Since it is undesirable to allow the plume to be swallowed by the duct at the top of the hood, these flame height calculations provide one guideline for the system design, namely how far above the floor (the assumed fire location) the inlet duct needs to be in order to just capture the biggest fire for which the system is designed. The routine user of the system can also use such calculations to estimate whether the hood height will accommodate the planned fire. Since all fires do not act like simple pool fires ${ }^{21}$, one must use these calculations as a rough guide only and not push the upper limit without being prepared for some plume swallowing $^{22}$.

Flame heights have been calculated to assist in the design of experiments and measurements using the various exhaust hoods in the Large Fire Research Facility. The primary consideration here is assuring that the visible flame tip does not enter the exhaust system. Prediction of flame height for the calibration gas burner is difficult. At low flow rates, the flame emanating from the burner can be classified as buoyant, using Delichatsios' Fire Froude Number [23]. However, with increasing gas flow the flame quickly transitions to a momentum dominated jet. Further complication of the problem results from flame merging. At low gas flow rates individual flamelets exist and then suddenly merge with increasing gas flow. It is unclear if the merging of individual flamelets occurs at the transition from a buoyant flame to a momentum driven jet.

To predict burner flame height, it was assumed that the burner flames behave in aggregate like a pool fire. The results of the pool fire calculation are also instructive in judging likely flame heights from other burning objects, as well as from the calibration gas burner. Figure 17 shows the calculated flame tip height as a function of heat release rate for pool fires with diameters of $0.5 \mathrm{~m}, 1.0 \mathrm{~m}$, and $2 \mathrm{~m}$. Note that heat release rate is the primary determinant of flame tip height; pool fire diameter is secondary. The flame tip height is defined as the sum of the mean flame height and one-half of the

\footnotetext{
${ }^{20}$ Also note that since all of these dispersive elements are in series, they are not strictly additive; rather the final result is the successive convolution of all preceding dispersive elements.

${ }^{21}$ Anything that impedes plume entrainment, such as a wall on one side of a fire, tends to increase flame height. Anything that tends to enhance plume entrainment, such as a multi-segmented fire will shorten the flame height.

${ }^{22}$ A small amount of plume swallowing will not likely suppress burning because the plume at its tip is over-aerated. This can be difficult to judge visually, however; a CO increase in the exhaust gases would be a better indicator. Since the gas temperature in the duct will go up rapidly if combustion continues there, there is a risk of damage to the system. Heavy swallowing of flames, especially for longer than times of the order of $10 \mathrm{~s}$, is to be avoided.
} 
intermittency flame length. The intermittency length gives the difference between the maximum and minimum visible flame height, whereas the mean flame height is defined as the mean value of the visible flame height. The mean flame height and the intermittency lengths were taken from Eq. (8) and Figure 14 in Heskestad [24]. Calculation of flame height for multiple jets that merge, using Heskestad's pool fire correlation, will over predict flame height.

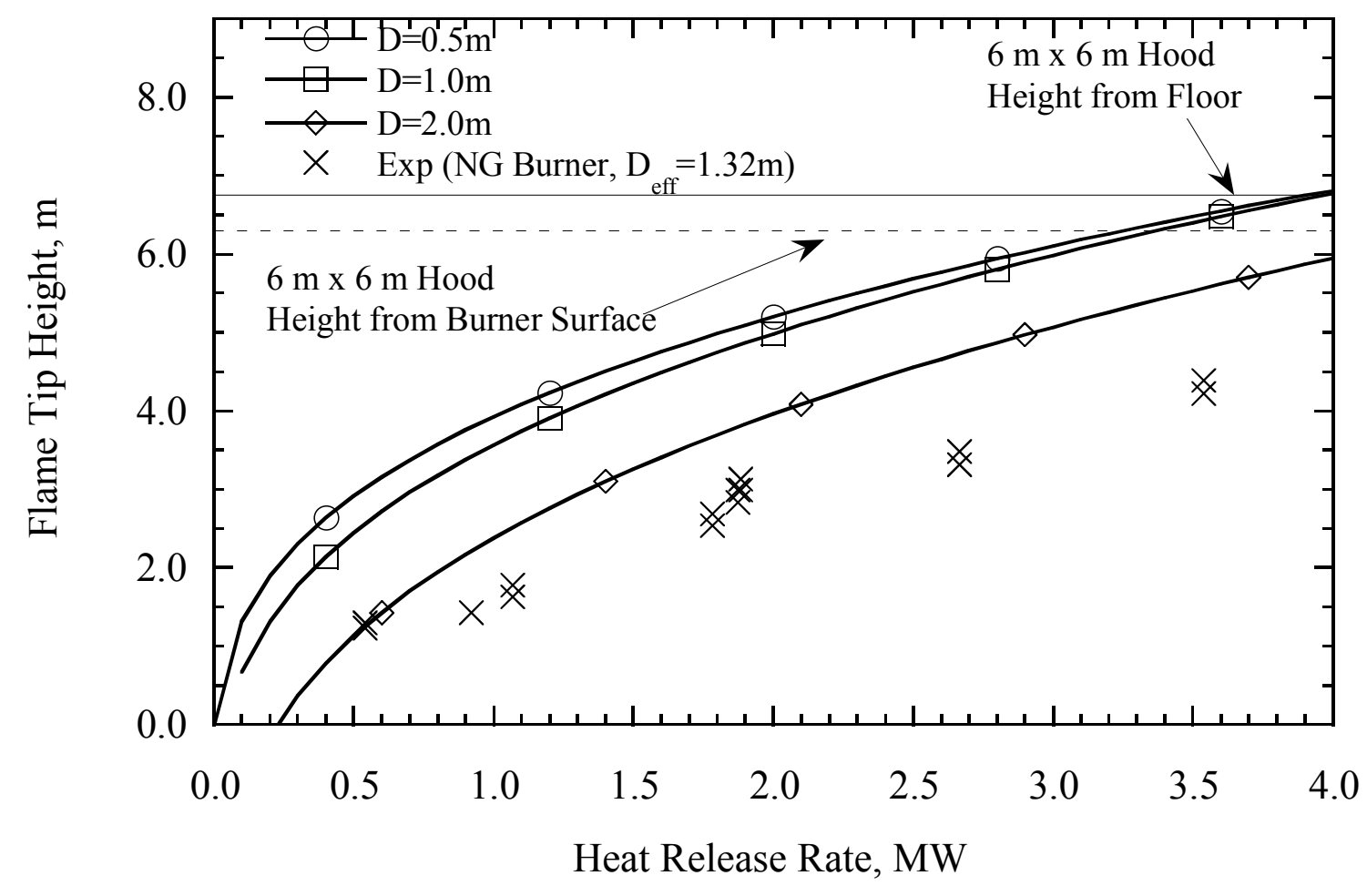

\section{Figure 17 Calculated flame tip heights for pool fires and actual results for the natural gas calibration burner.}

The average flame tip height for a $6 \mathrm{MW}$ fire in a $0.5 \mathrm{~m}$ burner is approximately $1 \mathrm{~m}$ higher than the average flame length. The plot shows two horizontal lines that represent the distance above the floor (solid line) and the distance above the calibration burner to the exhaust in the $6 \mathrm{~m} \times 6 \mathrm{~m}$ ( $3 \mathrm{MW}$ capacity) hood. Figure 17 shows that the $6 \mathrm{~m} \times 6 \mathrm{~m}$ hood may not accommodate a $4 \mathrm{MW}$ fire unless it has a diameter of $2 \mathrm{~m}$ or greater. Fires of $4 \mathrm{MW}$ or greater and with effective diameters of less than $2 \mathrm{~m}$ are better accommodated by the $9 \mathrm{~m} \times 12 \mathrm{~m}$ hood.

Actual flame tip heights were measured when all eleven tubes were open. Flame tip height was determined using a $20 \mathrm{~cm}$ diameter protractor (1 degree angular resolution) to measure the angle between the line of sight to the flame tip and a horizontal reference line. The vertical position of the protractor above the floor and the horizontal location from the center of the burner was recorded. The height of the flame tip above the horizontal reference line is the tangent of the angle multiplied by the distance from the burner. Flame tip height above the floor (includes burner height) was computed by 
adding the vertical position of the protractor to the previously determined height. The measured flame tip heights minus the burner height are shown in Figure 17. The scatter is due to a combination of the variability in the use of the simple tools and the difficulty in estimating the point defining the flame tip, which fluctuates strongly.

\section{Operation and Safety}

\subsection{Calorimeter}

The first steps to operating the calorimeter are to assure that the system is properly configured. This includes setting the exhaust hood flow to fit the anticipated fire size, bringing all components up to their normal operating temperatures, delivering the required flow from the sampling ports in the duct on the roof and feeding the correct flows to each of the analyzers. If any part of the gas analysis system has been opened (typically to insert clean water traps or particulate filters) it is checked for leaks. When everything is satisfactory, the data acquisition system (see Sec. 3.2 below) is initiated and calibration of the gas analyzers and zeroing of the pressure transducers on the bidirectional probes are performed. All analyzers are zeroed first using bottled nitrogen. They are then spanned with bottled calibration gases. After the system has fully recovered from the calibration process and is reading steadily once again the gas sample from the duct (with no fire), the no-fire baseline reading of the system is recorded by the data acquisition system. When the actual test is initiated, the baseline is again followed for three to five minutes before the fire is ignited (ignition is denoted with a marker channel). After the fire has extinguished naturally (or with an extinguishing agent), the post-test, no-fire reading of the system is recorded for at least three to five minutes. These before- and after-fire readings give information used to construct the system baseline that applies during the test. If the fire is located in an enclosure, more time is allowed for smoke to clear and for the system to equilibrate.

The preceding steps involve various manipulations of the valves and switches on the control panels. Detailed and stepwise instructions are described in NISTIR 7052 [25].

\subsection{Data Acquisition System}

The first series of steps to running the data acquisition system is to make sure that the computer and DAQ hardware have power and that the Measurement and Automation Explorer and LabView software packages are running. The DAQ program is then opened with LabView. Once the DAQ program is loaded, adjustments to operating parameters are made (these changes are made with the program loaded, but not running). The channels to be scanned are $\operatorname{set}^{23}$, the appropriate set of delay times for the hood flow is selected $^{24}$, span values (mainly gas cylinder volume fractions) are set, and calorimetry settings for the combustion products expansion factor and heat of combustion per mass of

\footnotetext{
${ }^{23}$ Generally, the calorimetry channels are well established and changes to the channel list would involve non-calorimetry-related measurements.

${ }^{24}$ If a hood flow other than the three offered is required, the channel delay times would have to be changed (and possibly measured first).
} 
oxygen are entered. Particular chart history settings (the number of points retained on a chart) and the scan rate or averaging period (the default is $200 / \mathrm{s}$ and $1 \mathrm{~s}$, respectively) must be entered before running the program. Ambient humidity and barometric pressure should be entered at this time and user-selected channels for display may also be set. These can be changed during the test as well.

At this point, the program is started, the main filename for the test is entered, and the calorimetry system is operated as described in Sec. 3.1. After the fire is ignited, the DAQ operator monitors conditions and performance and updates the humidity and barometric pressure periodically over the duration of the fire test. After the fire is extinguished, the system is allowed to return to ambient conditions to record a post-fire baseline. The DAQ operator also uses the event marker channels to mark events such as zeros, spans, ambient conditions, baseline HRR, ignition, extinguishing, and any other significant occurrences.

A detailed and stepwise description of the DAQ operating procedures is described in NISTIR 7052 [25].

\subsection{Calibration Burner}

It is recommended to operate the calibration burner prior to a series of fire tests for operational confirmation. Operation of the burner requires a minimum of two operators at all times, the safety officer and the DAQ operator. The safety officer is responsible for all manual tasks involved in start-up and shut-down of the burner, while the DAQ operator is responsible for all remotely controlled tasks such as specifying the burner output.

First the manual shut-off valve for the natural gas is opened and checks are made for proper operation of the igniters, the photoelectric sensor, and the solenoid valves. Once proper operation is confirmed, flow is initiated through the pilot tubes and the pilots are ignited using the DAQ burner control panel. Upon successful ignition a target heat release rate is specified at the DAQ burner control panel. The DAQ program provides a current to the natural gas control valve which has been calibrated to corresponding heat release rates, therefore giving remote control of the output of the burner. The burner and the DAQ burner control panel are monitored as the test proceeds, with all personnel being instructed to warn for unsafe conditions. The burner is shutdown by reducing the target heat release rate so that flow occurs through the pilot tubes and shutting off the flow control valve. The pilot flames eventually extinguish and the natural gas line is purged from the shut-off valve with nitrogen.

Detailed operation steps are described in NISTIR 7502. It is important to follow these procedures to ensure safe operation of the calibration burner. Improper operation of the burner could produce an explosive mixture of natural gas and air within the building, possibly resulting in a catastrophic event. Emergency shut-down procedures are also described in NISTIR 7502. 


\subsection{Safety}

A fire of any size, whether controlled or un-controlled, is inherently hazardous. Therefore, when dealing with large fires, safety is a priority concern. Many active and passive safety mechanisms are in place in the Large Fire Research Laboratory. The most important of these mechanisms is allowing only adequately trained and experienced personnel to operate and participate in fire tests. Safety steps have been documented as part of the operations procedures for many of the components and tasks involved in a fire test. A fire test requires at least three personnel to comprise a test team. Each member of the testing team has a specific role and is required to update an operations checklist prior to beginning a fire test. The safety officer conducts a short meeting of the team members prior to the fire test to explain the test and reconfirm each member's responsibility. During this meeting each operations checklist is collected and reviewed by the safety officer to ensure that no safety steps are omitted.

Other safety mechanisms include keeping the fire test area cleared for visual monitoring, employing communication devices to convey warning signals and event changes, having the properly sized water extinguishing system ready and, if necessary, having a trained and fully equipped firefighter on hand. There are safety systems to manage unforeseen failures of components like the natural gas burner such as manual shut-off valves and emergency shut-off buttons located near exits. Also the facility exhaust system is equipped with two exhaust trains to reduce the risk of complete failure of the system during a fire experiment. Finally, routine maintenance of the facility and its components is performed and safety procedures are reviewed annually.

\subsection{Baseline Heat Release Rate}

There is virtually always some drift in the gas analyzers, especially the oxygen analyzer. As a result there will be a non-zero (positive or negative) baseline measurement of heat release rate. This indicated value of heat release rate will exist before the fire test has started and after the fire (including smoldering) is fully extinguished (and the pre and post-test values will usually differ). The technique used to account for the baseline drift begins with allowing the heat release rate facility to operate for (3 to 5) min immediately prior to a fire test and ( 3 to 5) min immediately following full extinguishment of a fire test. The pre-test and post-test baselines are therefore determined, respectively. Figure 18 is a graphical example of a fire test performed with the calibration burner. Nominal heat release rates were $0.05 \mathrm{MW}, 0.65 \mathrm{MW}$ and $2.70 \mathrm{MW}$ and a baseline drift from 0.005 to $0.020 \mathrm{MW}$ was observed over the span of 54 minutes. 


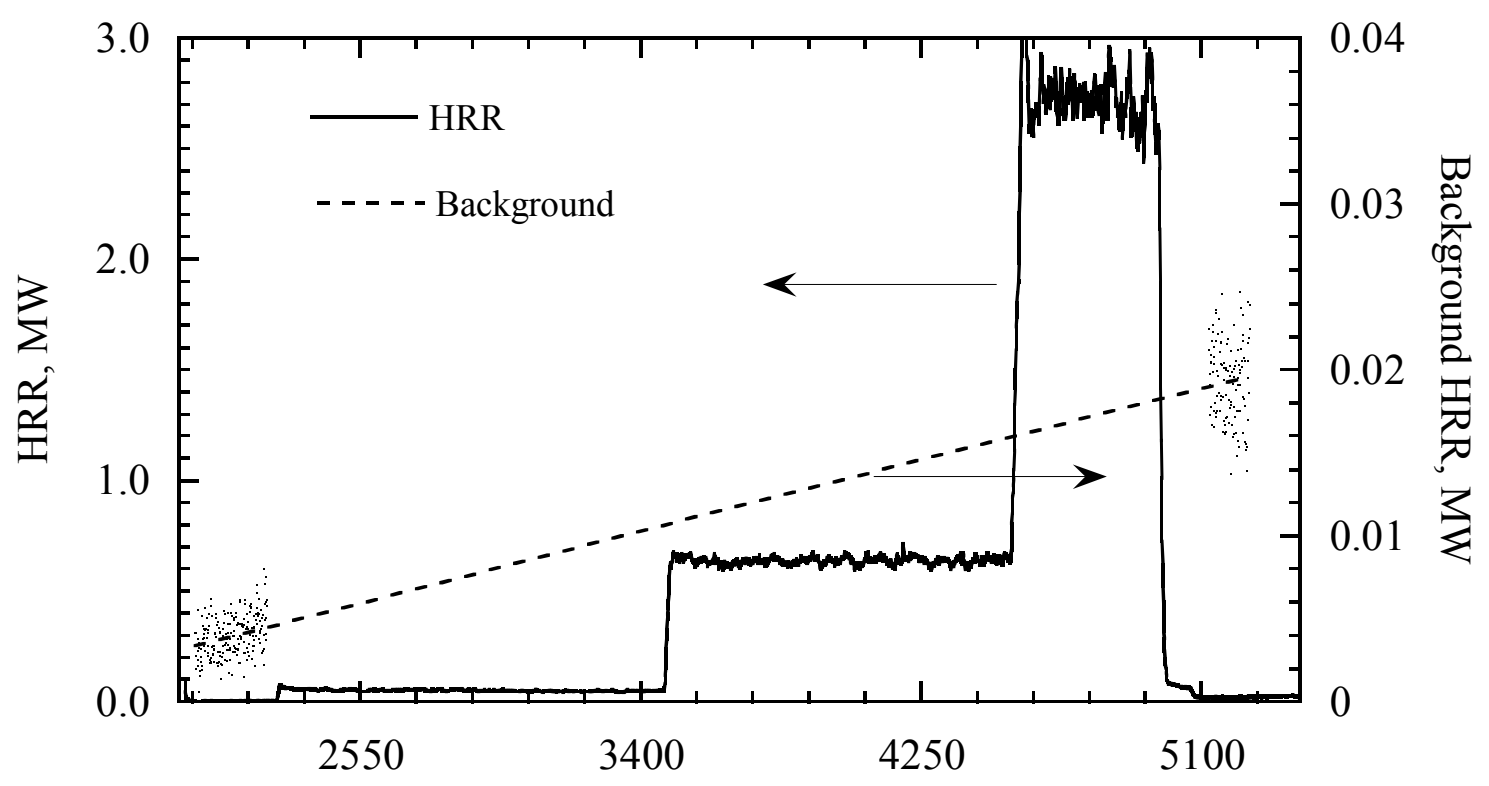

Time, $\mathrm{s}$

\section{Figure 18 Time history of uncorrected heat release (left axis) and baseline heat release rate (right axis).}

A time-varying relation for the baseline heat release rate, $\dot{q}_{b k g d, s y s}$, relative to which all heat release rate measurements during a test were made, is determined by performing a least squares linear fit to the pre- and post-test data, Eq. (14) (see Figure 18). This relation assumes that the baseline drift of the facility is linear over the entire duration of the fire test. (30 minute drift test of the gas analyzers resulted in mostly linear positive or negative drift, therefore confirming this assumption) The estimated baseline heat release rate at time $t$ is algebraically subtracted from the measured value of heat release rate at time t, Eq. (15). Performing this operation at each time step results in a time history of heat release rate corrected for the baseline drift of the system, $\dot{q}_{c r c t d, s y s}$. This operation is especially important when evaluating peak heat release rate. The baseline will affect the characteristics, such as height and width, of the peak heat release rate curve.

$$
\begin{aligned}
& \dot{q}_{b k g d, s y s}=m_{s y s} t+j_{s y s} \\
& \dot{q}_{c r c t d, s y s}=\dot{q}-\dot{q}_{b k g d, s y s}
\end{aligned}
$$

The method outlined above measures the drift of the system as a whole. It will be referred to as Method I. The system drift is a result of the drift of the system components.

Since the raw data from each instrument is recorded for the pre- and post- test measurements, the baseline heat release rate due to the component drift also can be computed. The heat release rate is derived from the measured depletion of oxygen, 
which is described mathematically (Eq. (7)) by the oxygen depletion factor, $\phi$. Measurements of $\mathrm{CO}_{2}$ and $\mathrm{CO}$ are also used to define $\phi$. For the present report, the baseline drift of the three gas analyzers $\left(\mathrm{O}_{2}, \mathrm{CO}_{2}\right.$, and $\left.\mathrm{CO}\right)$ is used to compute a baseline drift of heat release rate from conditions at time, $t=0$. Least squares linear fits of the voltage outputs of each instrument, Eq. (16) to (18), are used to compute the gas species volume fraction drift. The baseline volume fractions are substituted into Eq. (13) to compute the baseline heat release rate due to the instrument drift.

Computing the baseline heat release rate due to the drift of the components will be referred to as Method II, and is represented by Eq. (19). Baseline heat release rates are computed by both methods for two series of test at random times within a series. The results are presented in Table 4 and show good agreement for the two methods of baseline HRR determination. The fractional difference, $F_{d}$, defined as (Method I Method II)/Method I has a mean and standard deviation of $0.12 \pm 0.10$. This good agreement indicates that most of the background drift can be accounted for by the drift of the gas analyzers.

$$
\begin{gathered}
V_{\mathrm{O}_{2}, b k g d}=m_{\mathrm{V}_{2}} t+j_{V_{\mathrm{O}_{2}}} \\
V_{\mathrm{CO}_{2}, \text { bkgd }}=m_{V_{\mathrm{CO}_{2}}} t+j_{V_{\mathrm{CO}_{2}}} \\
V_{\mathrm{CO}, \mathrm{bkgd}}=m_{V_{\mathrm{CO}}} t+j_{V_{\mathrm{CO}}} \\
\dot{q}_{\text {bkgd,comp }}=\dot{q}\left(\ldots . ., V_{\mathrm{O}_{2}, \text { bkgd }}, V_{\mathrm{CO}_{2}, \text { bkgd }}, V_{\mathrm{CO}, \mathrm{bkgd}}, \ldots . .\right)
\end{gathered}
$$

Table 4 Baseline heat release rate comparison

\begin{tabular}{ccc}
\hline \hline \multicolumn{2}{c}{ Baseline heat release rate, $\mathrm{kW}$} & \\
$\begin{array}{c}\text { System } \\
\text { (Method I) }\end{array}$ & $\begin{array}{c}\text { Component } \\
\text { (Method II) }\end{array}$ & $F_{d}$ \\
\hline 14.8 & 11.6 & 0.22 \\
16.6 & 12.8 & 0.23 \\
17.4 & 11.6 & 0.26 \\
34.8 & 35.7 & -0.03 \\
39.5 & 38.8 & 0.02 \\
51.9 & 50.2 & 0.03 \\
55.8 & 52.1 & 0.07 \\
65.1 & 57.1 & 0.12 \\
& Avg $\pm \sigma$ & $0.12 \pm 0.10$ \\
\hline
\end{tabular}




\section{Assessment of Uncertainty}

A few studies exist which address the uncertainty of heat release rate measurements by oxygen consumption calorimetry. The studies vary in apparatus, version of the heat release rate equation, level of heat release rate, and detail of analysis. Axelsson et al. [26] estimated the heat release rate measurement uncertainty for the measurement as conducted in the Single Burning Item (prEN 13823) and the Room Corner Test (ISO 9705). The relative expanded uncertainty estimates ranged from 0.07 to 0.14 , depending on the apparatus and the heat release rate. The uncertainty of the oxygen concentration measurement, followed by the heat of combustion factor and the mass flow rate measurement were identified as the major sources of uncertainty. Details on the uncertainty of the oxygen and the mass flow rate measurements were presented. The study notes that for larger oxygen deficits the combined uncertainty of the heat release rate measurement is less. Enright and Fleischmann [27] performed an analytical estimate of the heat release rate measurement uncertainty for the cone calorimeter. They estimated relative expanded uncertainty ranging from 0.10 to 0.12 , depending on the heat release rate. The greatest sources of uncertainty identified were, the heat of combustion factor, the combustion expansion factor, and the oxygen measurement. Yeager [28] also performed an analytical uncertainty estimate for experiments conducted in a room compartment with a controlled supply of energy into the room and identified the volume flow rate and oxygen measurement as majors source of uncertainty. He reports a relative expanded uncertainty of 0.12 when the exhaust volume flow rate is optimized for the fire.

The oxygen depletion measurement and the exhaust mass flow rate measurement have been consistently reported as major sources of uncertainty. However, Janssens' [29] review of the results of heat release rate round robins brings attention to the uncertainty due to random effects such as material and burning variability, environmental effects, operator error, and measurement bias between laboratories. The impact of these effects is important and deserves further study. A crucial first step in such a study is a self-audit by the individual laboratories of their heat release measurement uncertainty. Such an assessment requires the use of a calibration burner with good repeatability to avoid the variability in the results from differences in the heat release rate for nominally identical solid fuel structures. The goal is to evaluate the calorimeter and one wants to avoid other sources of variability.

The self audit conducted here follows the methodology described in the ISO guidelines [30] and adopted by NIST [31]. The approach is to represent each component of uncertainty as a standard uncertainty. So called Type A uncertainties are those that can be computed based on statistics such as the standard deviation about the mean. The others, designated as Type B, require scientific judgment together with available data. A common example is knowing the maximum range of a variable and then converting this range into a standard uncertainty by dividing it by $2 \sqrt{ } 3$ [31].

The calculation of the uncertainty in the heat release rate requires the combining of many components of uncertainty. This is apparent from the heat release rate equation, Eq. (13), which is a function of more than ten variables. There are five new aspects to the uncertainty analysis presented here as compared to previous analyses. The first concerns 
the estimation of the uncertainty in the oxygen volume fraction to take into account the small noise relative to a much larger uncertainty in the calibration gas. A second is expressing all of the gas analyzer outputs in terms of their voltage to eliminate correlations induced in intermediate quantities by common measurement results. A third is subtracting a baseline drift from the gas analyzers and analyzing the uncertainty in the drift correction. The fourth is to perform the uncertainty propagation with a numerical method that is easily implemented in a spreadsheet program. And the fifth is to combine the total uncertainty based on the uncertainty propagation with the repeatability measurements to obtain a combined uncertainty and ultimately an expanded uncertainty corresponding to an approximate $95 \%$ confidence interval. The assessment begins with estimating the uncertainty of individual Type A and B components.

\subsection{Type A Uncertainty}

Voltage

The standard uncertainty is estimated using the sample standard deviation of data collected during periods of operation at constant heat release rate or without any heat input into the system. This applies to all gas analyzer voltages and pressure transducer voltages. For each analyzer there are at least three voltage measurements. First, the voltage corresponding to the zero gas (nitrogen), second the voltage corresponding to the span gas, and last the voltage corresponding to the gas volume fraction at time $t$. For example, the voltage for the oxygen analyzer corresponding to a volume fraction of 0.2095 was approximately $0.833 \mathrm{~V}$ and the uncertainty in the voltage reading by the DAQ was $\pm 25 \mu \mathrm{V}$.

\section{Temperature}

Type $\mathrm{K}$ thermocouples are employed for each of the temperature measurements. These thermocouples have fundamental error limits of $\pm 2.2 \mathrm{~K}$. Assuming a rectangular distribution, the standard uncertainty is computed by dividing the limit by $\sqrt{3}$. The thermocouples are directly in the exhaust stream and are subject to fluctuations due to the turbulence in the exhaust duct. The standard deviation of 300 temperature measurements is nominally $1.0 \mathrm{~K}$ and is chosen to represent the noise due to turbulence. Combining the two standard deviations in quadrature results in a standard uncertainty of $\pm 1.6 \mathrm{~K}$.

\section{Repeatability}

The mean and the standard deviation about the mean were computed for the six repeat heat release rate measurements for the nominal $0.05 \mathrm{MW}, 0.65 \mathrm{MW}$, and the $2.70 \mathrm{MW}$ natural gas burner flames.

\section{Linear Least Squares Coefficients}

The system and instrument drift data typically consist of 300 to 800 points. An Excel spreadsheet function "LINEST" is used to compute the coefficients for the linear fit. It also computes the standard deviation of the mean (or standard error) for each coefficient which is referred to here as the standard uncertainty. Before the regression analysis is run, the data are centered about the mean time, $\bar{t}$, which eliminates the covariance between the slope and the intercept. 


\subsection{Type B Uncertainty}

\section{Zero and Span Gases}

The zero gas is $99.99 \%$ nitrogen, therefore the measurements of zero $\mathrm{O}_{2}, \mathrm{CO}_{2}$, and $\mathrm{CO}$ volume fractions are assumed to have a standard uncertainty of \pm 0.0001 . The $\mathrm{O}_{2}$ span gas is breathing air that has an oxygen volume fraction of $0.2095 \pm 0.0005$. Span gases for $\mathrm{CO}_{2}$ and $\mathrm{CO}$ are purchased as a mixture of $\mathrm{CO}_{2} / \mathrm{CO} / \mathrm{N}_{2}$. The volume fractions are specified and each bottle is delivered with a certificate of analysis specifying the actual volume fraction with a relative standard uncertainty of \pm 0.005 .

\section{Relative Humidity}

Based on the manufacturer's technical specifications the accuracy of the humidity meter is $\pm 2 \% \mathrm{RH}$.

\section{Ambient Pressure}

The ambient pressure is read from a mercury barometer and corrected for temperature and altitude. The uncertainty in the reading is estimated to be $\pm 0.27 \mathrm{kPa}$.

\section{Bi-Directional Probe Constant, $\mathrm{C}_{\text {bdp, }}$}

For flow with Reynolds number (relative to probe diameter) greater than 3800 , the ratio of dynamic pressure to velocity is essentially constant and this constant value $(0.0698$ $\left.\mathrm{m}^{3} / \mathrm{K}-\mathrm{kg}\right)$ has been determined to be accurate to within $\pm 5 \%\left( \pm 0.0035 \mathrm{~m}^{3} / \mathrm{K}-\mathrm{kg}\right)[13]$. The nominal range of Reynolds number for flows over the $2.54 \mathrm{~cm}$ bi-directional probes is 2000 to 16000 .

\section{Duct Diameter}

The duct diameter, $1.52 \mathrm{~m}$, is measured with a tape measure. Due to the duct not being a perfect circle the standard uncertainty is assumed to be $\pm 0.01 \mathrm{~m}$.

Heat Release of Fuel per kg of Oxygen Consumed, $\left(\Delta H_{c}\right)_{\text {Mass } \_O_{2}}^{H C}$

The value of $\left(\Delta H_{c}\right)_{\text {Mass_ }}^{H C} O_{2}$ for use if the fuel properties are not known is taken to be 13.1 $\mathrm{MJ} / \mathrm{kg} \mathrm{O}_{2}$ based on the study of Huggett [5]. A slightly modified version of Table 2 of Huggett for typical synthetic polymers is used to compute the standard deviation in $\left(\Delta H_{c}\right)_{\text {Mass } O_{2}}^{H C}, \pm 0.35 \mathrm{MJ} / \mathrm{kg} \mathrm{O} \mathrm{O}_{2}$. The modifications were to delete polyoxymethylene, which is an outlier with an $\left(\Delta H_{c}\right)_{\text {Mass }}^{H C} O_{2}$ of $14.5 \mathrm{MJ} / \mathrm{kg} \mathrm{O}$, and to add cellulose with an $\left(\Delta H_{c}\right)_{\text {Mass }_{-} O_{2}}^{H C}$ of $13.59 \mathrm{MJ} / \mathrm{kg} \mathrm{O}_{2}$, which is representative of paper. The relative standard uncertainty is computed as \pm 0.027 .

Natural gas, which contains typically $94 \%$ methane (as supplied by the local natural gas company) is used for calibration burns. Fuel composition is periodically determined from gas chromatograph results. The value of $\left(\Delta H_{c}\right)_{\text {Mass }}^{H C} O_{2}$ for natural gas is 12.55 $\mathrm{MJ} / \mathrm{kg} \mathrm{O}_{2}$ with an estimated standard relative uncertainty of $\pm 0.00159\left( \pm 0.02 \mathrm{MJ} / \mathrm{kg} \mathrm{O}_{2}\right)$. It is computed from the enthalpy balance for the complete combustion of natural gas 
(major species) and oxygen to produce $\mathrm{CO}_{2}$ and $\mathrm{H}_{2} \mathrm{O}$. (The complete combustion of pure methane and oxygen, which is a simpler computation of the enthalpy balance, results in $\left(\Delta H_{c}\right)_{\text {Mass_ } O_{2}}^{H C}=12.54 \mathrm{MJ} / \mathrm{kg} \mathrm{O} \mathrm{O}_{2}$.) The NIST Chemistry WebBook lists the heat of formation for each molecule and the expanded uncertainty [32].

Heat Release of CO per kg of Oxygen Consumed, $\left(\Delta H_{c}\right)_{\text {Mass }_{-} \mathrm{O}_{2}}^{\mathrm{CO}}$

The value of $\left(\Delta H_{c}\right)_{\text {Mass_ }}^{C O}{ }_{2}$, computed from the enthalpy balance for the combustion of $\mathrm{CO}$ in oxygen to produce $\mathrm{CO}_{2}$, is $17.69 \mathrm{MJ} / \mathrm{kg} \mathrm{O}$ with an estimated standard relative uncertainty of $\pm 0.0006\left( \pm 0.01 \mathrm{MJ} / \mathrm{kg} \mathrm{O}_{2}\right)$. The NIST Chemistry WebBook lists the heat of formation for each molecule and the expanded uncertainty [32].

Combustion Products Expansion Parameter, $\alpha$

The expansion parameter $\alpha$ accounts for the volume of the combustion products exceeding that of the oxygen consumed. The quantity $\alpha$ can be related to the ratio of the moles of combustion products formed to the moles of oxygen consumed, which is denoted as $\beta$, via the following equation:

$$
\alpha=1+X_{O_{2}}^{o}(\beta-1)
$$

where $X_{O_{2}}^{o}$ is the volume fraction of oxygen in ambient air, which is assumed to be 0.2095. As an example, the combustion of one mole of methane $\left(\mathrm{CH}_{4}\right)$ requires two moles of oxygen and produces three moles of product made up of one mole of $\mathrm{CO}_{2}$ and two moles of water. The resulting values of $\beta$ and $\alpha$ are 1.5 and 1.105.

The values of $\alpha$ for a range of common polymers found in constructed facilities are listed in Table 5. The mean value of $\alpha, 1.10$, is used in the computation of the heat release rate if the properties of the fuel are unknown. In this case, the standard uncertainty for $\alpha$ is computed as the standard deviation of the values for the polymers listed in Table 5 with a value of \pm 0.048 and a standard relative uncertainty of \pm 0.044 .

Table 5 Expansion parameter $\alpha$ for polymers found in constructed facilities

\begin{tabular}{lccc}
\hline \multicolumn{1}{c}{ Polymer } & Formula & $\beta$ & $\alpha$ \\
\hline Polystyrene & $\left(-\mathrm{C}_{8} \mathrm{H}_{8^{-}}\right)$ & 1.200 & 1.042 \\
Polycarbonate & $\left(-\mathrm{C}_{16} \mathrm{H}_{11} \mathrm{O}_{3^{-}}\right)$ & 1.246 & 1.052 \\
Polyethylene & $\left(-\mathrm{C}_{2} \mathrm{H}_{4^{-}}\right)$ & 1.333 & 1.069 \\
Polymethylmethacrylate & $\left(-\mathrm{C}_{5} \mathrm{H}_{8} \mathrm{O}_{2^{-}}\right)$ & 1.500 & 1.105 \\
Polyvinylchloride & $\left(-\mathrm{C}_{2} \mathrm{H}_{3} \mathrm{Cl}^{-}\right)$ & 1.600 & 1.126 \\
Polyurethane & $\left(-\mathrm{C}_{13} \mathrm{H}_{6} \mathrm{O}_{6} \mathrm{~N}_{2^{-}}\right)$ & 1.630 & 1.132 \\
Cellulose & $\left(-\mathrm{C}_{6} \mathrm{H}_{10} \mathrm{O}_{5^{-}}\right)$ & 1.830 & 1.175 \\
Avg $\pm \sigma$ & & & $1.100 \pm 0.048$ \\
\hline
\end{tabular}




\subsection{Uncertainty Propagation}

Suppose a general equation can be applied to describe a measurement process which has an output $y$ and the output $y$ is based on a number of input quantities, $x_{i}$.

$$
y=y\left(x_{1}, x_{2}, x_{3}, \ldots ., x_{N}\right)
$$

In the case that all input quantities are uncorrelated, the combined relative expanded uncertainty is given by

$$
\frac{U_{e}(y)}{y}=k \frac{u_{c}(y)}{y}=k \sqrt{\sum_{i=1}^{N} s_{i}^{2}\left(\frac{u\left(x_{i}\right)}{x_{i}}\right)^{2}}
$$

In Eq. (22), $u\left(x_{i}\right)$ is the standard uncertainty for each input, $u_{c}(y)$ is the combined uncertainty, $k$ is the coverage factor, and $s_{i}$ is the associated dimensionless sensitivity coefficient given by

$$
s_{i}=\frac{\partial y}{\partial x_{i}} \frac{x_{i}}{y}
$$

\subsubsection{Calibration Burner}

An estimate of uncertainty for the natural gas burner heat output, $u_{t}\left(\dot{q}_{b u r n e r}\right)$, is obtained by applying the propagation of uncertainty as described in Eq. (22). This includes the uncertainty of the three measured variables; namely pressure $(\mathrm{P})$, temperature $(\mathrm{T})$ and volumetric flow rate $(\dot{V})$ and the uncertainty of the natural gas heat of combustion $\left(\left(\Delta H_{c}\right)_{N G}\right)$. The ideal heat output is computed from the following equation:

$$
\dot{q}_{\text {burner }}=\dot{V} \frac{P}{P_{r e f}} \frac{T_{r e f}}{T}\left(\Delta H_{c}\right)_{N G}
$$

Volumetric flow, temperature and pressure were measured and the volume flow rate was adjusted to represent the standard conditions for which the heat of combustion was determined. Since the ideal heat output is the multiplicative product of each measurement, the sensitivity coefficients reduce to 1.0 (or -1.0) and the resulting expression for the uncertainty is given in the following equation:

$$
\frac{u_{t}\left(\dot{q}_{\text {burner }}\right)}{\dot{q}_{\text {burner }}}=\sqrt{\left(\frac{u_{P}}{P}\right)^{2}+\left(\frac{u_{\dot{V}}}{\dot{V}}\right)^{2}+\left(-\frac{u_{T}}{T}\right)^{2}+\left(\frac{u_{\left(\Delta H_{c}\right)_{N G}}}{\left(\Delta H_{c}\right)_{N G}}\right)^{2}}
$$

The Type K thermocouple used to measure the natural gas temperature has error limits of $\pm 1.1 \mathrm{~K}$, which corresponds to a standard uncertainty of $\pm 0.64 \mathrm{~K}$ when a rectangular 
distribution is assumed. The uncertainty of the OmegaDyne pressure transducer is 0.10 $\%$ of the full range, which is $10.2 \mathrm{~atm}$ resulting in a standard uncertainty of $\pm 0.0102 \mathrm{~atm}$. Nominal temperature and pressure are $293 \mathrm{~K}$ and $2.02 \mathrm{~atm}$, respectively. The lower heating value of the natural gas heat of combustion was determined from gas chromatograph reports supplied by the local gas utility. The nominal value is 33,733 $\mathrm{kJ} / \mathrm{m}^{3}$ (computed for reference conditions of $1 \mathrm{~atm}$ and $300 \mathrm{~K}$ ) and the standard deviation, computed from gas chromatograph reports spanning six days, was $\pm 133 \mathrm{~kJ} / \mathrm{m}^{3}$. Neither of these three variables are expected to fluctuate significantly during a test. The volumetric flow rate was the only dynamic variable in this calculation. It is determined from the ratio of the measured frequency of pulses, $f$, and the meter factor, $\mathrm{K}$. The meter factor supplied by the manufacturer, $\mathrm{K}=5.08 \times 10^{-4}$ pulses $/ \mathrm{cm}^{3}$, is employed in the computation. This agrees with the mean meter factor taken from the results of the flow calibration [25]. The standard deviation about the mean meter factor over the calibration range is $\pm 0.03 \times 10^{-4}$ pulses $/ \mathrm{cm}^{3}$. Combined with the uncertainty in the pulse counting method, the standard relative uncertainty of the volumetric flow rate measurement is estimated at \pm 0.01 . The standard relative uncertainty for the temperature, pressure and natural gas heat of combustion are, $\pm 0.002, \pm 0.005$, and \pm 0.004 , respectively. Using Eq. (25), the total relative uncertainty for the ideal heat output of the calibration burner is calculated to be \pm 0.012 .

\subsubsection{Calorimetry}

The relationship which applies to the measurement of heat release rate is given by Eq. (13), which is reproduced here for convenience.

$$
\begin{aligned}
& \dot{q}=\left[\left(\Delta H_{c}\right)_{\text {Mass_o }}^{H C} \phi-\left(\left(\Delta H_{c}\right)_{\text {Mass_o }}^{\text {CO }}-\left(\Delta H_{c}\right)_{\text {Mass }_{-} O_{2}}^{H C}\right) \frac{1-\phi}{2} \frac{X_{C O}}{X_{O_{2}}}\right] \\
& \frac{\dot{m}_{e}}{1+\phi(\alpha-1)}\left[\frac{\left(1-X_{H_{2} O}^{o}\right) M_{O_{2}}}{M_{\text {air }}}\right] X_{O_{2}}^{o}
\end{aligned}
$$

with

$$
\phi=\frac{X_{O_{2}}^{o}\left(1-X_{C_{2}}-X_{C O}\right)-X_{O_{2}}\left(1-X_{C_{2}}^{o}\right)}{\left(1-X_{O_{2}}-X_{C_{2}}-X_{C O}\right) X_{O_{2}}^{o}}
$$

As written the expression for $\dot{q}$ contains parameters which are correlated or codependent, namely $X_{\mathrm{O}_{2}}$ and $X_{\mathrm{O}_{2}}^{o}$, which violates the assumption leading to Eq. (22). In order to avoid such co-dependencies induced by common inputs, Eq. (13) must be reduced to the most basic measurement inputs of instrument voltages, thermocouple temperatures, and constant parameters (universal, empirical and calibration). This process is described for each of the measurement devices in text to follow.

The resulting measurement value for the project at hand is the heat release rate corrected for the baseline or zero measurement bias, the algebraic subtraction of Eq. (13) and (19). 
The baseline heat release rate is determined by linear fits to the component data (Eq. (19), Method II). For the purpose of the uncertainty propagation, all data is centered about the mean time, $\bar{t}$ (determined from the baseline data), which eliminates the covariance between the slope, $\mathrm{m}$, and the intercept, $\mathrm{j}$.

$$
a=m(t-\bar{t})+j
$$

It is important to recognize that the quantity $\phi$ is proportional to $\left(X_{O_{2}}^{o}-X_{O_{2}}\right)$ since the volume fraction of $\mathrm{CO}$ and $\mathrm{CO}_{2}$ are small compared to that of oxygen. In addition the difference in the oxygen volume fractions is typically quite small. Some care must be taken in estimating the uncertainty in this case. An example is presented by Kragten [33] which illustrates the potential danger caused by ignoring correlations induced in intermediate measurement results by shared inputs. A similar example affecting the assessment of heat release rate is appended. The example illustrates the importance of performing an uncertainty analysis for the most basic inputs such as instrument voltage outputs and constants (empirical or universal). The relations for converting the instrument voltage outputs to units of more scientific significance follow.

Oxygen Analyzer

The oxygen analyzer produces a DC voltage $[\mathrm{V}]$ that is converted to the oxygen volume fraction by the following relation (includes the pressure correction):

$$
X_{O_{2}}=\frac{V_{O_{2}}-V_{O_{2}, \text { Zero }}}{V_{O_{2}, \text { Span }}-V_{O_{2}, \text { Zero }}}\left(X_{O_{2}, \text { Span }}-X_{O_{2}, \text { Zero }}\right)\left(\frac{V_{O_{2}, \text { press,Zero }}}{V_{O_{2}, \text { press }}}\right)
$$

where:

$V_{O_{2}}=$ voltage measured by oxygen sensor at time, $\mathrm{t}$

$V_{O_{2}, \text { Zero }}=$ voltage measured by oxygen sensor for the zero gas

$V_{O_{2}, \text { Span }}=$ voltage measured by oxygen sensor for the span gas

$X_{O_{2}, \text { Span }}=$ oxygen volume fraction of the span gas, bottled air (0.2095)

$X_{O_{2}, \text { Zero }}=$ oxygen volume fraction of the zero gas, nitrogen $\left(\mathrm{N}_{2}\right)$

$X_{\mathrm{O}_{2}}=$ oxygen volume fraction computed with respect to voltage measurement at time, $\mathrm{t}$

$V_{O_{2}, \text { press }}=$ voltage measured by absolute manometer to monitor pressure in the oxygen analyzer at time, $\mathrm{t}$

$V_{O_{2}, \text { press,Zero }}=$ voltage measured by absolute manometer to monitor pressure in the oxygen analyzer during the zeroing of the instrument

The oxygen sensor is calibrated before each fire test to determine $V_{O_{2} \text {,Span }}$ and $V_{O_{2} \text {,Zero }}$. Absolute pressure is measured at the oxygen analyzer and the output is corrected for pressure fluctuations relative to the output when the instrument is zeroed. 
Similarly, the relation converting the voltage output to the ambient oxygen volume fraction is:

$$
X_{O_{2}}^{o}=\frac{V_{O_{2}}^{o}-V_{O_{2}, \text { Zero }}}{V_{O_{2}, \text { Span }}-V_{O_{2}, \text { Zero }}}\left(X_{O_{2}, \text { Span }}-X_{O_{2}, \text { Zero }}\right)\left(\frac{V_{O_{2}, \text { press,Zero }}}{V_{O_{2}, \text { press }}^{o}}\right)
$$

The ambient oxygen measurement is conducted immediately after the spanning of the instruments. This value is then held as a constant in the computation.

\section{Carbon Dioxide Analyzer}

The carbon dioxide analyzer produces a DC voltage [V] that is converted to the carbon dioxide volume fraction by the following relation:

$$
X_{\mathrm{CO}_{2}}=\frac{V_{\mathrm{CO}_{2}} R F_{\mathrm{CO}_{2}}-V_{\mathrm{CO}_{2}, \text { Zero }} R F_{\mathrm{CO}_{2}, \text { Zero }}}{V_{\mathrm{CO}_{2}, \mathrm{Span}} R F_{\mathrm{CO}_{2}, \mathrm{Span}}-V_{\mathrm{CO}_{2}, \text { Zero }} R F_{\mathrm{CO}_{2}, \text { Zero }}}\left(X_{\mathrm{CO}_{2}, \mathrm{Span}}-X_{\mathrm{CO}_{2}, \text { Zero }}\right)
$$

where:

$V_{\mathrm{CO}_{2}}=$ voltage measured by $\mathrm{CO}_{2}$ analyzer at time, $\mathrm{t}$

$V_{\mathrm{CO}_{2}, \text { Zero }}=$ voltage measured by $\mathrm{CO}_{2}$ analyzer for the zero gas

$V_{\mathrm{CO}_{2} \text {,Span }}=$ voltage measured by $\mathrm{CO}_{2}$ analyzer for the span gas

$X_{\mathrm{CO}_{2}, \text { Span }}=\mathrm{CO}_{2}$ volume fraction of the span gas, $\mathrm{CO}_{2} / \mathrm{CO} / \mathrm{N}_{2}$ mixture

$X_{\mathrm{CO}_{2}, \text { Zero }}=\mathrm{CO}_{2}$ volume fraction of the zero gas, $\mathrm{N}_{2}$

$R F_{\mathrm{CO}_{2}}=$ range factor for the $\mathrm{CO}_{2}$ voltage measured at time, $\mathrm{t}$

$R F_{\mathrm{CO}_{2}, \text { Zero }}=$ range factor for the $\mathrm{CO}_{2}$ voltage measured when the instrument is zeroed

$R F_{\mathrm{CO}_{2}, \text { Span }}=$ range factor for the $\mathrm{CO}_{2}$ voltage measured when the instrument is spanned

The range factors are specific to the $\mathrm{CO}_{2}$ analyzer employed. Depending on the range selected by the analyzer, a voltage is sent to the appropriate range channel of the data acquisition system. This voltage $\left(V_{R i}\right)$ is entered into the following relation to determine the range factor. The range factors are written to the adjusted data file.

$$
R F_{C O_{2}}=A V_{R 1}+B V_{R 2}+C V_{R 3}+D V_{R 4}
$$

Similarly, the voltage output converted to the ambient carbon dioxide volume fraction is:

$$
X_{\mathrm{CO}_{2}}^{o}=\frac{V_{\mathrm{CO}_{2}}^{o} R F_{\mathrm{CO}_{2}}^{o}-V_{\mathrm{CO}_{2}, \text { Zero }} R F_{\mathrm{CO}_{2}, \text { Zero }}}{V_{\mathrm{CO}_{2}, \mathrm{Span}} R F_{\mathrm{CO}_{2}, \mathrm{Span}}-V_{\mathrm{CO}_{2}, \text { Zero }} R F_{\mathrm{CO}_{2}, \text { Zero }}}\left(X_{\mathrm{CO}_{2}, \mathrm{Span}}-X_{\mathrm{CO}_{2}, \text { Zero }}\right)
$$




\section{Carbon Monoxide Analyzer}

The carbon monoxide analyzer produces a $\mathrm{DC}$ voltage $[\mathrm{V}]$ that is converted to the carbon monoxide volume fraction by the following relation:

$$
X_{C O}=\frac{V_{C O} R F_{C O}-V_{C O, \text { Zero }} R F_{C O, \text { Zero }}}{V_{C O, \text { Span }} R F_{C O, \text { Span }}-V_{C O, \text { Zero }} R F_{C O, \text { Zero }}}\left(X_{C O, \text { Span }}-X_{C O, \text { Zero }}\right)
$$

where:

$V_{C O}=$ voltage measured by $\mathrm{CO}$ analyzer at time, $\mathrm{t}$

$V_{C O, \text { Zero }}=$ voltage measured by $\mathrm{CO}$ analyzer for the zero gas

$V_{C O, \text { Span }}=$ voltage measured by $\mathrm{CO}$ analyzer for the span gas

$X_{C O, \text { Span }}=\mathrm{CO}$ volume fraction of the span gas, $\mathrm{CO}_{2} / \mathrm{CO} / \mathrm{N}_{2}$ mixture

$X_{C O, \text { Zero }}=\mathrm{CO}$ volume fraction of the zero gas, $\mathrm{N}_{2}$

$R F_{C O}=$ range factor for the $\mathrm{CO}$ voltage measured at time,t.

$R F_{C O, Z e r o}=$ range factor for the $\mathrm{CO}$ voltage measured when the instrument is zeroed

$R F_{C O, \text { Span }}=$ range factor for the $\mathrm{CO}$ voltage measured when the instrument is spanned

The range factors will be specific to the $\mathrm{CO}$ analyzer employed. Depending on the range selected by the analyzer, a voltage is sent to the appropriate range channel of the data acquisition system. This voltage $\left(V_{R i}\right)$ is entered into the following relation to determine the range factor. The range factors are written to the adjusted data file.

$$
R F_{C O}=A V_{R 1}+B V_{R 2}+C V_{R 3}+D V_{R 4}
$$

\section{Ambient Water Vapor}

Relative humidity $(R H,[\%])$ is read from a humidity meter located in the data acquisition control room. The ambient temperature $\left(T_{a m b},\left[{ }^{\circ} \mathrm{C}\right]\right)$ is measured from a thermocouple located on the data acquisition rack. The signal condition modules convert the thermocouple millivolt signal to degrees $\mathrm{C}$ before it is used in the HRR computation. Ambient pressure $\left(P_{a m b}\right.$, [torr] $)$ is read from a mercury barometer located in the high bay area of the Large Fire Laboratory. The reading is corrected for altitude and temperature. The three measurements are used in the following relation [34] to infer the volume fraction of water vapor at ambient conditions.

$$
\begin{aligned}
X_{H_{2} O}^{o}= & \frac{R H}{100} \frac{760}{P_{a m b} 101.3}\left(5.5259 \times 10^{-7} T_{a m b}^{4}+1.7195 \times 10^{-5} T_{a m b}^{3}+1.5678 \times 10^{-3} T_{a m b}^{2}\right. \\
& \left.+0.043725 T_{a m b}+0.611\right)
\end{aligned}
$$

Exhaust Duct Bi-Directional Probes and Thermocouples

The bi-directional probes produce a DC voltage $\left(V_{b d p, i}\right)$ that is converted to a differential pressure by the following relation: 


$$
\Delta P_{i}[P a]=133.322 b_{i}\left(V_{b d p, i}-V_{b d p, i, Z e r o}\right)
$$

where $b_{i}$ [torr / V] is the calibration coefficient of each probe and $133.322[\mathrm{~Pa} /$ torr] is the conversion factor for torr to Pascals. The voltage measured when each probe is zeroed is $V_{b d p, i, \text { Zero }}$.

At each probe location a temperature is measured, $T_{b d p, i}$. The signal condition modules convert the thermocouple millivolt signal to degrees $\mathrm{C}$. The pressure differential and temperature measurements are employed in the following relation to infer the exhaust gas velocity at each probe location.

$$
U_{b d p, i}=C_{b d p} \sqrt{\Delta P_{i}\left(T_{b d p, i}+273.15\right)}
$$

where

$$
C_{b d p}=\frac{1}{C} \sqrt{\frac{2 R}{P_{r e f} M W_{\text {air }}}}=0.0698
$$

when $C=1.08 \pm 0.05$ as determined by McCaffrey and Heskestad [13].

The average velocity and average temperature for the six probes are computed to represent the velocity and temperature in the exhaust duct at the gas sampling point.

$$
\begin{gathered}
U_{a v g}=\frac{0.0698}{6} \sum_{i=1}^{6} \sqrt{133.322 b_{i}\left(V_{b d p, i}-V_{b d p, i, \text { Zero }}\right)\left(T_{b d p, i}+273.15\right)} \\
T_{\text {avg }}=\frac{1}{6} \sum_{i=1}^{6}\left(T_{b d p, i}+273.15\right)
\end{gathered}
$$

The mass flow rate $([\mathrm{kg} / \mathrm{s}])$ of the exhaust duct is then computed by the following relation:

$$
\dot{m}_{e}=\frac{\frac{0.0698}{6} \sum_{i=1}^{6} \sqrt{133.322 b_{i}\left(V_{b d p, i}-V_{b d p, i, Z e r o}\right)\left(T_{b d p, i}+273.15\right)}}{\frac{1}{6} \sum_{i=1}^{6}\left(T_{b d p, i}+273.15\right)} \rho_{\text {air }, \text { ref }} T_{r e f} \frac{\pi D^{2}}{4}(40)
$$

where $\rho_{\text {air,ref }}(1.1767 \mathrm{~kg} / \mathrm{m} 3)$ is the density of the reference gas (dry air), $T_{r e f}(300 \mathrm{~K})$ is the temperature of the reference gas, and $D(1.52 \mathrm{~m})$ is the inside diameter of the exhaust duct at the probe location.

A close inspection of all of the relations presented above will reveal the co-dependent input parameters of Eq. (13). The co-dependent pairs are $\left(X_{\mathrm{O}_{2}}, X_{\mathrm{O}_{2}}^{o}\right),\left(X_{\mathrm{CO}_{2}}, X_{\mathrm{CO}_{2}}^{o}\right)$, and $\left(U_{b d p, i}, T_{b d p, i}\right)$. These parameters share variables or one is dependent upon the other as in 
the case of $U_{b d p, i}$ and $T_{b d p, i}$. Therefore it is recommended to break down the computation to the basic input measurements before beginning an uncertainty propagation to properly account for the co-dependence in intermediate quantities.

A major justification for the added complexity to the uncertainty propagation is specific to the heat release measurement as conducted in this laboratory and is illustrated by the appended example. The heat release measurement is based on oxygen consumption calorimetry and is therefore directly proportional to the difference between the measurements of oxygen and ambient oxygen volume fraction, $\left(X_{\mathrm{O}_{2}}^{o}-X_{\mathrm{O}_{2}}\right)$. The combined uncertainty for each term of the oxygen difference is dominated by the uncertainty of the oxygen volume fraction of the span gas. This uncertainty is on the order of 3 times greater than the oxygen difference measured in small fires. By rewriting Eq. (13) in terms of the basic inputs, the uncertainty of the span gas will be correctly accounted for and will not give an erroneously large uncertainty for the oxygen difference, as would be the case if Eq. (13) were used directly.

Rewriting Eq. (13) in terms of the basic input measurements results in a final equation that consists of 64 input parameters. The parameters are listed in Table 6 and the equations, in terms of basic inputs, for each measurement instrument were presented above.

A numerical approach to Eq. (22) as described by Kragten [33] has the advantage of being easily implemented in an Excel spreadsheet. The method numerically approximates all the partial derivatives and calculates the combined standard uncertainty without the use of intermediate quantities that violate the condition of mutual independence. It is a spreadsheet-based format that offers relatively easy tracking of the contribution of uncertainty of each parameter. An example of the spreadsheet developed for this project is shown in Figure 19. The details of creating a spreadsheet uncertainty propagation are explained in Ref. [33].

The uncertainty of the heat release rate measurement varies with the operating conditions of the calorimeter and the size of the fire. A series of experiments was conducted with the natural gas calibration burner targeted at $0.50 \mathrm{MW}, 0.65 \mathrm{MW}$, and $2.70 \mathrm{MW}$, to produce nominal values for the uncertainty analysis. The measurements were corrected for the background drift by applying Method II as described in Sec. 3.5 and the uncertainty propagation was performed on the resulting relation for the corrected heat release rate. Due to the background correction the number of parameters increases from 64 to 70 . 


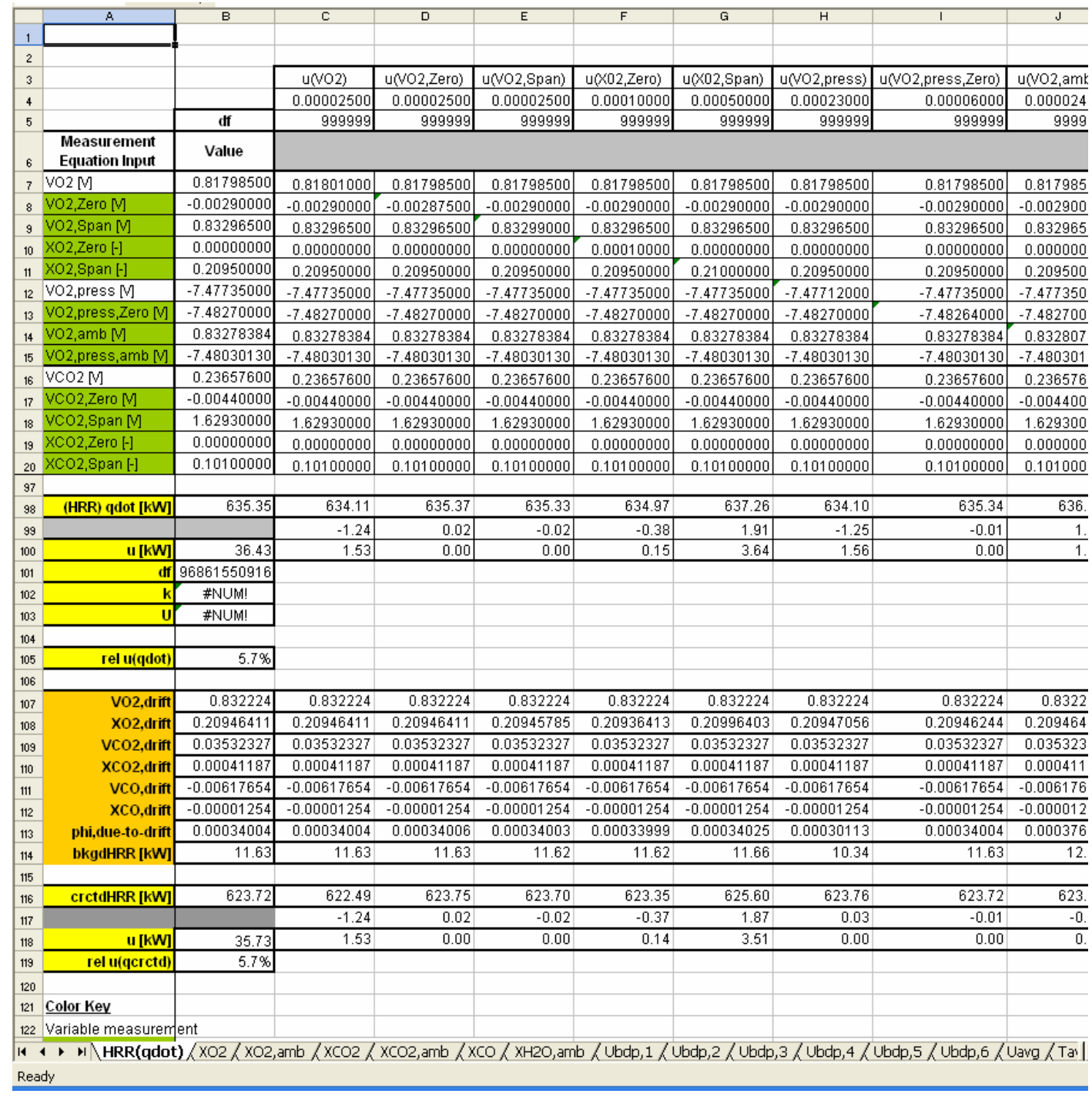

Figure 19 Example of Kragten spreadsheet for computing HRR uncertainty.

The uncertainty for these measurements is presented in Table 6 including the total relative uncertainty, $u_{t}$. Each of the 70 input parameters is listed with its nominal value, relative standard uncertainty and its non-dimensional sensitivity coefficient. The quantities labeled as "Constant" are quantities that may or may not vary between uses of the calorimeter while those labeled "Variable" fluctuate during use of the calorimeter. Type A or B determinations are indicated by either " $A$ " or " $B$ " in parenthesis. By visual inspection of the table, the product of the sensitivity coefficient and the relative standard uncertainty help to quantify the contribution to the total uncertainty. Therefore parameters with absolute values of sensitivity coefficients equal to or greater than unity are expected to make a greater contribution to the total uncertainty. 
Table 6 Corrected heat release rate relative uncertainty

\begin{tabular}{|c|c|c|c|c|c|}
\hline \multirow{2}{*}{$\begin{array}{c}\text { Parameter/measurement } \\
\text { [units] (type) }\end{array}$} & \multirow[b]{2}{*}{$\begin{array}{l}\text { Nominal } \\
\text { value }\end{array}$} & \multirow{2}{*}{$\begin{array}{c}\text { Relative } \\
\text { standard } \\
\text { uncertainty, } \\
u\left(x_{i}\right) / x_{i}\end{array}$} & \multicolumn{3}{|c|}{ Sensitivity coefficient, $\left|S_{i}\right|$} \\
\hline & & & $\begin{array}{l}0.05 \\
\mathrm{MW}\end{array}$ & $\begin{array}{l}0.65 \\
\mathrm{MW}\end{array}$ & $\begin{array}{l}2.70 \\
\mathrm{MW}\end{array}$ \\
\hline \multicolumn{6}{|c|}{$X_{O_{2}}, X_{O_{2}}^{o},[-]$} \\
\hline$V_{o_{2}},[\mathrm{~V}]$ (variable) & 0.817985 & $0.00003(\mathrm{~A})$ & 1113 & 80.2 & 16.35 \\
\hline$V_{\mathrm{O}_{2}, \text { Zero }},[\mathrm{V}]$ (constant) & -0.002900 & $0.00869(\mathrm{~A})$ & 0.004 & 0.004 & 0.004 \\
\hline$V_{\mathrm{O}_{2}, \text { Span }},[\mathrm{V}]$ (constant) & 0.832965 & $0.00003(\mathrm{~A})$ & 1.253 & 1.256 & 1.24 \\
\hline$X_{O_{2}, \text { Zero }},[-]($ constant $)$ & 0.0000 & $\begin{array}{l}0.0001(\mathrm{~B}) \\
\text { absolute }\end{array}$ & - & - & - \\
\hline$X_{O_{2}, \operatorname{Span}},[-]($ constant $)$ & 0.2095 & $0.00239(\mathrm{~B})$ & 1.258 & 1.261 & 1.245 \\
\hline$V_{\mathrm{O}_{2}, \text { press }},[\mathrm{V}]$ (variable) & -7.47735 & $0.00003(\mathrm{~A})$ & 1.774 & 1.776 & 1.752 \\
\hline $\begin{array}{l}V_{O_{2}, \text { press }, \text { Zero }},[\mathrm{V}] \\
\text { (constant) }\end{array}$ & -7.48270 & $0.00001(\mathrm{~A})$ & 1.257 & 1.260 & 1.244 \\
\hline$V_{\mathrm{O}_{2}}^{o},[\mathrm{~V}]$ (constant) & 0.832784 & $0.00003(\mathrm{~A})$ & 0.515 & 0.514 & 0.506 \\
\hline$V_{O_{2}, \text { press }}^{o},[\mathrm{~V}]$ (constant) & -7.480301 & $0.00001(\mathrm{~A})$ & 0.517 & 0.516 & 0.508 \\
\hline \multicolumn{6}{|c|}{$X_{\mathrm{CO}_{2}}, X_{\mathrm{CO}_{2}}^{o},[-]$} \\
\hline$V_{\mathrm{CO}_{2}},[\mathrm{~V}]$ (varaible) & 0.236576 & $0.01704(\mathrm{~A})$ & 0.549 & 0.169 & 0.133 \\
\hline$V_{\mathrm{CO}_{2}, \text { Zero }},[\mathrm{V}]$ (constant) & -0.00440 & $0.10400(\mathrm{~A})$ & 0.000 & 0.000 & 0.000 \\
\hline$V_{\mathrm{CO}_{2}, \operatorname{Span}},[\mathrm{V}]$ (constant) & 1.629300 & $0.00046(\mathrm{~A})$ & 0.135 & 0.139 & 0.127 \\
\hline$X_{\mathrm{CO}_{2}, \text { Zero }},[-]$ (constant) & 0.0000 & $\begin{array}{l}0.0001(\mathrm{~B}) \\
\text { absolute }\end{array}$ & - & - & - \\
\hline$X_{\mathrm{CO}_{2}, \text { Span }},[-]$ (constant) & 0.10100 & $0.00500(\mathrm{~B})$ & 0.136 & 0.139 & 0.127 \\
\hline$R F_{\mathrm{CO}_{2}},[-]$ (variable) & 1.039 & $0.00000(\mathrm{~B})$ & 0.549 & 0.169 & 0.133 \\
\hline$R F_{\mathrm{CO}_{2}, \text { Zero }},[-]$ (constant) & 1.039 & $0.00000(\mathrm{~B})$ & 0.000 & 0.000 & 0.000 \\
\hline$R F_{\mathrm{CO}_{2}, \text { Span }},[-]$ (constant) & 6.209 & $0.00000(\mathrm{~B})$ & 0.136 & 0.139 & 0.127 \\
\hline$V_{\mathrm{CO}_{2}}^{o},[\mathrm{~V}]($ constant $)$ & 0.033502 & $0.01309(\mathrm{~A})$ & 0.001 & 0.001 & 0.001 \\
\hline $\mathrm{RF}_{\mathrm{CO}_{2}}^{o},[-]$ (constant) & 1.039 & $0.00000(\mathrm{~B})$ & 0.414 & 0.030 & 0.006 \\
\hline
\end{tabular}

Values expected to contribute significantly to the total uncertainty are in bold. 
Table 6 Continued - Corrected heat release rate relative uncertainty

\begin{tabular}{|c|c|c|c|c|c|}
\hline \multirow{3}{*}{$\begin{array}{c}\text { Parameter/measurement } \\
\text { [units] (type) }\end{array}$} & \multirow{3}{*}{$\begin{array}{l}\text { Nominal } \\
\text { value }\end{array}$} & \multirow{3}{*}{$\begin{array}{c}\text { Relative } \\
\text { standard } \\
\text { uncertainty, } \\
u\left(x_{i}\right) / x_{i}\end{array}$} & \multicolumn{3}{|c|}{ Sensitivity coefficient, $\left|s_{i}\right|$} \\
\hline & & & 0.05 & 0.65 & 2.70 \\
\hline & & & MW & MW & MW \\
\hline \multicolumn{6}{|c|}{$X_{C O},[-]$} \\
\hline$V_{C O},[\mathrm{~V}]$ (variable) & -0.01014 & $0.04726(\mathrm{~A})$ & 0.066 & 0.004 & 0.001 \\
\hline$V_{C O, \text { Zero }},[\mathrm{V}]($ constant $)$ & -0.00320 & $0.14629(\mathrm{~A})$ & 0.000 & 0.000 & 0.000 \\
\hline$V_{\text {CO,Span }},[\mathrm{V}]($ constant $)$ & 2.20140 & $0.00029(\mathrm{~A})$ & 0.013 & 0.000 & 0.000 \\
\hline$X_{C O, Z e r o},[-]($ constant $)$ & 0.0000 & $\begin{array}{c}0.0001(\mathrm{~B}) \\
\text { absolute }\end{array}$ & - & - & - \\
\hline$X_{C O, \text { Span }},[-]$ (constant) & 0.09080 & $0.00500(\mathrm{~B})$ & 0.013 & 0.000 & 0.000 \\
\hline$R F_{C O},[-]$ (variable) & 0.62 & $0.00000(\mathrm{~B})$ & 0.066 & 0.004 & 0.001 \\
\hline$R F_{C O, \text { Zero }},[-]$ (constant) & 0.62 & $0.00000(\mathrm{~B})$ & 0.054 & 0.004 & 0.001 \\
\hline$R F_{C O, S p a n},[-]$ (constant) & 6.069 & $0.00000(\mathrm{~B})$ & 0.013 & 0.000 & 0.000 \\
\hline \multicolumn{6}{|c|}{$X_{\mathrm{H}_{2} \mathrm{O}}^{o},[-]$} \\
\hline$R H,[\%]$ (variable) & 45 & $0.04038(\mathrm{~B})$ & 0.020 & 0.020 & 0.021 \\
\hline$P_{a m b},[$ torr $]$ (variable) & 754.10 & $0.00266(\mathrm{~B})$ & 0.020 & 0.020 & 0.021 \\
\hline$T_{a m b},\left[{ }^{\circ} \mathrm{C}\right]$ (variable) & 30.0 & $0.05095(\mathrm{~A})$ & 0.035 & 0.035 & 0.036 \\
\hline \multicolumn{6}{|c|}{$\mathrm{U}_{\text {bdp,avg }},[\mathrm{m} / \mathrm{s}], \mathrm{T}_{\text {bdp,avg }},[\mathrm{K}], \dot{m}_{e},[\mathrm{~kg} / \mathrm{s}]$} \\
\hline $\begin{array}{l}C_{b d p},[\mathrm{~m} 3 / \mathrm{K}-\mathrm{kg}] \\
(\text { constant) }\end{array}$ & 0.0698 & 0.05014 (B) & 1.00 & 1.00 & 1.00 \\
\hline$b_{i},[$ torr/V] (constant) & 0.10 & $0.00000(\mathrm{~B})$ & 0.083 & 0.083 & 0.083 \\
\hline$V_{b d p, i},[\mathrm{~V}]($ variable $)$ & 1.80721 & $0.06231(\mathrm{~A})$ & 0.082 & 0.082 & 0.082 \\
\hline$V_{\text {bdp }, i, \text { Zero }},[\mathrm{V}]$ (constant) & -0.014417 & $0.79906(\mathrm{~A})$ & 0.000 & 0.000 & 0.000 \\
\hline$T_{b d p, i},[\mathrm{~K}]$ (variable) & 343.0 & $0.00466(\mathrm{~A})$ & 0.010 & 0.010 & 0.010 \\
\hline$\rho_{\text {air }, r e f},\left[\mathrm{~kg} / \mathrm{m}^{3}\right]$ (constant) & 1.1767 & $0.00000(\mathrm{~B})$ & 1.000 & 1.000 & 1.000 \\
\hline$T_{r e f},[\mathrm{~K}]$ (constant) & 300 & $0.00000(\mathrm{~B})$ & 1.000 & 1.000 & 1.000 \\
\hline$D,[\mathrm{~m}]($ constant $)$ & 1.52 & 0.00661 (B) & 2.007 & 2.007 & 2.007 \\
\hline \multicolumn{6}{|c|}{ Constants } \\
\hline$\left(\Delta H_{c}\right)_{\text {Mass_o }}^{H C},[\mathrm{MJ} / \mathrm{kg}$ & 12.55 & 0.00159 (B) & 0.981 & 1.000 & 1.000 \\
\hline $\begin{array}{l}\text { O }] \text { (constant) } \\
\left(\Delta H_{c}\right)_{\text {Mass }_{-} O_{2}}^{C O},[\mathrm{MJ} / \mathrm{kg}\end{array}$ & 17.60 & $0.00057(\mathrm{~B})$ & 0.019 & 0.000 & 0.000 \\
\hline $\left.\mathrm{O}_{2}\right],($ constant $)$ & & & & & \\
\hline$\alpha,[-]($ constant $)$ & 1.10 & $0.04364(\mathrm{~A})$ & 0.003 & 0.019 & 0.079 \\
\hline $\begin{array}{l}M W_{\mathrm{O}_{2}},[\mathrm{~kg} / \mathrm{mole}] \\
\text { (constant) }\end{array}$ & 32.00 & $0.00000(\mathrm{~B})$ & 1.000 & 1.000 & 1.000 \\
\hline $\begin{array}{l}M W_{\text {air }},[\mathrm{kg} / \mathrm{mole}] \\
\text { (constant) }\end{array}$ & 28.967 & $0.00000(\mathrm{~B})$ & 1.000 & 1.000 & 1.000 \\
\hline
\end{tabular}

Values expected to contribute significantly to the total uncertainty are in bold. 
Table 6 Continued - Corrected heat release rate relative uncertainty

\begin{tabular}{|c|c|c|c|c|c|}
\hline \multirow{3}{*}{$\begin{array}{c}\text { Parameter/measurement } \\
\text { [units] (type) }\end{array}$} & \multirow{3}{*}{$\begin{array}{l}\text { Nominal } \\
\text { value }\end{array}$} & \multirow{3}{*}{$\begin{array}{c}\text { Relative } \\
\text { standard } \\
\text { uncertainty, } \\
u\left(x_{i}\right) / x_{i}\end{array}$} & \multicolumn{3}{|c|}{ Sensitivity coefficient, $\left|s_{i}\right|$} \\
\hline & & & 0.05 & 0.65 & 2.70 \\
\hline & & & MW & MW & MW \\
\hline \multicolumn{6}{|c|}{$V_{O_{2}, d r i f t},[\mathrm{~V}]$} \\
\hline$m_{V_{O_{2}}},[\mathrm{~V} / \mathrm{s}]($ constant $)$ & $-2.43 \times 10^{-7}$ & $0.00344(\mathrm{~A})$ & 0.269 & 0.002 & 0.002 \\
\hline$j_{V_{O_{2}}},[\mathrm{~V}]($ constant $)$ & 0.832475 & $0.00000(\mathrm{~A})$ & 1115 & 81.99 & 18.10 \\
\hline \multicolumn{6}{|c|}{$V_{\mathrm{CO}_{2}, \text { drift }},[\mathrm{V}]$} \\
\hline$m_{V_{\mathrm{CO}_{2}}},[\mathrm{~V} / \mathrm{s}]($ constant $)$ & $9.09 \times 10^{-7}$ & $0.14630(\mathrm{~A})$ & 0.000 & 0.000 & 0.000 \\
\hline$j_{V_{\mathrm{CO}_{2}}},[\mathrm{~V}]($ constant $)$ & 0.034387 & $0.00403(\mathrm{~A})$ & 0.414 & 0.031 & 0.007 \\
\hline \multicolumn{6}{|c|}{$V_{C O, d r i f t},[\mathrm{~V}]$} \\
\hline$m_{V_{C O}},[\mathrm{~V} / \mathrm{s}]($ constant $)$ & $-7.95 \times 10^{-7}$ & $0.71062(\mathrm{~A})$ & 0.002 & 0.000 & 0.000 \\
\hline$j_{V_{C O}},[\mathrm{~V}]($ constant $)$ & -0.00536 & $0.02411(\mathrm{~A})$ & 0.051 & 0.004 & 0.001 \\
\hline$t,[\mathrm{~s}]($ variable) & & $0.00000(\mathrm{~B})$ & 0.217 & 0.002 & 0.003 \\
\hline \multicolumn{3}{|c|}{$u_{t} / \dot{q}_{c r c t d}$} & 0.075 & 0.053 & 0.053 \\
\hline
\end{tabular}

Values expected to contribute significantly to the total uncertainty are in bold.

At first glance, parameters with sensitivity coefficients much greater than unity are expected to be the largest contributors to the combined uncertainty. However these parameters (the oxygen analyzer voltage, $V_{\mathrm{O}_{2}}$, and the intercept for oxygen analyzer voltage drift measurement, $j_{V_{O_{2}}}$ ) have very small relative uncertainty. Their contribution is most significant at very low heat release rate, as evidenced by the increase in the magnitude of the sensitivity coefficient. The parameters with sensitivity coefficients near unity and standard relative uncertainty greater than 0.01 are the significant contributors across the entire range of heat release rate. Such parameters are the bi-directional probe flow constant, $C_{b d p, i}$, and the exhaust duct diameter, $D$ (and the heat release rate of the fuel, $\left(\Delta_{c} H\right)_{\text {Mass } O_{2}}^{H C}$, for fuels of unknown composition). The relative uncertainty contribution from these two parameters combined is a little more than \pm 0.050 and essentially sets the lower limit of uncertainty of the system. In the most practical case, the fuel will be of unknown composition and the uncertainty of $\left(\Delta_{c} H\right)_{\text {Mass } O_{2}}^{\mathrm{HC}}$ will increase from \pm 0.002 to \pm 0.027 , therefore increasing the lower limit of uncertainty to \pm 0.058 . The probe constant, $\mathrm{C}_{\mathrm{bdp}, \mathrm{i}}$, and the duct diameter are employed in the mass flow rate measurement. Improvement in the uncertainty of both of these variables or an independent measurement of the mass flow rate measurement with a standard relative uncertainty less than \pm 0.050 is recommended. It is important to realize that the oxygen depletion for large fires is actually quite small due to the need to capture the plume in the 
exhaust duct and dilute it so that complete combustion will occur. The 3MWHRRF is designed for large fires. The lowest dilution rates are not optimum for small fires and therefore the uncertainty will be greater for the smaller fires, as evidenced by the increasingly large sensitivity coefficient for the oxygen sensor voltage, $V_{O_{2}}$.

It is recommended to apply the most comprehensive baseline correction, Method II, to data used for uncertainty analysis. This method of baseline correction reduces the codependency of variables that violate the rules of the uncertainty propagation as previously discussed. The baseline correction and associated uncertainty is a fourth innovation of this uncertainty analysis. ${ }^{25}$

Table $750 \mathrm{~kW}$ fire uncertainty comparison for the two methods of corrected HRR

\begin{tabular}{ccc}
\hline \multirow{2}{*}{$\begin{array}{c}\text { Baseline HRR, } \\
\text { MW }\end{array}$} & \multicolumn{2}{c}{$u_{t} / \dot{q}_{\text {crtd }}$} \\
\cline { 2 - 3 } & Method I correction & Method II correction \\
\hline 0.010 & 0.103 & 0.070 \\
0.052 & 0.135 & 0.075 \\
\hline
\end{tabular}

For large fires, $500 \mathrm{~kW}$ and above, the combined relative standard uncertainty computed for the Method I correction agrees with that of the Method II correction to within 0.005 (therefore these results are omitted for clarity). The fact that the two methods give similar results means that the simpler Method I correction can be applied to routine test runs and the uncertainty computed. The uncertainty results are compared in Table 7 for very small fires and demonstrate a lesser degree of agreement. The two examples considered suggest that as the magnitude of the baseline drift increases the discrepancy between the uncertainty results increases. The combined uncertainty is larger for the Method I correction due to the co-variance between the correction and the measurement. This co-variance has a negligible effect for larger fires.

\subsection{Repeatability, Expanded Uncertainty, and Confirmation Comparison}

\section{Repeatability}

The last component of the uncertainty analysis is the repeatability of the measurement system. The Large Fire Research Facility employs a natural gas burner to produce a known value of heat release rate. The burner operation and uncertainty are presented in Sec. 3.3 and Sec. 4.3.1, respectively. One cannot have a validated calorimeter without a high quality burner. The two facilities go hand in hand.

\footnotetext{
${ }^{25}$ When applying either the Method I or the Method II correction, the data should be centered about the mean time as discussed in Sec. 4.1 and 4.3.1.
} 
Table 8 Burner and calorimetry repeatability

\begin{tabular}{|c|c|c|}
\hline Burner HRR, MW & $\begin{array}{c}\text { Calorimetry HRR, } \\
\text { MW }\end{array}$ & $\begin{array}{c}\text { Exhaust flow rate, } \\
\mathrm{m}^{3} / \mathrm{min}\end{array}$ \\
\hline 0.045 & 0.039 & 622.7 \\
\hline 0.047 & 0.049 & 641.3 \\
\hline 0.048 & 0.040 & 615.3 \\
\hline 0.043 & 0.045 & 829.2 \\
\hline 0.050 & 0.053 & 844.3 \\
\hline 0.050 & 0.052 & 805.2 \\
\hline $\begin{array}{c}0.047 \pm 0.003 \\
(\operatorname{Avg} \pm \sigma)\end{array}$ & $0.046 \pm 0.006$ & \\
\hline 0.619 & 0.623 & 673.9 \\
\hline 0.620 & 0.603 & 701.5 \\
\hline 0.621 & 0.620 & 689.6 \\
\hline 0.622 & 0.627 & 880.3 \\
\hline 0.625 & 0.605 & 895.2 \\
\hline 0.618 & 0.617 & 862.0 \\
\hline $\begin{array}{c}0.621 \pm 0.003 \\
(\operatorname{Avg} \pm \sigma)\end{array}$ & $0.616 \pm 0.010$ & \\
\hline 2.610 & 2.706 & 870.9 \\
\hline 2.642 & 2.645 & 894.5 \\
\hline 2.624 & 2.656 & 874.1 \\
\hline 2.620 & 2.673 & 1038.3 \\
\hline 2.657 & 2.649 & 1056.9 \\
\hline 2.641 & 2.675 & 1035.9 \\
\hline $\begin{array}{c}2.633 \pm 0.017 \\
(\operatorname{Avg} \pm \sigma)\end{array}$ & $2.667 \pm 0.023$ & \\
\hline
\end{tabular}

Tests were conducted to quantify the repeatability of the measurement facility. The burner was run at three set points for heat release rate over two hood exhaust flow conditions, resulting in six separate conditions. Three repeat measurements were conducted at each condition over a period of two days. The conditions were ordered by first randomly choosing one of the two exhaust flow conditions to begin a series of tests for the three randomly ordered heat release rate settings and then repeating the process for the second exhaust flow condition. The two-step randomization was necessary in order to remain at an exhaust flow setting for a series of tests due to the difficulty of reproducing the exhaust flow conditions. However, the acquired data did not indicate that the exhaust flow rate has a measurable effect on the results; therefore the two sets of three repeats were combined.

The standard deviation of the repeat measurements was used to compute the repeatability relative standard uncertainty, $u_{r}$. The results of the repeat measurements together with their estimated uncertainties are given in Table 8. The results in the table were arrived at with the following analysis: 1) each heat release rate measurement in time was corrected for the baseline drift by algebraic subtraction, 2) the average heat release rate was 
computed from 300 measurements conducted at steady conditions, 3) the mean and standard deviation about the mean were computed for the HRR for the 6 measurements.

\section{Expanded Relative Uncertainty}

The combined uncertainty, $u_{c}$, is computed by adding in quadrature the total uncertainty from the uncertainty propagation with the repeatability uncertainty:

$$
u_{c}=\sqrt{u_{t}^{2}+u_{r}^{2}}
$$

Finally, the relative expanded uncertainty, $U_{e}$, is computed as $2 u_{c}$. The results for the calibration burner and the heat release rate calorimeter are presented in Table 9. Ideally the repeatability (standard deviation) is an estimate of the total uncertainty, therefore the uncertainty as computed in Eq. (41) is a conservative estimate due to some level of double counting the uncertainty. The uncertainty computed from the equation modeling the heat release rate fails to account for sources of uncertainty not included in the model such as operator error, certain environmental conditions, or undetected equipment failures. The combined uncertainty is computed in this manner in order to address these possible sources of uncertainty.

\section{Table 9 Expanded relative uncertainty results}

\begin{tabular}{ccc}
\hline \hline \multirow{2}{*}{$\begin{array}{c}\text { Nominal HRR, } \\
\text { MW }\end{array}$} & \multicolumn{2}{c}{$U_{e} / \dot{q}_{\text {crctd }}$} \\
\cline { 2 - 3 } & Burner & Calorimeter \\
\hline 0.05 & 0.115 & 0.273 \\
0.65 & 0.025 & 0.110 \\
2.70 & 0.027 & 0.107 \\
\hline
\end{tabular}

The calorimeter results of Table 9 are for a natural gas fire, which is a fire from a well characterized fuel where the uncertainty of the heat of combustion term is small. In the case that the fuel is not well characterized, the uncertainty of the heat of combustion term will increase and the increase in the expanded relative uncertainty (calorimeter output) is estimated to increase by 0.01 due to the addition in quadrature.

\section{Comparison of Calorimeter and Burner Output}

The results of the oxygen calorimetry should closely agree with the burner output. A comparison factor, $\mathrm{C}_{\mathrm{HRR}}$, is determined from the ratio of the oxygen calorimetry and burner heat release rates. It is used as a validation and quality control factor for the calorimetry. When $\mathrm{C}_{\mathrm{HRR}}$ is observed to fall outside predetermined bounds, it is time to troubleshoot the systems, calorimetry and calibration burner.

$$
C_{H R R}=\frac{\dot{q}_{\text {crctd }}}{\dot{q}_{\text {burner }}}
$$


The results for $\mathrm{C}_{\mathrm{HRR}}$ versus burner output are plotted in Figure 20 and were arrived at with the following analysis: 1) each heat release rate measurement in time was corrected for the baseline drift by algebraic subtraction, 2) the mean heat release rate was computed from 300 measurements conducted at steady conditions, 3) the comparison factor was computed from the mean values.

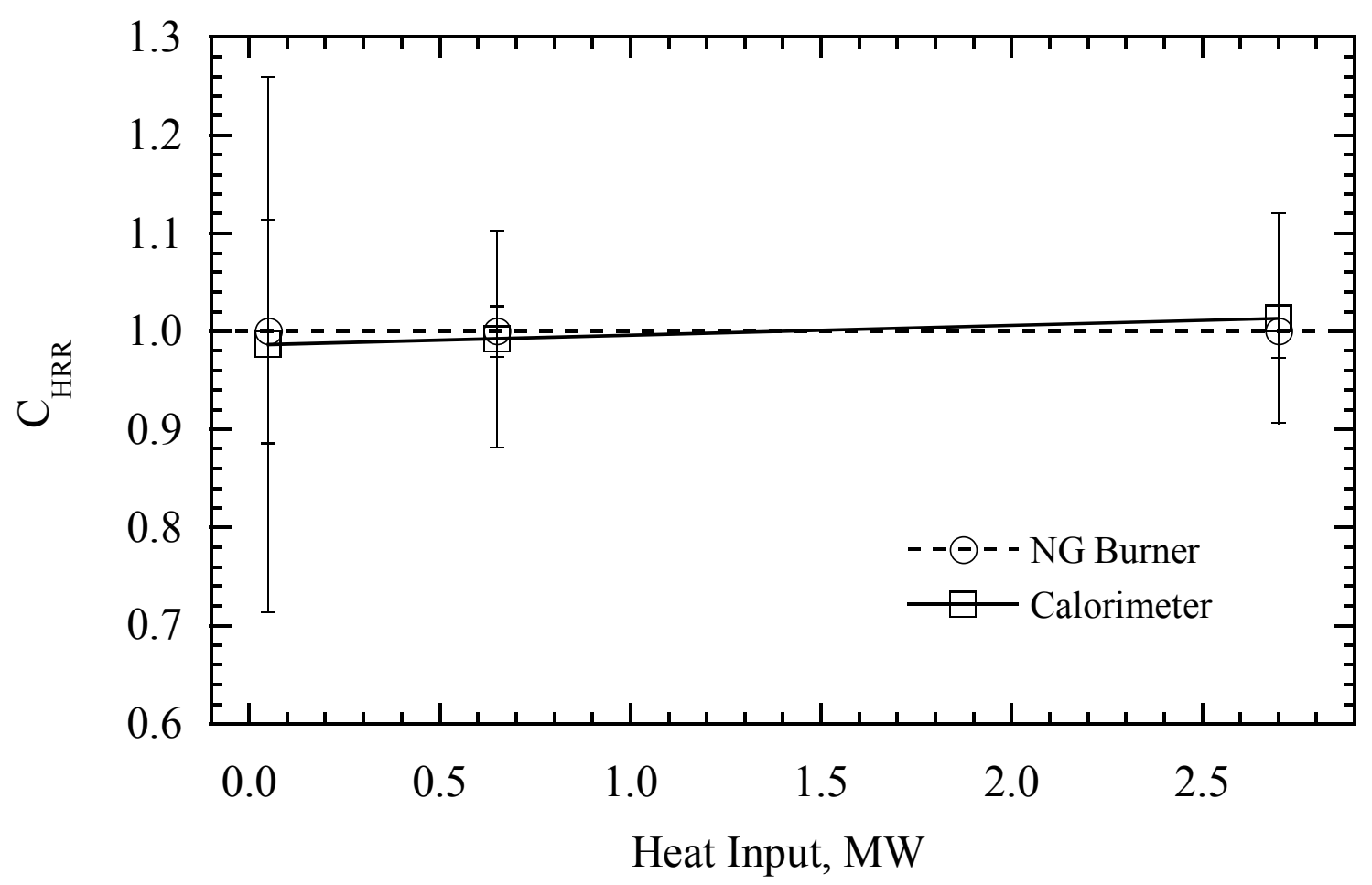

Figure 20 Burner and calorimeter comparison with respect to heat release rate.

The relative agreement between the oxygen calorimetry and the burner output is better than 0.98 for the entire range of heat release rates considered ( 0.05 to $2.70 \mathrm{MW})$. The bars represent the expanded relative uncertainty from Table 9. The uncertainty of the calorimetry is greater than the uncertainty of the burner heat release rate measurement and greater than the discrepancy between the calorimetry and the burner measurements.

\section{Internal Quality Control Procedures}

\subsection{Certified Operator}

The custodial operator of the system should be adequately trained on all components of the system through thorough review of instrument manuals and consultation with the manufacturer's technical representatives. The operator should be capable of training additional operators. The custodial operator is responsible for all Quality Control Procedures and scheduled maintenance. The operator should maintain a log book of all scheduled and unscheduled maintenance and facility modifications and upgrades. 


\subsection{Calibration of Instruments}

The oxygen, carbon dioxide, and carbon monoxide meters must be calibrated with a zero gas and span gas prior to running a fire test. Because the results of the calibration are inputs to the data acquisition program the calibrations are performed using the data acquisition program.

\section{Oxygen Meter:}

The oxygen meter should be zeroed with nitrogen gas of $99.998 \%$ purity (zero gas). (If zero gas is unavailable, $99.95 \%$ purity will suffice.) The meter should be spanned with a gas mixture similar to ambient air. The oxygen content of the mixture must be $20.95 \%$ and the balance must be nitrogen. Certification tickets should accompany the gas bottles and each minor component concentration should be certified accurate to $\pm 1 \%$ (from expanded uncertainty) of the concentration. The meter must be zeroed and spanned prior to each fire test where HRR is measured. The oxygen meter must be constantly powered up in order to establish a thermal equilibrium in the paramagnetic cell. If constant power to the meter is not an option, then it must be powered up at least 24 hours prior to use.

\section{Carbon Dioxide Meter:}

The carbon dioxide meter should be zeroed with nitrogen gas of $99.998 \%$ purity (zero gas). (If zero gas is unavailable, $99.95 \%$ purity will suffice.) The meter should be spanned with a gas mixture of carbon dioxide, carbon monoxide, and nitrogen. The concentrations should be $2 \%$ carbon dioxide, $0.1 \%$ carbon monoxide with nitrogen making up the remainder. Certification tickets should accompany the gas bottles and each minor component concentration should be certified accurate to $\pm 1 \%$ (from expanded uncertainty) of the concentration. The meter must be zeroed and spanned prior to each fire test where HRR is measured. The carbon dioxide meter must be constantly powered up in order to establish a thermal equilibrium in the instrument. If constant power to the meter is not an option, then it must be powered up at least $24 \mathrm{~h}$ prior to use.

\section{Carbon Monoxide Meter:}

The meter is identical to the carbon dioxide meter and the same requirements as listed above apply.

\section{Relative Humidity Meter:}

The humidity meter should be set for 1 day readings of relative humidity (see THDX manual) and the temperature output should be in units of Celsius. The instrument should be calibrated every 12 months. It is recommended to return it to the factory for calibration for the greatest accuracy. The instrument may be calibrated in house with salt capsules and a controlled environment. (see THDX manual)

Natural Gas Calorimeter:

The natural gas calorimeter should be run continuously during facility operating hours (five day week). Upon startup at the beginning of the each week, the instrument should be calibrated. Either a single point or double point calibration may be performed (see COSA CW95 manual). Calibration gases should be traceable to NIST primary standards for either gas composition or specific calorific value. Such gases are Ultra High Purity 
Methane (99.99\%), Specific BTU Methane (1010 BTU), and a certified mixture of methane $(91 \%)$ and ethane $(9 \%)$. Certification tickets should accompany the gas bottles and each component concentration should be certified accurate to $\pm 1 \%$ (from expanded uncertainty) of the concentration. At least once per month, a random weekly gas chromatograph report should be acquired from the local natural gas supplier to compare the two independent measurements of calorific values.

Natural Gas Flowmeter:

The natural gas flowmeter, Instromet IRMA 15M-125, should be calibrated at the NIST Fluid Flow Facility every five years or more frequently if deemed necessary.

\section{Bi-Directional Probes and Pressure Transducers:}

The bi-directional probes should be blown out with high-pressure air at the end of each day of testing. The high-pressure air should be applied for a minimum of 15 seconds. This procedure is very important when sooty fuels are burned. The pressure transducers should be calibrated annually. The calibration can be conducted in-house using a Dwyer Model 1430 point gage manometer. This device allows accurate imposition of the very low pressures.

\subsection{Calibration Records}

A record of all calibration certificates/reports for each instrument and calibration standards associated with the heat release rate measurement should be compiled in a single notebook and kept in the control room. An archived copy of this notebook should be kept by the facility supervisor.

The following list is an example of such records:

Carbon Dioxide and Carbon Monoxide span gas mixture certificate of analysis

Oxygen span gas certificate of analysis

Nitrogen zero gas certificate of analysis

Natural gas calorimeter calibration gases certificate of analysis

Natural gas calorimeter calibration curves

Natural gas flowmeter calibration report

Heat release rate comparison curves for the natural gas burner and calorimeter measured outputs

Pressure transducer calibrations

Oxygen analyzer calibration report

Carbon Dioxide analyzer calibration report

Carbon Monoxide analyzer calibration report

\subsection{Traps and Filters}

A new dry ice trap should be installed prior to each fire test. The traps must be cleaned and allowed to dry for at least 24 hours before use. 
The desiccant trap must be emptied and re-filled with dry desiccant (Drierite) if one quarter of the column appears to have changed color due to water. A desiccant trap may last for several fire tests.

The particle filters upstream of the control room sampling pumps should be checked daily or prior to each fire test. If they are a grayish color, not bright white, then they should be replaced.

The particle filter for the roof sampling pump should be checked monthly. It is important to keep a clean filter at this position so as to not increase the load on the sampling pump.

\subsection{Data Acquisition}

There should be a single version of the data acquisition program with a default configuration for basic heat release rate calorimetry. The input signals required for computing heat release rate should have permanent input channels that are not modified in any way. A list of these channels along with the description of the input and the channel settings should be readily visible to the data acquisition operator. In the event that modifications or replacement of instruments occur, the associated modifications to the data acquisition program must be documented in the log book.

\subsection{Data Archiving}

The data acquisition computer hard disk should be backed-up daily by NIST Central Computing. Fire test data should be archived on permanent media such as CD or DVD and properly filed for convenient retrieval. A copy of the archived data should reside outside of the Large Fire Research Facility.

\subsection{Confirmation of HRR Facility}

Confirmation of the complete facility using the natural gas calibration burner should be performed at the start and finish of a test series. For test series lasting multiple weeks intermediate confirmations should be performed at the start of each week.

An extensive confirmation check may include numerous gas flow rates but more typically a three point check is performed. The gas flow rates (heat release rates) chosen should encompass the expected peak values ${ }^{26}$ for the test series of interest as well as lower levels (perhaps much lower levels, if a wide variety of HRR peak values is anticipated).

\footnotetext{
${ }^{26}$ The hood is nominally capable of measuring $3 \mathrm{MW}$ fires using its highest flow rates. It has been used for brief $5 \mathrm{MW}$ fires with good results. However, the upper limit depends strongly on plume entrainment rates, which can vary with the geometry of the fire and the plume's height of origin below the hood. With the calibration burner, there is little smoke to indicate any filling of the hood and/or skirt-enclosed volume, so it is very difficult to know when the plume is partially spilling out. The best clue of plume spillage comes when the data are analyzed, if the highest HRR point measured falls appreciably below the straight line formed by all of the lower HRR points.
} 
The data should be reduced by first plotting HRR vs time and noting time intervals that satisfy the requirement of near constancy of the HRR calculated from the measured gas flow of the calibration burner. Extract the data for each such interval (preferably at least three minutes long but two minutes may be satisfactory) and compute the average and standard deviation of each such data interval. For the same time intervals, compute the average and standard deviation for the HRR (corrected for baseline drift) calculated from the hood system measured parameters (oxygen level, hood flow, etc.). Plot the two results versus each other as "Actual HRR" for the natural gas calibration burner output on the $\mathrm{x}$-axis and "Apparent HRR" for the oxygen consumption calorimetry calculated result on the y-axis. Perform a linear least squares fit of the data using a graphing package or spreadsheet statistics. Compare the results to previous such data for the system. The slopes typically agree within $1 \%$ to $2 \%$.

\section{Concluding Remarks}

The 3 Megawatt Heat Release Rate Facility (3MWHRRF) developed at NIST is capable of accurately measuring heat release rates in the range of 0.10 to $3.0 \mathrm{MW}$ including brief peaks as high as $5 \mathrm{MW}$. The expanded uncertainty ( $95 \%$ confidence interval) is $11 \%$ of the heat release rate for fire sizes larger than $400 \mathrm{~kW}$. The $3 \mathrm{MWHRRF}$ is able to accurately measure peak heat release rates for peaks with full-width-half-maximum equal to $15 \mathrm{~s}$ or greater. The design features that permit this response are described in this report. It is expected that this response should enable the facility to satisfactorily measure the peak heat release rate for most fuel assemblies.

The heat release rate can be displayed in near real-time. Innovative programming was required to combine at least 30 signal outputs and to include corrections for sampling/instrumental delay and response times so that near real-time output could be obtained. The general design of the software is provided.

A natural gas calibration burner with an accurate heat output and the capability of generating short, repeatable pulses is essential for validating the 3MWHRRF. An accurate flow metering valve enabled the burner output to have an expanded uncertainty equal to $2.7 \%$ of the heat release rate. By use of a fast response flow controller, it is possible to generate square-wave pulse widths varying from $5 \mathrm{~s}$ to $60 \mathrm{~s}$. The repeatability of the corrected pulse heights for the burner was typically within $3 \%$ for the entire range of the peak heat release rates and pulse-widths studied. The design of the burner including the special flow control and flow metering capabilities are presented.

The previously used uncertainty analyses for heat release rate do not appropriately account for the correlation effects in computing the oxygen difference relative to the background value and the effect of the drift in the gas analyzer outputs. A more appropriate approach to the uncertainty analysis has been utilized to include these effects by basing the analysis on the voltage outputs of the instruments and the use of a straightforward numerical method for uncertainty propagation computed with an electronic spreadsheet. The results of the analysis identify the major source of 
uncertainty as the bi-directional probes used to compute the exhaust duct volume flow rate. The accuracy of the exhaust duct volume flow measurement could be improved by calibrating the probes in a controlled flow or by implementing a tracer gas volume flow measurement.

It is possible to fabricate a facility for making accurate heat release rate measurements by using mainly commercially available instruments. The 3MWHRRF utilizes commercially available equipment for the calorimeter, data acquisition/analysis system, and calibration burner. A general overview of the system hardware, operations and procedures was presented. Detailed information on specialized hardware, model numbers of the commercial products, and operational procedures is presented in greater detail in NISTIR 7052 [25]. It is thought that this information will be useful for testing organizations to modify their facility or to design a new heat release rate facility for large fires. 


\section{Reference List}

[1] V. Babrauskas and R. D. Peacock, Heat Release Rate - the Single Most Important Variable in Fire Hazard, Fire Safety Journal 18 (3), 255-272 (1992).

[2] V. Babrauskas, Heat Release Rates, The SFPE Handbook of Fire Protection Engineering, 3rd Edition (Section 3, Chap 1), National Fire Protection Association and The Society of Fire Protection Engineers, Quincy, MA, P. J. DiNenno, D. Drysdale, C. L. Beyler, and W. D. Walton, eds., 1-37 (2002).

[3] R. D. Peacock, G. P. Forney, P. A. Reneke, R. W. Portier, and W. W. Jones, CFAST, The Consolidated Model of Fire Growth and Smoke Transport, NIST/TN1299 NIST, Gaithersburg, MD, (1993).

[4] W. J. Parker and M. E. Long, Development of a Heat Release Rate Calorimeter at NBS, (ASTM STP 502), American Society for Testing and Materials, Philadelphia, PA, 135-151 (1972).

[5] C. Huggett, Estimation of Rate of Heat Release by Means of Oxygen- Consumption Measurements, Fire and Materials 4 (2), 61-65 (1980).

[6] A. Tewarson, Generation of Heat and Chemical Compounds in Fires, The SFPE Handbook of Fire Protection Engineering, 3rd Edition (Section 3, Chap 4), National Fire Protection Association and The Society of Fire Protection Engineers, Quincy, MA, P. J. DiNenno, D. Drysdale, C. L. Beyler, and W. D. Walton, eds., 82161 (2002).

[7] D. L. Sensenig, Oxygen Consumption Technique for Determining the Contribution of Interior Wall Finishes to Room Fires, NBS/TN-1128 NIST, Gaithersburg, MD, (1980).

[8] W. J. Parker, Calculations of the Heat Release Rate by Oxygen-Consumption for Various Applications, Journal of Fire Sciences 2 (5), 380-395 (1984).

[9] W. J. Parker and M. L. Janssens, Oxygen Consumption Calorimetry, Heat Release in Fires, (Chap 3), Elsevier Applied Science, New York, V. Babrauskas and S. J. Grayson, eds., 31-59 (1992).

[10] L. Y. Cooper, Some Factors Affecting the Design of a Calorimeter Hood and Exhaust, Journal of Fire Protection Engineering 6 (3), 99-112 (1994).

[11] G. Heskestad, Fire Plumes, Flame Height and Air Entrainment, The SFPE Handbook of Fire Protection Engineering, 3rd Edition (Section 2, Chap 1), National Fire Protection Association and The Society of Fire Protection Engineers, Quincy, MA, P. J. DiNenno, D. Drysdale, C. L. Beyler, and W. D. Walton, eds., 117 (2002). 
[12] J. S. Battye and et al., Shell Flow Meter Engineering Handbook, 2nd Edition McGraw-Hill Book Co., London, G. W. A. Danen, ed., (1985).

[13] B. J. McCaffrey and G. Heskestad, Robust Bidirectional Low-Velocity Probe for Flame and Fire Application, Combust. Flame 26 (1), 125-127 (1976).

[14] Measurement and Instruments, ASHRAE Handbook. Fundamentals, (Chap 13), American Society of Heating, Refrigerating, and Air-Conditioning Engineers, Atlanta, Ga., 13.14-13.15 (1993).

[15] B. Messerschmidt and P. van Hees, Influence of Delay Times and Response Times on Heat Release Measurements, Fire and Materials 24 (2), 121-130 (2000).

[16] D. D. Evans and L. H. Breden, Numerical Technique to Correct Heat Release Rate Calorimetry Data for Apparatus Time Delay, NBSIR 77-1302 National Bureau of Standards, Gaithersburg, MD, (1977).

[17] A. Abramowitz and R. E. Lyon, Comparison of Heat Release Rate From Deconvoluted OSU and Oyxgen Consumption Principle Calorimeter Signals, Interscience Communications Limited, London, England, 161-170 (1993).

[18] W. H. Press, B. P. Flannery, S. A. Teukolsky, and W. T. Vetterling, Numerical Recipes, The Art of Scientific Computing, Cambridge University Press, Cambridge, England, 412- (1986).

[19] CBUF, Fire Safety of Upholstered Furniture - The Final Report of the CBUF Research Programme, EUR 16477 EN Interscience Communications, Ltd., London, B. Sundstrom, ed., (1996).

[20] G. I. Taylor, The Dispersion of Matter in Turbulent Flow Through a Pipe, Proc. R. Soc. London A (223), 446-468 (1954).

[21] J. Smith, Chemical Engineering Kinetics, 2nd Edition (Chaps 6 and 13), McGraw-Hill, New York, (1970).

[22] J. Crank, The Mathematics of Diffusion, Oxford University Press, London, (1964).

[23] M. A. Delichatsios, Air Entrainment into Buoyant Jet Flames and Pool Fires, The SFPE Handbook of Fire Protection Engineering, 2nd Edition (Section 2, Chap 2), National Fire Protection Association and The Society of Fire Protection Engineers, Quincy, MA, 21-23 (2003).

[24] G. Heskestad, Luminous Heights of Turbulent-Diffusion Flames, Fire Safety Journal 5 (2), 103-108 (1983).

[25] R. A. Bryant, T. J. Ohlemiller, E. L. Johnsson, A. Hamins, B. S. Grove, W. F. Guthrie, A. Maranghides, and G. W. Mulholland, The NIST 3 MW Quantitative 
Heat Release Rate Facility - Description and Procedures, NISTIR 7052 NIST, Gaithersburg, MD, (2003).

[26] J. Axelsson, P. Andersson, A. Lonnermark, P. VanHees, and I. Wetterlund, Uncertainties in Measuring Heat and Smoke Release Rates in the Room/Corner Test and the SBI, SP Report 2001:04 SP Swedish National Testing and Research Institute, Boras, Sweden, (2001).

[27] P. A. Enright and C. M. Fleischmann, Uncertainty of Heat Release Rate Calculation of the ISO5660-1 Cone Calorimeter Standard Test Method, Fire Technology 35 (2), 153-169 (1999).

[28] R. W. Yeager, Uncertainty Analysis of Energy-Release Rate Measurement for Room Fires, Journal of Fire Sciences 4 (4), 276-296 (1986).

[29] M. L. Janssens, Variability in Oxygen Consumption Calorimetry Tests, (1427), American Society for Testing and Materials, Dallas, TX, 147-162 (2002).

[30] Guide to the Expression of Uncertainty in Measurement, International Organization for Standardization, Switzerland, (1995).

[31] C. E. Kuyatt and B. N. Taylor, Guidelines for Evaluating and Expressing the Uncertainty of NIST Measurement Results, NIST/TN-1297 NIST, Gaithersburg, MD, (1994).

[32] H. Y. Afeefy, J. F. Liebman, and S. E. Stein, Neutral Thermochemical Data, NIST Chemistry WebBook, NIST Standard Reference Database Number 69, NIST, Gaithersburg, MD, P. J. Linstrom and W. G. Mallard, eds., (2003).

[33] J. Kragten, Calculating Standard Deviations and Confidence-Intervals With A Universally Applicable Spreadsheet Technique, Analyst 119 (10), 2161-2165 (1994).

[34] J. B. Jones and G. A. Hawkins, Engineering Thermodynamics, 2nd Edition John Wiley \& Sons, Inc., New York, 724- (1986). 


\section{Appendix A Nomenclature}

$a$

$\beta$

$\phi$

$\rho$

$b$

C

$D$

$\Delta H_{c}$

j

$k$

$m$

$\dot{m}$

$M$

$P$

$\Delta P$

$\dot{q}$

$R$

$R F$

$R H$

$s$

$t$

T

$u$

$U$

V

$\dot{V}$

$X$

Subscripts

bdp

$\mathrm{c}$

$D$

e

inc

$N G$

$\mathrm{r}$

$\mathrm{t}$

Superscripts

$H C$

$o$ combustion products expansion factor

ratio of moles of combustion products to moles of oxygen consumed

oxygen depletion factor

density, $\mathrm{kg} / \mathrm{m}^{3}$

pressure transducer calibration coefficient, torr $/ \mathrm{V}$

constant or comparison factor

duct diameter, $\mathrm{m}$

heat of combustion, $\mathrm{kJ} / \mathrm{kg}$ or $\mathrm{kJ} / \mathrm{m}^{3}$

intercept of linear least squares fit

uncertainty coverage factor

slope of linear least squares fit

mass loss rate or mass flow rate, $\mathrm{kg} / \mathrm{s}$

species molecular weight, $\mathrm{kg} / \mathrm{kmole}$

absolute pressure, $\mathrm{Pa}$

differential pressure, $\mathrm{Pa}$

heat release rate, $\mathrm{MW}$

universal gas constant, $8.314 \mathrm{~kg} \mathrm{~m} / \mathrm{s}^{2} \mathrm{~K}$ mol

voltage range factor

relative humidity, $\%$

sensitivity coefficient

time, $\mathrm{s}$

temperature, $\mathrm{K}$

uncertainty

expanded uncertainty or velocity, $\mathrm{m} / \mathrm{s}$

instrument output voltage, $\mathrm{V}$

volume flow rate, $\mathrm{m}^{3} / \mathrm{s}$

species volume fraction

bi-directional probe

combined

duct

exhaust or expanded

incoming

natural gas

repeatability

total

hydrocarbon

ambient conditions 


\section{Appendix B Uncertainty Comparison Example}

\section{B.1 Uncertainty in the Difference of Correlated Measurement Quantities}

The uncertainty in the volume fraction measurement of a gas is assumed to have two components, one a result of the uncertainty in the calibration gas, $u_{c a l}$, and the second arising from the electronic noise of the instrument, $u_{n}$. Two measurements of volume fraction are conducted, $X_{1}$ and $X_{2}$, with the same instrument, after a single calibration and at separate times. The algebraic difference of the measurements, $\Delta X$, is the quantity of interest. Figure 1 is a graphical representation of the measurement example. The volume fraction of the calibration gas is $X_{S}$ and its standard uncertainty, $u_{c a l}$, is represented by error bars. Likewise, the standard uncertainty due to the noise is shown with error bars at measurements 1 and 2. Using propagation of uncertainty (i.e. "root-sum-of-squares"), one obtains the following expression for the uncertainty for $X_{1}$ :

$$
u\left(X_{1}\right)=\left(u_{c a l}^{2}+u_{n}^{2}\right)^{1 / 2} .
$$

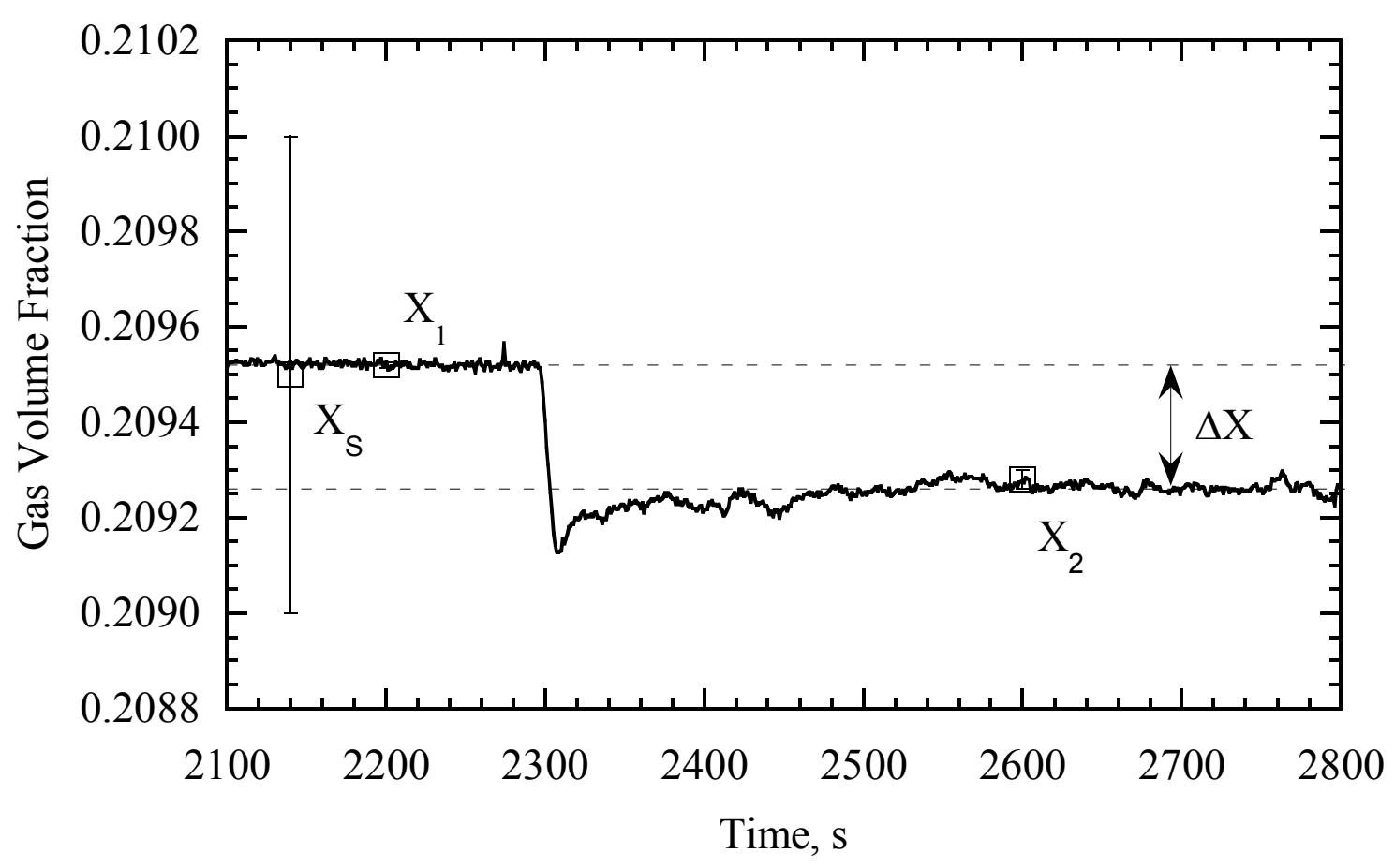

Figure 1 Example of co-dependent difference measurement.

A similar expression is obtained for the uncertainty for $u\left(X_{2}\right)$. Treating the two quantities as independent, one obtains an uncertainty in the difference in the oxygen volume fractions equal to $\sqrt{2}$ times the expression in Eq. B1). For the oxygen measurement, $u_{\text {cal }}$ is typically a factor of 20 greater than $u_{n}$. This leads $u(\Delta X)$ being approximately equal to 
$\sqrt{ } 2 u_{c a l}$. Using this standard approach, one obtains an overestimate of the uncertainty by about a factor of 20 . The actual uncertainty is more nearly equal to $u_{n}$ than $u_{c a l}$. The basic reason for the overestimate is that, in the case of oxygen the two gas measurements are not independent because they share the same calibration. Therefore, if the calibration gas is low by $1 \%$ of the specified value, it will be low for both measurements.

To account for this lack of independence, the volume fraction measurements are expressed in terms of the calibration gas volume fraction, $X_{S}$, the voltage of the analyzer corresponding to the calibration gas, $V_{\mathrm{S}}$, and the voltage corresponding to the gas volume fraction at measurement $1, V_{1}$, and to the voltage corresponding to the volume fraction at measurement $2, V_{2}$. In this case, the difference in the volume fractions is expressed as:

$$
\Delta X=X_{1}-X_{2}=\frac{X_{S}}{V_{S}}\left(V_{1}-V_{2}\right)
$$

Carrying out the uncertainty propagation based on $X_{S}, V_{S}, V_{1}$, and $V_{2}$, which are all independent measurements, one obtains the following expression for the uncertainty:

$$
\frac{u(\Delta X)}{\Delta X}=\left(\left(\frac{u\left(X_{S}\right)}{X_{S}}\right)^{2}+\left(-\frac{u\left(V_{S}\right)}{V_{S}}\right)^{2}+\left(\frac{V_{1}}{V_{1}-V_{2}} \frac{u\left(V_{1}\right)}{V_{1}}\right)^{2}+\left(\frac{-V_{2}}{V_{1}-V_{2}} \frac{u\left(V_{2}\right)}{V_{2}}\right)^{2}\right)^{1 / 2}
$$

It is seen from Eq. (B3) that the uncertainty of the calibration, the first term, is only counted once. The remaining three terms account for the uncertainty of the noise. It is important to recognize that the last two terms are more heavily weighted when the difference in voltage (i.e. volume fraction) is small. To further illustrate the example, it is assumed that $X_{S}=0.21, \quad V_{S}=V_{l}=1.0 \quad \mathrm{~V}, \quad V_{2}=0.995 \quad \mathrm{~V}, \quad u\left(X_{S}\right)=u_{\text {cal }}$, and $u\left(V_{S}\right)=u\left(V_{1}\right)=u\left(V_{2}\right)=u_{n}, u_{c a l}=20 u_{n}$, from which $\Delta X=0.00105$. Computing the uncertainty using Eq. (B3):

$$
\begin{gathered}
\frac{u(\Delta X)}{\Delta X}=\left(\left(\frac{u_{c a l}}{0.21}\right)^{2}+\left(-u_{n}\right)^{2}+\left(\frac{1}{0.005} u_{n}\right)^{2}+\left(\frac{-1}{0.005} u_{n}\right)^{2}\right)^{1 / 2} \\
\frac{u(\Delta X)}{\Delta X}=\left(\left(4.76 u_{c a l}\right)^{2}+u_{n}^{2}\left(2 \times 200^{2}+1^{2}\right)\right)^{1 / 2} \approx\left(\left(4.76\left(20 u_{n}\right)\right)^{2}+u_{n}^{2}\left(2 \times 200^{2}\right)\right)^{1 / 2}=298 u_{n}
\end{gathered}
$$

Recall that in the first example $u(\Delta X)$ was equal to $\sqrt{ } 2 u_{c a l}=20 \sqrt{ } 2 u_{n}$. Compared to the second example where $u(\Delta X)=\Delta X 298 u_{n}=0.31 u_{n}$, it is clear that the uncertainty was overestimated $^{1}$ when the co-dependency of the variables was ignored. This example shows the importance of properly accounting for co-dependent variables and is one of the new aspects of this uncertainty assessment.

\footnotetext{
${ }^{1}$ Although in this case failing to account for the correlation in the volume fractions lead to an overestimate of the uncertainty in their difference, in other cases an underestimate might occur.
} 
It is apparent from the above example that a straightforward application of Eq. (22) to the heat release rate equation (Eq. (13)) such as illustrated in the first example will not account for the co-dependent effects. To account for these effects, the procedure in the second example is followed to express the variables in terms of the most basic measurement inputs of instrument voltages, thermocouple temperatures, and constant parameters (universal, empirical and calibration). In this process, both the effect of the instrument span gas and zero gas is considered whereas in the example above only the span gas was considered. The relations for each instrument or combination of instruments for converting the basic measurement inputs to scientific units are presented in the main text. 